\title{
The control of carbon translocation in a sea anemone-dinoflagellate symbiosis from New Zealand
}

Tiffany Bock

This thesis is submitted for the part fulfillment for the degree of Master of Science 


\section{Acknowledgements}

This is dedicated to my mom and dad for all the support they've given and patience they've shown me over the years.

Thank you to Simon Davy for always answering my questions and helping me learn so much throughout this process.

I would never have been able to finish this project without all the help and support

from friends and labmates; Chris Gibbons, Dan Logan, Milena Palka, Shyam Morar, Jess Fraser, Anne Cawthorn, Jess Field

And a very special thank you to Andy Allison who was amazing throughout this; helping with anemone collection, transportation, formatting, printing, and was always there to support me when I needed it. 


\section{Abstract}

Anthopleura aureoradiata, a common sea anemone of New Zealand's intertidal mudflats and rocky shores, hosts symbiotic dinoflagellates of the genus Symbiodinium. This study investigated the control of photosynthetic carbon translocation in this symbiosis, and in particular the presence and operation of socalled 'host release factor' (HRF). Evidence for HRF exists in a number other algalinvertebrate symbioses, where tissue extracts of the host stimulate carbon release by isolated algal symbionts. However, its identity remains elusive and it has never been studied before in A. aureoradiata.

Translocation of photosynthetically-fixed carbon in the intact symbiosis and in the presence of host tissue extract was measured using a ${ }^{14} \mathrm{C}$ label. Zooxanthellae in the intact symbiosis released around $40 \%$ of their photosynthetically-fixed carbon to the anemone. Isolated zooxanthellae, however, translocated only $8 \%$, even less than the amount of photosynthate liberated by zooxanthellae in FSW alone (11\%). Photosynthetic rates per algal cell were similar in the intact symbiosis and both host homogenate and FSW incubations, meaning that the total amount of photosynthetically-fixed carbon released (in $\mathrm{pg} \mathrm{C} / \mathrm{cell} / \mathrm{h}$ ) by the zooxanthellae in these different situations reflected the \%translocation values.

Given the failure of homologous zooxanthellae (i.e. those from A. aureoradiata) to respond to homogenized host tissue, it was tested whether zooxanthellae from other host species (i.e. cultured heterologous algae) responded. Heterologous zooxanthellae representing 5 clades (A-E) of Symbiodinium were incubated in host tissue homogenate and photosynthate release again measured with ${ }^{14} \mathrm{C}$. The \%translocation varied from $12-51 \%$ in A. aureoradiata homogenate and $17-67 \%$ in FSW, again suggesting a lack of an active HRF in the homogenized tissues of this sea anemone. Photosynthetic rates amongst the different heterologous algae also varied widely with, for instance, freshly isolated zooxanthellae from $A$. aureoradiata having 6-fold higher photosynthetic rates than cultured algae from the same clade (clade A).

The zooxanthellae of $A$. aureoradiata are known to be N-sufficient in the field, and studies with other species have demonstrated that $\mathrm{N}$-deficient zooxanthellae release more photosynthate in response to HRF than do N-sufficient ones. Therefore, 
induction of an HRF effect was attempted by starving sea anemones, and hence their zooxanthellae, prior to incubation of freshly isolated zooxanthellae in homogenized tissue. However, even after 8 weeks of starvation, the zooxanthellae showed no signs of N-deficiency (as indicated by the extent to which ammonium enhanced the rate of dark ${ }^{14} \mathrm{C}$ fixation), meaning that the relationship with $\mathrm{HRF}$ activity could not be examined. The ability of these temperate zooxanthellae to maintain their $\mathrm{N}$ sufficiency, even after relatively long periods of food deprivation, may indicate a lower reliance on host feeding for nitrogen than is seen in tropical zooxanthellae, or a greater capacity to use internal stores of nitrogen.

The lack of photosynthate release by both homologous and heterologous zooxanthellae in host homogenate, as opposed to substantial carbon released in the intact symbiosis, suggests that control of carbon translocation in A. aureoradiata is not related to the activity of an HRF; alternatively, if an HRF is present, its activity is hindered when the symbiosis is disrupted. Further study is needed to determine what is responsible for the control of photosynthate translocation in the A. aureoradiataSymbiodinium symbiosis. 


\section{Contents}

I. Chapter 1 - Introduction

1.1 Symbiosis 1

1.2 Invertebrate-algal symbioses 2

1.3 Symbiodinium 3

1.4 Diversity 4

1.5 Acquisition 6

$\begin{array}{lll}1.6 & \text { Specificity } & 7\end{array}$

Host-Symbiont Interactions

1.7 Photophysiology 8

1.8 Nitrogen Fluxes and Status 10

1.9 Host Release Factor $\quad 12$

1.10 Anthopleura aureoradiata 14

1.11 Aims and Objectives $\quad 15$

II. Chapter 2 - Photosynthetic carbon release in

Anthopleura aureoradiata-host release factor activity vs. in hospite photosynthate release

2.1 Assay for Host Release Factor Activity 16

Materials and Methods

2.2 Experimental Organisms 17

2.3 Host Release Factor Activity 18

2.4 Carbon Translocation in the Intact Symbiosis 20

2.5 Influence of HRF on Photosynthetic Health 21

2.6 Statistical Analysis 23

Results

2.7 Carbon Translocation in the Intact Symbiosis and Isolated 24

2.8 Influence of HRF on Photosynthetic Health 27

Discussion

$2.9 \quad$ Host Release Factor

III. Chapter 3 - Heterologous Algae and HRF Response in A. aureoradiata Host Tissue Homogenate

3.1 Heterologous Zooxanthellae and Host Factor Assays 31

Materials and Methods

3.2 Algal Clades from Culture 32

3.3 HRF Response in Heterologous vs. Homologous Algae 33

3.4 Statistical Analysis 33 Results

3.5 HRF Effect vs. Cladal Diversity 
Discussion

3.6 Diversity

IV. Chapter 4 - Nutritional Status Effects

4.1 Nutritional Status and Carbon Translocation 40

Materials and Methods

4.2 Experimental Organisms 41

4.3 Nutritional Status of Zooxanthellae 42

4.4 'HRF' Activity vs. Nitrogen Status 45

4.5 Data Analysis 45

Results

4.6 Nutritional History and Zooxanthellar Nitrogen Sufficiency 46

4.7 Translocation Rates and Starvation 49

Discussion

4.8 Nitrogen Status 51

4.9 Effects of Starvation on HRF Effects 52

V. Chapter 5 - Discussion

5.1 How Does the Symbiotic Relationship with Zooxanthellae Benefit Anthopleura aureoradiata? 54

5.2 How is Carbon Translocation Regulated 56

$\begin{array}{ll}\text { VI. References } & 58\end{array}$

$\begin{array}{ll}\text { VII. Appendix } & 73\end{array}$

List of Figures

1.1A TEM Photo of Aiptasia pallida and Zooxanthellae in Tissue

1.1B Anthopleura aureoradiata Tentacle Showing Zooxanthellae

1.2 Cladeogram of Zooxanthellar Clades

$\begin{array}{lll}1.3 & \text { Anthopleura aureoradiata } & 14\end{array}$

2.1A Pauatahanui Inlet - Satellite View 17

2.1B Pauatahanui Inlet - Ground View 17

2.2 Light Bank 19

2.3 Pulse Amplitude Modulated Fluorometer 22

2.4 Well-plate set-up for PAM Experiments 23

2.5 Photosynthetic Rates - Intact Symbiosis and Isolated 24

2.6 Percent Translocation - Intact Symbiosis and Isolated 25

2.7 Translocation Rates - Intact Symbiosis and Isolated 26

2.8 Photosynthetic Health Over Time 27 
3.1 Zooxanthellae Cultures $\quad 32$

3.2 Photosynthetic Rates - Cultured Algae 35

3.3 Translocation Rates - Cultured Algae 36

3.4 Percent Translocation - Cultured Algae 37

4.1 Nitrogen Status Determination Method Flowchart 44

4.2 Dark Fixation Rates vs. Starvation 46

4.3 Ammonium Enhancement Ratio vs. Starvation 47

4.4A Photosynhtetic Rates vs. Starvation 48

4.4B $\mathrm{V}_{\mathrm{D}}: \mathrm{V}_{\mathrm{L}}$ Ratio vs. Starvation 48

4.5 Photosynthetic Rates in Host Homogenate vs. Starvation 49

4.6A Translocation Rates in Host Homogenate vs. Starvation 50

4.6B Percent Translocation in Host Homogenate vs. Starvation 50

A1.1 Re-infection Technique 74

A1.2 Cell Counts in Re-Infected A. aureoradiata 77

\section{List of Tables}

1.1 Translocation percentages in temperate and tropical sea anemones

2.1 Significant differences in Photosynthetic Health 27

3.1 Table of Zooxanthellae Clade Types and Information 33

3.2 Table of T-Test Comparisons from Cladal HRF 34

4.1 Artificial Seawater Recipe 41

A1.1 Cell Counts of Experiment 4 


\section{Introduction}

\section{1 - Symbiosis}

Symbiosis was first defined in 1879 by Anton de Bary, who described it as the 'living together of unlike organisms' (Douglas and Smith 1987). Originally discovered in plants, symbioses have now been found to be an essential part of the biosphere.

Examples of symbioses have been found in nearly every type of environment from the deep seas to volcanic cones and everywhere in between. The smaller partner in the symbiosis is usually referred to as the 'symbiont' and the larger organism as the 'host', but these distinctions are not always clear. The resulting partnership is known as the holobiont (Castro and Huber 2005). Most symbioses can be placed into four broad categories: commensalism, a relationship that is beneficial to one party without affecting the second party; ammensalism, when one party is unaffected by the presence of the other, but there are deleterious effects on the second party; parasitism, in which one party gains and the other party is negatively affected; and mutualism, a relationship in which both parties benefit (Douglas and Smith 1987). Symbiotic relationships can occur both intracellularly (within the host cells) or extracellularly (outside the host cells); they can also be defined as an ectosymbiosis (occurring outside the host) or an endosymbiosis (occurring within the host) (Douglas and Smith 1987). Symbioses are additionally defined as being either facultative symbioses, in which both partners can survive without the other, or obligate symbioses, in which one or both partners depend on the other for survival (Stachowicz 2001). 


\section{2 - Invertebrate-Algal Symbioses}

Symbioses between invertebrates and unicellular algae have been recognized in the marine environment since the $19^{\text {th }}$ century. Named 'zooxanthellae' by Brandt in 1881, some of these algae were defined as dinoflagellates after further work by Klebs (1884), Brandt (1885), Chatton (1923), and Hovasse (1924) (cited in Coffroth and Santos 2005). One of the most well-known invertebrate-dinoflagellate symbioses in the marine environment is that which occurs in coral reef ecosystems. Cnidarian corals form a symbiotic relationship with photosynthetic dinoflagellates of the genus Symbiodinium. This intracellular symbiosis is an obligate mutualism in which the dinoflagellates photosynthesize and translocate photosynthetically-fixed carbon, typically in the form of glycerol and other simple molecules, to the host at a rate capable of meeting its respiratory demands (Muscatine et al. 1984; Porter et al. 1984). Symbiodinium cells also promote the conservation and recycling of nitrogen within the symbiosis, making it available for incorporation by the dinoflagellates (Ambariyanto and Hoegh-Guldberg 1996).

Known as photosymbioses, such photosynthetic symbiotic relationships between algae and cnidarians are likely responsible for the survival and growth of coral reefs in the nutrient-poor waters of the tropics. Tropical regions are known for having high light levels, high temperatures, and low food and nutrient levels (Stoddart 1969). This lack of readily available food in the water column of the tropics would not sustain corals without the photosynthetic carbon provided by the zooxanthellae, which supports the idea that the basis of the symbiosis is nutritional, with the dinoflagellates playing a significant role in the nourishment and physiology of the host (Muscatine and Porter 1977). These tropical ecosystems are also often nitrogenlimited, so the dinoflagellates' survival may depend on the nitrogen made available by the host (Muscatine and Porter 1977; Muller-Parker and D'Elia 1997). The symbiosis between Symbiodinium and invertebrates is not limited to coral species, as Symbiodinium spp. also form photosymbiotic relationships with other Cnidaria (e.g. sea anemones, jellyfish and zoanthids) and Mollusca (e.g. giant clams) (Trench 1993; Rowan 1998; Lobban et al. 2002).

Photosymbiotic relationships with zooxanthellae have been found in temperate waters as well, which usually have seasonally reduced irradiances and a greater 
supply of inorganic nutrients and particulate food (Muller-Parker and Davy 2001). Temperate regions have inorganic nutrient concentrations an order of magnitude higher than those in tropical waters, which would seem to make the need for photosymbiotic relationships low (Muller-Parker and Davy 2001). However, these relationships have been found in many temperate species, including the anemones Anthopleura ballii (Davy et al. 1996) and Anthopleura elegantissima (Engebretson and Muller-Parker 1999), hard corals e.g. Plesiastrea versipora (Davy et al. 2006), and the soft corals such as Capnella gaboensis (Sutton and Hoegh-Guldberg 1990).

\section{3 - Symbiodinium}

Formally described in 1962 by Freudenthal, Symbiodinium is a genus of photosynthetic dinoflagellates with a worldwide distribution. Found in high abundance (possibly $>10^{6}$ algal symbionts per $\mathrm{cm}^{2}$ in a healthy coral), understanding Symbiodinium is critical to understanding the evolution, present distribution, and future of coral reefs (Muscatine \& Porter 1977; Hoegh-Guldberg 1999). Ranging in diameter from 5-10 $\mu \mathrm{m}$, zooxanthellae are usually found in complex vacuoles within host gastrodermal cells of cnidarians (Trench 1979; Fitt and Trench 1983; Wakefield et al. 2000); in giant clams the zooxanthellae reside extracellularly in elaborate tubular systems (Norton et al. 1992). Algae within the host cells are surrounded by a host-derived symbiosome (Rands et al. 1993). The symbiosome has been defined as a membrane-bound compartment of the host cell, located in the cytoplasm of eukaryotic cells, which contains one or more symbionts and certain metabolic components (Roth et al. 1988) (Figure 1.1A, B). The outer membrane of the symbiosome is host derived and allows for control of nutrient availability to the algae (Miller and Yellowlees 1989). Zooxanthellae maintained in culture for multiple generations lack symbiosomes (Trautman et al. 2002). 

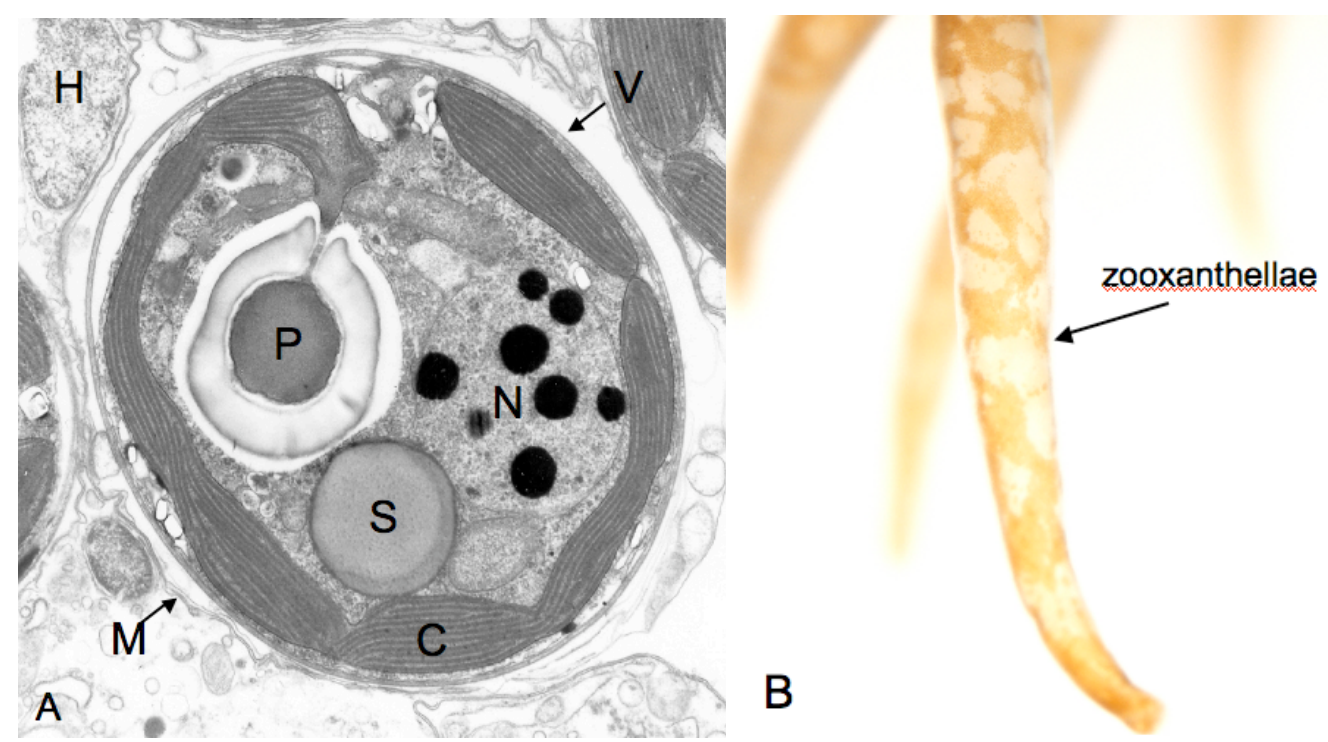

Figures 1.1A \& B: 1.1A) TEM picture of zooxanthellae in Aiptasia pallida tissue $(\mathrm{M}=$ symbiosome membrane $\mathrm{P}=$ pyrenoid; $\mathrm{N}=$ nucleus; $\mathrm{S}=$ starch; $\mathrm{C}=$ chloroplast; $\mathrm{V}=$ perialgal vacuole; $\mathrm{H}=$ host animal tissue Photo: Gisele Muller-Parker 1.1B) - Tentacle of Anthopleura aureoradiata with visible zooxanthellae areas Photo: Chris Gibbons.

To avoid digestion by host cells, zooxanthellae must be recognized as 'self' by the host, which is important when considering the acquisiton of zooxanthellae and their incorporation into the cytoplasmic environment of the host cell (Trench 1979).

\section{4 - Diversity}

From their classification in 1962 until the late 1970s, all symbiotic dinoflagellates of the genus Symbiodinium were classified as one species, Symbiodinium microadriaticum. In 1980, Schoenberg and Trench published a series of papers that challenged the single species idea based on behavioral, infectivity, physiological and ultrastructural experimental evidence (Schoenberg and Trench 1980a-c). With advances in molecular genetic techniques, huge diversity has now been discovered within the Symbiodinium genus (Rowan and Powers 1991a,b; LaJeunesse 2001; Santos et al. 2001; reviewed by Baker 2003). Early studies of genetic diversity used DNA/DNA hybridization and allozymes, finding differences within Symbiodinium as large as those between algae in different classes (Blank and Huss 1989). Subsequent work was done using sequences derived from nuclear small subunit ribosomal DNA (18S-rDNA). This work also showed very high diversity, comparable to orders of free-living dinoflagellates (Rowan and Powers 1991a,b, 
1992). This led to the implementation of a classification system that divides Symbiodinium into several clades i.e. Symbiodinium clades A, B, C (Rowan and Powers 1991) D (Carlos et al. 1999), E, F (LaJeunesse 2001), G (Pochon et al. 2001), and $\mathrm{H}$ (Pochon et al. 2004). The phyologeny of these clades has been described as in Figure 1.2:

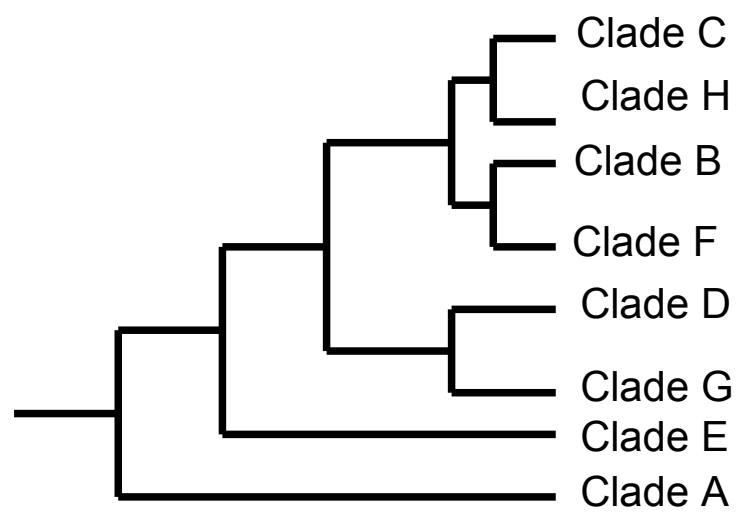

Figure 1.2: The phylogenetic relationships between the major clades of Symbiodinium. The arrangement is a cladogram synthesized from Pochon et al. (2004) The positioning of Symbiodinium clades B, C, F and $\mathrm{H}$ varies depending on the method of tree generation and the molecules analyzed (sourced from Coffroth and Santos 2005).

These groupings have been supported by further work with chloroplast and mitochondrial genes (Santos et al. 2001; Takabayashi et al. 2004). This has shown considerable within-clade diversity, giving rise to the idea that each clade is comprised of multiple strains or "species" (Rowan 1998). This diversity has predominantly been explored using 18S, 5.8S and 28S rDNA (Baker and Rowan 1997; Darius et al. 1998; Carlos et al. 1999; Loh et al. 2001; Burnett 2002; Barneah et al. 2004; Karako-Lampert et al. 2004;) and, most extensively, the more variable ribosomal internal transcribed spacer (ITS) regions have been studied (LaJeunesse 2001; Santos et al. 2001; LaJeunesse 2002; Diekmann et al. 2003).For instance, LaJeunesse (2001) used sequence variation within the ITS regions to find as many as 76 sequence differences just within clade A.

Physiological differences between zooxanthellar 'types' may generate variability in host-symbiont pairings given the correlation of environmental parameters with symbiont distribution seen in many surveys (Rodriguez-Lanetty et al. 2001; LaJeunesse et al. 2004a). Mapping the physiology of zooxanthellae onto current knowledge of their diversity has not received the attention it deserves, but physiological variation clearly exists, and is responsible for some variation in host- 
symbiont pairings. For example, the different 'types' of zooxanthellae differ in their responses to environmental changes and have different thermal tolerances (IglesiasPrieto and Trench 1997; Kinzie et al. 2001; Perez et al. 2001; Bhagooli and Hidaka 2004). The differences in thermal tolerance have been documented for Symbiodinium of clade $\mathrm{D}$, which dominates at sites with elevated temperatures and on reefs that have suffered temperature-induced bleaching in the past (Chen et al. 2003; Fabricius et al. 2004; Berkelmans and van Oppen 2006). Some studies even attributed distinctive phenotypes to various phylotypes of Symbiodinium; for example, $\mathrm{C}$ was defined as a 'specialist', E as 'stress-tolerant', and A as 'invasive or opportunistic' (Rowan 1998). However, not all studies have concluded that clade level identity correlates with physiological function (Kinzie et al. 2001; Savage et al. 2002; La Jeunesse et al. 2003; Tchernov et al. 2004). Tchernov (2004) found that algae from different clades responded similarly to elevated temperatures while algae from the same clade showed significantly different responses (Tchernov et al. 2004). The study by Savage et al. (2002) found significant variation in irradiance responses among isolates from within each of clade A, B and C from Bermuda, suggesting that variation within clades could contribute to the persistence of symbiosis in the face of climate change (Savage et al. 2002).

\section{5 - Acquisition}

Most known host species ( $\sim 85 \%)$ acquire zooxanthellae from environmental pools (known as 'open' or 'horizontal' transmission); the remaining species acquire zooxanthellae parentally (known as 'closed' or 'vertical' transmission) (Schwarz et. al. 2002). Although some species can survive without their symbiont or host in habitats with sufficient external nutrition, most cannot. Thus, the prevalence of horizontal transmission is surprising, as it leaves both organisms involved to live separately for a time. However, it may allow opportunity for a symbiosis to be established with a symbiont that may be better suited to the current local environmental conditions (Buddemeier and Fautin 1993; Van Oppen, 2004).

Symbiont specificity is determined at various life stages, depending on host taxa. With most cnidarians, zooxanthellae are acquired early in life by either vertical or horizontal transmission. In some taxa, such as Caribbean octocorals, host polyps 
initially take up multiple clades of symbionts and establish a dominant clade as the polyp develops (Coffroth et al. 2001), while in many other taxa, host species are passed a 'type' of zooxanthella from the parent and do not change this symbiont type over time (Coffroth et al. 2001). Larvae of the coral Fungia scutaria acquire symbionts by horizontal transmission but, interestingly, take up algae of the same symbiont type as that found in the adult, even though they do not live in close proximity (Rodriquez-Lanetty et al. 2004). In some host species, it appears that the mode of transmission is correlated with the 'type' of symbiont. In the Red Sea, host species with horizontal transmission tend to associate with clade $\mathrm{C}$ symbionts, while scleractinians and others with vertical transmission tend to have clade A zooxanthellae (Barneah et al. 2004; Karako-Lampert et al. 2004); this trend has not been seen in other regions with clades B, C and D, despite horizontal transmission of symbionts. Levels of symbiont diversity within acroporid corals do not differ with the method of transmission, suggesting that the mode of transmission does not affect symbiont diversity within a host species (van Oppen 2004). This is contentious, with LaJeunesse (2004) suggesting that vertical transmission selects for host-symbiont specificity, leading to symbiont specialization and greater diversity of zooxanthellae on the reef (LaJeunesse et al. 2004a, b).

\section{6 - Specificity}

Specificity refers to the different 'types' of zooxanthellae that can associate with a particular species of host, or how many species of host a particular type of zooxanthella can associate with. A first step to studying specificity is to investigate the distribution of Symbiodinium diversity among the various host species and phyla (e.g. Cnidaria, Mollusca, Foraminifera) with which it forms associations. With exceptions, a survey of host-symbiont pairings shows that symbiont types are not randomly distributed among hosts, and that each species generally associates with the same type across its individuals (Schoenberg and Trench 1980a, b, c; Rowan and Powers 1991a, b). Early studies suggested that the same symbiont is found within a host throughout a geographical distribution, while symbionts differ between host species (Schoenberg and Trench 1980a, b, c). Genetic data have shown that in many cases, a particular type of Symbiodinium associates with only one or a few host 
species, while in other cases, either the host or symbiont is more flexible and can associate with varied host species/symbiont types (reviewed in Baker 2003). For example, LaJeunesse (2002) documented 69 types of Symbiodinium on a single reef, but the majority of host species associated with a particular symbiont type (LaJeunesse 2002). It should be noted that though the majority of host species associate with a particular type of symbiont, but the symbiont found in a species is really just a subset of the types that can possibly be present in the host. Many studies have found that hosts can be induced to take up different types of zooxanthellae (Trench 1971a; Kinzie 1974; Kinzie and Chee 1979; Schoenberg and Trench 1980a, c; Colley and Trench 1983; Coffroth et al. 2001; Santos et al. 2001). The ability of the host to harbour multiple types of zooxanthellae suggests that specificity of hostsymbiont relationships seen in the field may be partially dependent on the local environment (Rowan and Knowlton 1995; LaJeunesse and Trench 2000; RodriguezLanetty et al. 2001).

\section{Host-Symbiont Interactions}

\section{7 - Photophysiology}

Zooxanthellae within host tissues fix inorganic carbon into organic carbon through photosynthesis. As suggested by Muscatine et al. (1984), carbon not used by the zooxanthellae for respiration or growth may be translocated to the host predominantly as glycerol, glucose, organic acids, amino acids, and possibly lipids, which may be used to create lipid stores in the host (Muscatine 1967; Trench 1971; Muscatine et al. 1972; Schmitz and Kremer 1977; Kellogg and Patton 1983; Battey and Patton 1987; Muscatine et al. 1994; Grant et al. 1997; Wang et al. 1997; Whitehead and Douglas 2003). These translocated photosynthetic products are then potentially available for respiration, growth and reproduction of the host, though some may be released from the symbiosis as mucus or dissolved organic matter (Muscatine et al. 1981; Edmunds and Davies 1986; Rinkevich 1989; McCloskey et al. 1994).

In 1967, Muscatine used ${ }^{14} \mathrm{C}$ labeling to measure release of photosynthetic products from Symbiodinium freshly isolated from the clam Tridacna crocea and the coral Pocillopora damicornis incubated in homogenized host tissue. It was found that 
zooxanthellae release significant amounts of soluble photosynthate to the animal homogenate. This method, however did not quantify amounts of photosynthate released, nor did it assess the extent to which the needs of the host were satisfied by the released product. Later, Trench (1971 a-c) ran a series of experiments using ${ }^{14} \mathrm{C}$ to measure release of photosynthetic products in the sea anemone Anthopleura elegantissima, both in the intact symbiosis, and in the presence of host homogenate. Throughout the three experiments, about $40-50 \%$ of the fixed ${ }^{14} \mathrm{C}$ was liberated both in the intact symbiosis and in host homogenate incubations (Trench 1971a-c).

In 1981, Muscatine et al. derived an equation to calculate the fractional contribution of translocated zooxanthellar carbon to the host's daily respiratory carbon requirements (CZAR):

$\mathrm{CZAR}=\quad \begin{aligned} & \begin{array}{l}\text { Zooxanthellae fixed } \\ \text { carbon }\end{array} \\ & \end{aligned}$

This equation incorporates $\mathrm{O}_{2}$-flux measures of photosynthesis and respiration, which are converted into carbon equivalents, and in the first instance employed a ${ }^{14} \mathrm{C}$ tracer to measure the percent of photosynthetically-fixed carbon translocated to the host. Subsequently, however, Muscatine et al. (1984) estimated the percent of fixed carbon translocated using the so-called 'growth rate method', which assumes that all carbon not used for zooxanthellar growth (measured through microscopy techniques) is translocated to the host. Use of this method led to estimates of $>90 \%$ translocation in several species, from both temperate and tropical regions (Muscatine et al. 1984; Steen and Muscatine 1984; Davy et al. 1996) (Table 1.1), though it is important to note that this method does not account for possible photosynthetic products stored by the zooxanthellae. 
Table 1.1: Translocation percentages in temperate and tropical sea anemones determined with both ${ }^{14} \mathrm{C}$ bicarbonate and the growth rate methods.

\begin{tabular}{|c|c|c|c|}
\hline Species & $\begin{array}{c}\text { Translocation \% } \\
{ }^{14} \text { C Method }\end{array}$ & $\begin{array}{c}\text { Translocation \% } \\
\text { Growth Rate Method }\end{array}$ & Reference \\
\hline $\begin{array}{c}\text { Anemonia viridis } \\
\text { Temperate }\end{array}$ & 45.4 & $\begin{array}{c}75.3-98.6 \\
\text { low-high light }\end{array}$ & $\begin{array}{c}\text { Davy et al. 1996, } \\
1997\end{array}$ \\
\hline $\begin{array}{c}\text { Anthopleura ballii } \\
\text { Temperate }\end{array}$ & 33.8 & $\begin{array}{c}46.8-96.5 \\
\text { low-high light }\end{array}$ & $\begin{array}{c}\text { Davy et al. 1996, } \\
1997\end{array}$ \\
\hline $\begin{array}{c}\text { Anthopleura } \\
\text { elegantissima } \\
\text { Temperate }\end{array}$ & 29 & 92.7 & $\begin{array}{c}\text { Fitt et al. 1982; } \\
\text { Engebretson and } \\
\text { Muller-Parker 1999 }\end{array}$ \\
\hline $\begin{array}{c}\text { Cereus } \\
\text { pedunculatus } \\
\text { Temperate }\end{array}$ & 48.6 & $27.9-97.7$ & $\begin{array}{c}\text { Davy et al. 1996, } \\
1997\end{array}$ \\
\hline $\begin{array}{c}\text { Aiptasia pulchella } \\
\text { Tropical }\end{array}$ & $12-22.4$ & $98.0-99$ & $\begin{array}{c}\text { Muller-Parker 1985, } \\
\text { unpubl. (sourced } \\
\text { from Muller-Parker } \\
\text { and Davy 2001) }\end{array}$ \\
\hline
\end{tabular}

When the CZAR is estimated for a whole day, it shows that in many cnidarian species with zooxanthellae, more than sufficient carbon is fixed and translocated by zooxanthellae to satisfy the host's carbon demand for respiration (McCloskey et al. 1994; Davy et al. 1996), except where light is limited by cloud cover, season or habitat (e.g. sediment or depth) (Davies 1991; Davy et al. 1996).

\section{8 - Nitrogen Fluxes and Status}

Zooxanthellar symbioses have been found mainly in tropical regions, where low levels of nutrients are often found. Zooxanthellae provide carbon products for the host, but host animals also require nitrogen, which is often the nutrient in shortest supply in the marine environment (Thomas 1970; Ryther and Dunstan 1971). One way to satisfy this requirement is by feeding on zooplankton in the water column, but this would supply only a fraction of the required nutrients in tropical seas. This potential lack of nutrients emphasizes the importance of nitrogenous excretions from host animals to zooxanthellar growth and survival (Cook and D'Elia, 1987; Rees, 1991). Nitrogen can be acquired from a variety of sources, 1- dissolved inorganic nitrogen in seawater; 2- dissolved organic nitrogen in seawater; 3- plankton and suspended particulate matter caught by the host. Dissolved inorganic nitrogen can be taken up from seawater as both ammonium $\left(\mathrm{NH}_{4}^{+}\right)$(Kawaguti 1953; Muscatine and D’Elia 1978; Wilkerson and Trench 1986; Grover et al. 2002) and nitrate $\left(\mathrm{NO}_{3}^{-}\right)$ 
(Franzisk 1973; Wilkerson and Trench 1986). Both host and zooxanthellae are capable of assimilating ammonium, though it is done by different pathways. In the animal, ammonium assimilation takes place via the NADP-glutamate dehydrogenase (NADP-GDH) pathway (Miller and Yellowlees 1989; Roberts et al. 2001). The zooxanthellae have been found to assimilate ammonium by the glutamine synthetase/glutamine 2-oxoglutarate amido transferase (GS/GOGAT) pathway. Both pathways convert the ammonium to the amino acid glutamate that can be used to synthesize other amino acids (Wilkerson and Muscatine 1984; Roberts et al. 2001). Nitrate is taken up by both the animal and the zooxanthellae, but only zooxnthellae are capable of converting it into ammonium for assimilation into amino acids (Miller and Yellowlees 1989).

Nitrogen converted into amino acids can then be incorporated into proteins and used for growth. Organic nitrogen can also be passed from zooxanthellae to the animal; for example, the amino acid alanine has been identified in photosynthetic products released by zooxanthellae in host homogenate incubations (Lewis and Smith 1971; Trench 1971; Sutton and Hoegh-Guldberg 1990). Zooxanthellae have been found to take up nitrogenous compounds from the animal, though quantities have not been established (Muscatine and D'Elia 1978).

Most host-symbiont pairings cannot take up sufficient nitrogen from the surrounding environment, and must rely either on nitrogen conservation or recycling to sustain enough nitrogen for growth and survival. Nitrogen conservation is best described as the conservation of nitrogen as the result of the preferential use of photosynthetic carbon received from algal cells for host respiration over amino acids (Wang and Douglas 1998). Nitrogen recycling is a complex procedure involving the transfer of the animal nitrogenous waste to the algal cells, and the translocation of these compounds back to the animal after assimilation of the nitrogen into useable compounds of nutritional value to the animal (Lewis and Smith 1971). There is not much evidence for recycling of nitrogen, beyond the translocation of small quantities of amino acids, though it is often alluded to (Muscatine and Porter 1977). Nitrogen conservation was originally proposed for a freshwater symbiosis (the hydra-Chlorella symbiosis) by Rees (1986), but it is applicable to marine cnidarian symbioses as well (Wang and Douglas 1998). Once assimilated, the nitrogen may be used by the zooxanthellae for growth, or they may release some of it back to the host as amino 
acids (Trench, 1971a, b, c; Rahav et al. 1989; Sutton and Hoegh-Guldberg 1990; Markell and Trench 1993; McAuley and Cook 1994).

Nitrogen deficiency, as applied to algae, is defined as "algae that have been maintained in a growth-limiting concentration, or in the absence, of a given nutrient, but in the presence of a utilizable source of carbon, which is usually accumulated photosynthate" (Rees, 1991). Zooxanthellae appear to be nitrogen limited, as densities and growth rates increase when nitrogen is supplied in the form of particulate food or supplemental ammonium or nitrate (Hoegh-Guldberg and Smith 1989; Muscatine et al. 1989; Stimson and Kinzie 1991). Evidence for nitrogen deficiency in tropical symbioses was first evidenced by Rees, who used the general characteristics of nutrient-deficient unicellular algae to determine that the host might withhold nutrients from the zooxanthellae (Rees 1991). Since then, much stronger evidence for nutrient deficiency in zooxanthellae has been found. Cook et al. (1992) used ammonium enhancement of dark carbon fixation to measure nutritional status of zooxanthellae from Atlantic corals, and found evidence of nitrogen deficiency in the field; this method has been widely used to estimate nitrogen status of zooxanthellae (Cook et al. 1992, 1994; Davy and Cook 2001; Davy et al. 2006). Moreover, the fact that the temperate anemone Anthopleura elegantisima excretes ammonia into the surrounding seawater rather than retaining it all also suggests nitrogen sufficiency (Jensen and Muller-Parker 1994).

\section{9 - Host Release Factor}

In many marine invertebrates containing symbiotic zooxanthellae, there is substantial movement of photosynthetic products from the algae to the animal tissues (Muscatine\& Hand 1958; Muscatine 1967; von Holt \& von Holt 1968; Muscatine \& Cernichiari 1969). Muscatine, in his 1967 study, found that zooxanthellae released significant amounts of photosynthate when incubated in host homogenate, when compared to incubation in seawater, giving rise to the idea of a 'host release factor' response (Muscatine, 1967). This idea was supported by later experiments by Trench (1971c), who suggested that the 'host release factor' response is not just an experimental artifact, but may well represent the result of an interaction between animal host and algal symbiont which occurs in the intact symbiosis (Trench, 1971c). 
These findings have been supported by later works (Muscatine et al. 1972; Masuda et al. 1994; Engebretson and Muller-Parker 1999), all indicating the presence of some 'host release factor' (HRF) in host tissue homogenates. This HRF may be either a chemical signal present in the tissues of the host organisms that stimulates the release of photosynthetic products from the algae, or it might contain a substrate that can be directly metabolized by the zooxanthellae to produce the compounds that are then released (Biel et al. 2007). Both temperate and tropical species have shown effects of a host release factor, though there have been some species, eg. the soft coral Capnella gaboensis whose tissue illicit no increased translocation and even induce negative effects on isolated algae (Sutton and Hoegh-Guldberg 1990). The compound has not yet been conclusively defined, and its properties appear variable in different hosts. For example, the properties of the HRF have been described as heat labile or heat stable, enhancing carbon fixation or not, and behaving like a substance with a molecular mass $<10 \mathrm{kDa}$ or $\sim 1 \mathrm{kDa}$ (Gates, 1995). Gates proposed that the HRF in the Hawaiian reef coral $P$. damicornis is a set of free amino acids (FAAs), and found that incubation of algae in a mixture of mycosporine-like amino acids, as well as synthetic FAA mixtures induced the elevated release of photosynthate (Gates 1995; Gates 1999). Withers et al. (1998), incubated algae in a low molecular weight fraction of the animal homogenate and in an homogenate containing the free amino acids found in the low molecular weight fraction: aspartate, glutamate, serine, histidine, arginine, glycine, threonine, alanine, tyrosine, valine, phenyalanine, leucine, and lysine. The free-amino acids did induce the increased release of photosynthate, but not to the same extent as the original homogenate, raising questions about the validity of free amino acids as the main constituent of the HRF. Cook and Davy (2001) tested a synthetic host factor made up of glycine, alanine, and glutamic acid and found a significant response only with alanine, increasing with concentrations up to $50 \mathrm{mM}$; neither of the other amino acids had significant effects on translocation rates (Cook and Davy 2001), again raising doubts over the role of FAAs. Some possible ways that HRF stimulates the release of photosynthate from zooxanthellae include changing the permeability of the algal cell membrane to glycerol (Muscatine 1967; Trench 1971; Muscatine et al. 1972), stimulation of glycerol synthesis, and inhibition of further processing of glycerol into energy stores within algae (Hinde 1988) or inducing the release of glycerol from storage compounds (Muscatine 1967). 
The diversion of carbon compounds away from storage within the zooxanthellae is consistant with the extent of HRF induced release increasing as zooxanthellae become increasingly nitrogen deficient when starved (Davy and Cook 2001b).

\subsection{0 - Anthopleura aureoradiata}

The sea anemone Anthopleura aureoradiata was first described in 1908 by Stuckey, who put it in the family Bunodidae and genus Bunode (Figure 1.3).

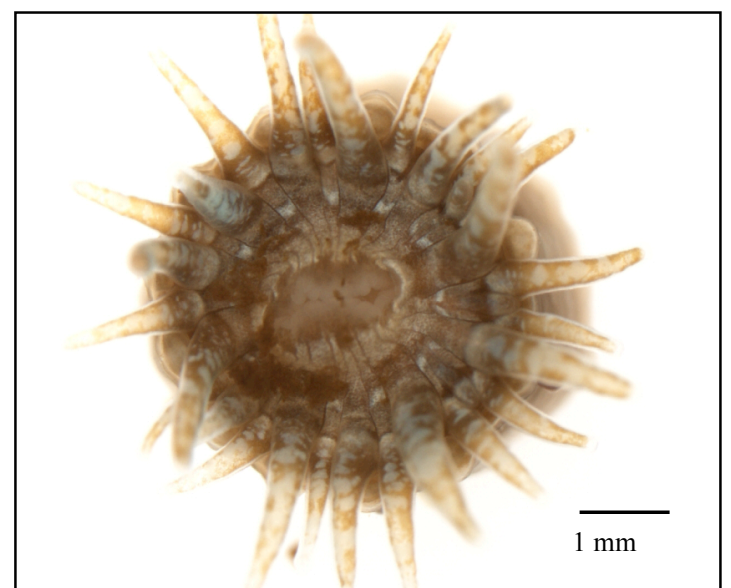

Figure 1.3: Anthopleura aureoradiata as seen through dissecting microscope. Photo courtesy of Chris Gibbons

Originally found at Oriental Bay, Wellington (Stuckey 1908), it has since been found to range from Stewart Island in the south, through New Zealand to Cape Reinga in the far north. Ranging in size from about 5-12 mm wide, it is found on both rocky intertidal shores and mudflats, where it lives on the shells of the cockle Austrovenus stutchburyi; these cockles are usually found $5-10 \mathrm{~cm}$ deep in the mud at low tide. At high tides, the cockles migrate up to the surface of the mud such that the anemone can extend its tentacles above the surface. A. aureoradiata is symbiotic with zooxanthellae of clade A (Phillips 2006) throughout its range. 


\subsection{1 - Aims and Objectives}

The aim of this study was to determine if host release factor is present in Anthopleura aureoradiata, and to ascertain if any response is specific for homologous zooxanthellae or can induce a response in heterologous symbionts.

Specifically, this aim was achieved by:

1- Determining if tissue from Anthopleura aureoradiata exhibits a host release factor response with freshly isolated homologous zooxanthellae, and comparing this host release factor response with translocation rates in the intact symbiosis;

2- Establishing if the host release factor response (if any) seen with homologous zooxanthellae, is also seen in heterologous zooxanthellae (cultured from other host species);

3- Establishing whether host release factor response, if any, is enhanced by nitrogen deficiency and hence reduced algal growth. 


\section{Photosynthetic carbon release in Anthopleura aureoradiata-host release factor activity vs. in hospite photosynthate release}

\section{1 - Assay for Host Release Factor Activity}

Translocation of photosynthetic products from symbiotic zooxanthellae to host animal is known to be the basis of all invertebrate-dinoflagellate symbioses. Zooxanthellae translocate photosynthetically fixed carbon to their hosts for use in respiration, growth and reproduction (Muscatine et al. 1983, 1984; McCloskey et al. 1994). The products are translocated most commonly as glycerol, though glucose, organic acids, amino acids, and even lipids have been identified as translocated compounds (Trench 1971a-c; Muscatine et al. 1972; Kellogg and Patton 1983; Battey and Patton 1987; Muscatine et al. 1994; Grant et al. 1997; Wang et al. 1997; Whitehead and Douglas 2003). Muscatine (1967) discovered that the algae also release these photosynthetic products when isolated from the host, but only in the presence of host tissue. This indicates the presence of some 'host release factor' (HRF) in the host tissues that stimulates photosynthate release in the zooxanthellae. First observed in the giant clam Tridacna crocea and the coral Pocillopora damicornis by Muscatine (1967), it has since been observed in many invertebratealgal symbioses, both temperate and tropical, including Plesiastrea versipora, Zoanthus robustus, Aiptasia pallida, Montastraea annularis, and Anthopleura elegantissima. There are some species which have been observed to have no HRF in the tissues, and at least one (Capnella gaboensis), in which the host homogenate actually causes the algal cells to lyse (Sutton and Hoegh-Guldberg 1990). The actual identity of the HRF has not yet been determined, though it has been suggested to be a mixture of free amino acids (FAAs) (Gates et al. 1995, 1999). However, some 
authors argue against the role of FAAs, (Wang and Douglas 1997; Withers et al. 1998; Cook and Davy 2001).

Also of note, Grant et al. (2001) ran trials looking at HRF in the coral Plesiastrea versipora and discovered a photosynthesis inhibiting factor (PIF), which partially inhibits carbon fixation in freshly isolated symbiotic algae. PIF was isolated from the coral $P$. versipora, and has effects on symbiotic algae from several symbioses and on cultured algae (Grant et al. 2001).

This chapter aims to determine using radioisotopic $\left({ }^{14} \mathrm{C}\right)$ labelling if there is evidence for host release factor in the temperate sea anemone Anthopleura aureoradiata; this anemone has never been surveyed for HRF activity. Furthermore, this chapter aims to compare photosynthetic and translocation rates of isolated zooxanthellae with those in the intact symbiosis.

\section{Materials and Methods}

\section{2 - Experimental Organisms}

All specimens of Anthopleura aureoradiata were collected from Pauatahanui Inlet mudflats, located $30 \mathrm{~km}$ north of Wellington, New Zealand. Pauatahanui is an east-west running arm of the Porirua Harbor, with much of the shores having been filled in by sand and silt from the surrounding hills. Sampling sites were near the mouth of the inlet, on the mudflats (Figures 2.1A\&B).

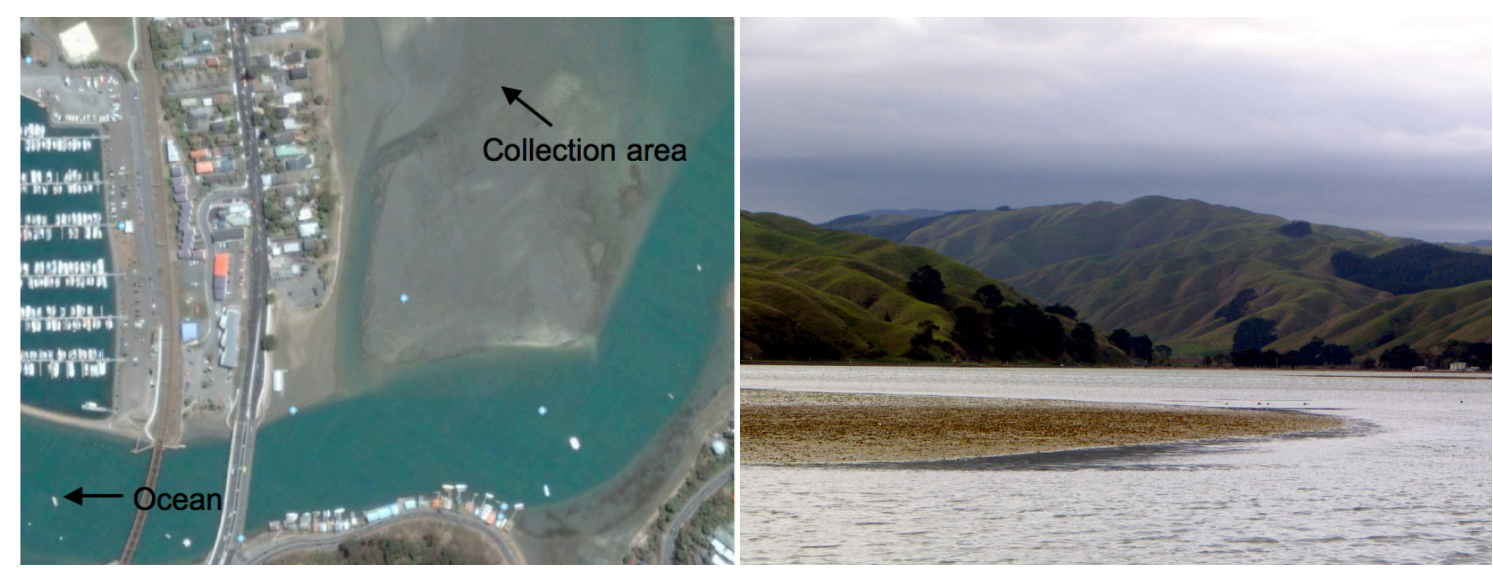

Figures 2.1 A\&B: 2.1A)Satellite photo of Pauatahanui Inlet Image: Google Earth 2.1B) Photo of the mudflats at Pauatahanui Inlet. Photo courtesy of Milena Palka 
Anemones were found on the shells of the cockle Austrovenus stutchburyi dug from between 5 and $10 \mathrm{~cm}$ below the mud surface at low tide. Anemones were then picked off the shells of the cockles and taken back to the lab where they were transferred into bowls containing $1 \mu \mathrm{m}$-filtered seawater (FSW). Water was changed 24 hours later and anemones were moved into an incubator, where they were maintained until use in experiments.

Anemones were maintained at $17^{\circ} \mathrm{C}+/-1^{\circ} \mathrm{C}$ in a Contherm incubator on a $12 \mathrm{~h}$ light/ $12 \mathrm{~h}$ dark cycle. The irradiance was $\sim 250 \mu \mathrm{mol}$ photons $/ \mathrm{m}^{2} / \mathrm{s}$. Anemones were fed Artemia sp. nauplii once weekly for standard maintenance. Water was changed and debris removed 24 hours after each feeding. Feeding schedules were adjusted when required for experiments.

All anemones used to study translocation in the intact symbiosis and in host homogenate were collected and maintained as described previously, with weekly feedings. Anemones were used within 3 weeks of collection throughout trials.

\section{3 - "Host Release Factor" Activity}

To test for evidence of a host release factor effect in the temperate $A$. aureoradiata symbiosis, freshly collected anemones were employed. Host-tissue homogenate was prepared by blending 5-10 symbiotic anemones of the same nutritional history in a handheld Wheaton glass tissue grinder. The resulting homogenate was centrifuged at $12,000 \mathrm{~g}$ for 5 minutes to separate out the zooxanthellae. The animal-tissue supernatant was poured off and saved for protein content analysis. This analysis was done using the Shakir modification of the Lowry procedure (Shakir et al. 1994). The host homogenate was stored in the refrigerator $\left(4^{\circ} \mathrm{C}\right)$ during preparation of the algae, or in the freezer $\left(-17.9^{\circ} \mathrm{C}\right)$ if being saved for experiments on subsequent days. All animal homogenates were adjusted to the same protein concentration with FSW. Zooxanthellae were re-suspended in $5 \mathrm{~mL}$ FSW and then centrifuged again at $12,000 \mathrm{~g}$ for 5 minutes to further eliminate any residual animal tissue. After re-suspending again in $4 \mathrm{~mL} \mathrm{FSW}, 6$ hemacytometer counts were taken for each algal cell suspension and $300 \mu \mathrm{L}$ pipetted into each of 10x $1.6 \mathrm{~mL}$ microcentrifuge tubes. Samples $(600 \mu \mathrm{L})$ of animal homogenate were added to each of 4 tubes, $600 \mu \mathrm{L}$ FSW added to each of 4 control tubes, and $600 \mu \mathrm{L}$ of $20 \%$ 
formalin (buffered with sodium borate) were added to 2 tubes for estimating background activity (i.e. for formalin-killed cells). All tubes were then labelled with $16 \mu \mathrm{L} \mathrm{NaH}^{14} \mathrm{CO}_{3}$ (containing $6 \mu \mathrm{Ci}$ activity). Samples $(100 \mu \mathrm{L})$ were immediately taken from the formalin vials and were pipetted into $20 \mathrm{~mL}$ scintillation vials to which 5 mL OptiScint Hi-Safe II Scintillation Cocktail (Perkin-Elmer) were added and radioactivity read for background values. Remaining vials were incubated on a light bank (Figure 2.2) (irradiance of 250-300 $\mu \mathrm{mol}$ photons $/ \mathrm{m}^{2} / \mathrm{s}$ ); this light level is sufficient to saturate photosynthesis (C. Gibbons, new unpublished data), for 30 minutes.

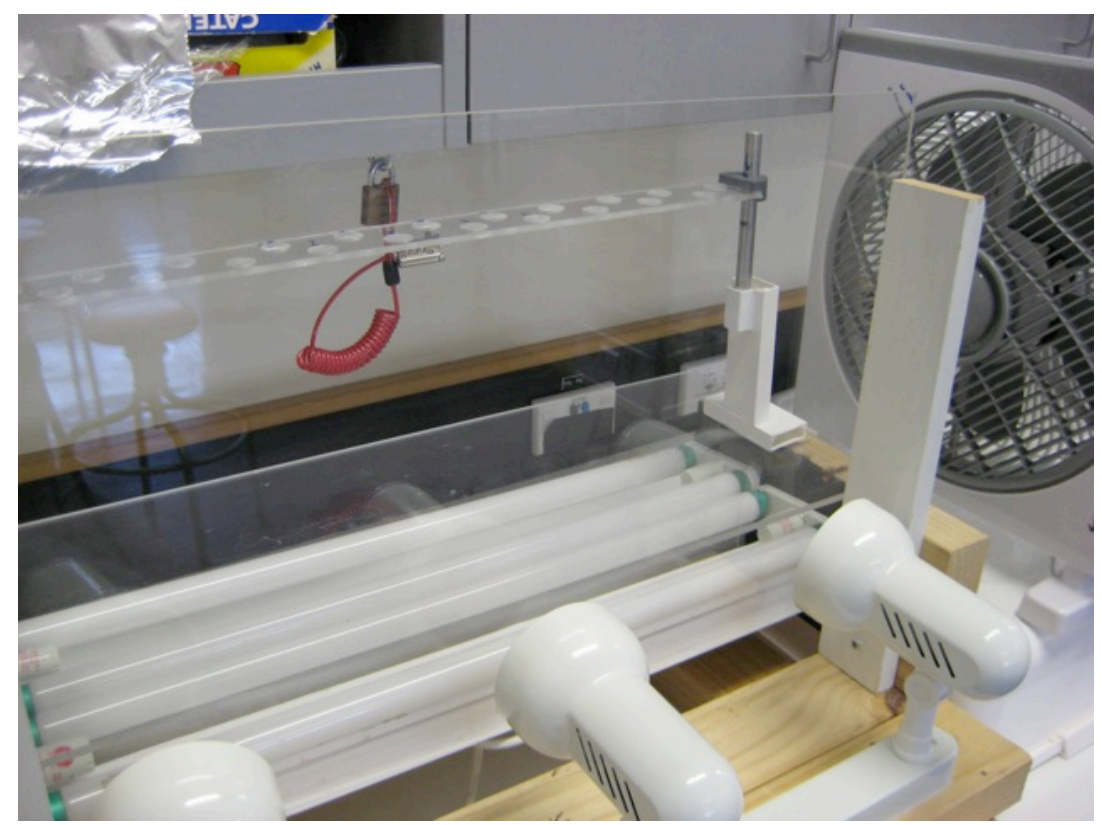

Figure 2.2: Light bank used for all ${ }^{14} \mathrm{C}$ incubations.

Tubes were vortexed every 10 minutes to ensure continued suspension of algae in the incubation medium. After incubation, tubes were vortexed and $300 \mu \mathrm{L}$ samples were taken of the combined zooxanthellae and animal mixture, and pipetted into $20 \mathrm{~mL}$ glass scintillation vials. All tubes were then centrifuged at $12,000 \mathrm{~g}$ for 2 minutes to separate the animal and algal fractions. Three hundred $\mu \mathrm{L}$ of the supernatant (animal homogenate, FSW or formalin) was pipetted into $20 \mathrm{~mL}$ scintillation vials. All vials were then acidified with $300 \mu \mathrm{L}$ of $1 \mathrm{~N} \mathrm{HCl}$ and allowed to dry to eliminate unincorporated ${ }^{14} \mathrm{C}$. When dry, $300 \mu \mathrm{L}$ dd $\mathrm{H}_{2} \mathrm{O}$ were added, 
followed by $5 \mathrm{~mL}$ OptiPhase Hi-Safe II scintillation fluid. Radioactivity counts were then taken with a Wallac 1409 liquid scintillation counter.

Fixed carbon, translocated carbon, and percent translocation were calculated using the host and algal fractions and dissolved organic carbon (DOC) as in equations 1,2 , and 3 below.

Carbon fixed $=$ Host + Algal fraction $\quad+\quad$ DOC $^{*} \quad$ (Eq. 1) Translocated carbon $=$ Supernatant $1+2$ (i.e. total animal fraction) $+\mathrm{DOC}^{*}(\mathrm{Eq} .2)$ $\%$ Translocation $=($ Translocated carbon/Fixed Carbon $) \times 100$

* - DOC only used in measurements in the intact symbiosis

Photosynthesis and carbon translocation rates, both calculated in grams $\mathrm{C} /$ cell/h, were determined using the mean specific activity (grams $\mathrm{C} / \mathrm{dpm}$ ), the number of zooxanthellae, and the incubation time. Mean specific activity was calculated using an assumed inorganic carbon content of $0.024 \mathrm{~g} \mathrm{C}$ per liter of seawater (Davy and Cook 2001a).

\section{4 - Carbon Translocation in the Intact Symbiosis}

To study carbon translocation in the intact symbiosis, three anemones were allowed to settle overnight in separate $20 \mathrm{~mL}$ glass scintillation vials with $5 \mathrm{~mL} 1 \mu \mathrm{m}$ filtered seawater (FSW). A fourth vial was filled with $5 \mathrm{~mL}$ of FSW alone and served to provide background values for the ambient medium. Before the incubations, the FSW was replaced with fresh FSW and16 $\mu \mathrm{L}$ of $\mathrm{NaH}^{14} \mathrm{CO}_{3}(\sim 6 \mu \mathrm{Ci})$ were added to all 4 vials and the contents mixed. Two samples of $100 \mu \mathrm{L}$ each were immediately taken from the background seawater vial and $5 \mathrm{~mL}$ of OptiPhase Hi-Safe II scintillation fluid added. The specific activity of the added ${ }^{14} \mathrm{C}$ was measured with these samples. Anemones were then incubated on the light bank as previously described at an irradiance of $\sim 250 \mu \mathrm{mol}$ photons $/ \mathrm{m} 2 / \mathrm{s}$ for 30 minutes. After the incubation, all work was carried out in low light $\left(<1 \mu \mathrm{mol}\right.$ photons $\left./ \mathrm{m}^{2} / \mathrm{s}\right)$. Two samples of $200 \mu \mathrm{L}$ FSW were taken from each vial for measurement of dissolved organic carbon (DOC) release by the anemones. Anemones were then removed from the scintillation vials and rinsed in unlabelled FSW to eliminate excess $\mathrm{NaH}^{14} \mathrm{CO}_{3}$. 
Each anemone was homogenized in $1.5 \mathrm{~mL}$ FSW in a Wheaton ground glass tissue grinder. Of this homogenate, $1.3 \mathrm{~mL}$ was transferred into a $1.6 \mathrm{~mL}$ microcentrifuge tube and the remainder saved for zooxanthella counts. Tubes were vortexed and 200 $\mu \mathrm{L}(\mathrm{n}=2)$ of homogenate (algae + animal) from each tube were pipetted into clean 20 $\mathrm{mL}$ glass scintillation vials. Tubes were then centrifuged at 12,000 $\mathrm{g}$ for $1 \mathrm{~min}$ to separate animal and zooxanthella fractions. Two samples per anemone $(200 \mu \mathrm{L})$ of the supernatant were taken from each tube and placed in clean $20 \mathrm{~mL}$ glass scintillation vials. The algal pellet was then re-suspended in $1 \mathrm{~mL} \mathrm{FSW}$ and recentrifuged. Two samples $(200 \mu \mathrm{L})$ were taken of this second supernatant and kept separate from the first in clean $20 \mathrm{~mL}$ glass scintillation vials. The $200 \mu \mathrm{L}$ set aside from the original homogenate was centrifuged at $12,000 \mathrm{~g}$ for 1 minute and the supernatant poured off. The algal pellet was re-suspended in $0.5 \mathrm{~mL} \mathrm{FSW}$ and 6 cell counts were taken with a hemacytometer. All vials, except the added activity ones, were acidified with $200 \mu \mathrm{L}$ of $1 \mathrm{~N} \mathrm{HCl}$ to drive off unincorporated ${ }^{14} \mathrm{C}$. Vials were then left to dry completely and $5 \mathrm{~mL}$ OptiScint Hi-Safe II scintillation fluid added. Radioactivity was determined with a liquid scintillation counter as before.

The photosynthetic rate, carbon release rate and percentage release were calculated as for the host homogenate incubations.

\section{5 - Influence of HRF on Photosynthetic Health}

In light of the lysing and photoinhibition of zooxanthellae when exposed to Capnella gaboensis tissue homogenate (Sutton and Hoegh-Guldberg 1990), and the lack of host release factor response seen in homogenate experiments, questions were raised about the possibility of the animal homogenate affecting the photosynthetic health of the zooxanthellae. Pulse Amplitude Modulated (PAM) fluorometry (Figure 2.3) was employed to measure photosynthetic health of the zooxanthellae in host homogenate. PAM fluorometry has been used in many previous studies (e.g. Beer et al. 1998; Jones et al. 1999; Ralph et al. 1999) to measure health of zooxanthellae in corals and other hosts, and is a useful tool to quickly check if low translocation rates are due to photoinhibition or mortality of the algae. 


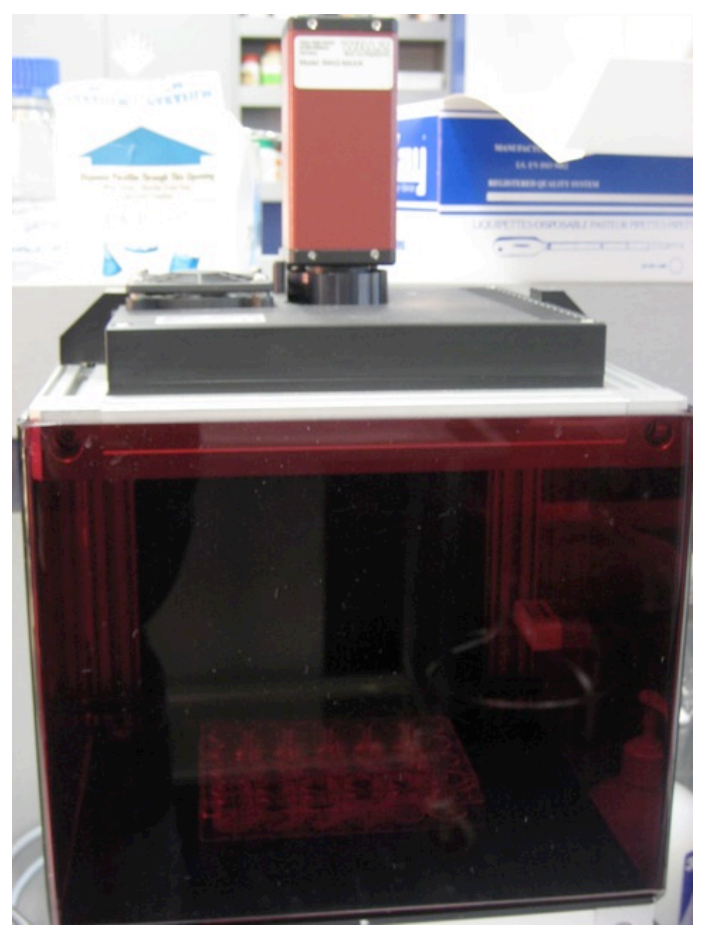

Figure 2.3: Heinz Walz Imaging PAM unit with well-plate in position for fluoremetry readings of zooxanthellae and host homogenate/FSW/Formalin incubations.

PAM fluorometry measures photosynthetic health by flashing a range of light intensities at a sample and measuring the fluorescence energy emitted by the sample. The measurement used to represent photosynthetic health is $\mathrm{Fv} / \mathrm{Fm}$, where Fm is the maximum fluorescence and $\mathrm{Fv}$ is the difference between the minimum (dark) fluorescence and the maximum fluorescence. To check for effects of the host tissue homogenate on the zooxanthellae, anemones were homogenized in a glass tissue grinder and the zooxanthellae extracted by centrifuging for $5 \mathrm{mins}$ at $12000 \mathrm{~g}$. The supernatant was poured off and the zooxanthellae resuspended in $5 \mathrm{~mL}$ FSW and centrifuged again to rinse off any residual animal tissue. The algae were then resuspended in $6 \mathrm{~mL} \mathrm{FSW}$ and 6 hemocytometer counts taken. Animal tissue homogenate was prepared in advance as before and diluted down to $50 \%$ and $25 \%$ strength with FSW. Zooxanthellae $(300 \mu \mathrm{L})$ were then pipetted into each of 20 wells on a well plate, and $600 \mu \mathrm{L}$ host homogenate (100, 50, or $25 \%$ strength)/FSW/ formalin was added as shown in Figure 2.4: 


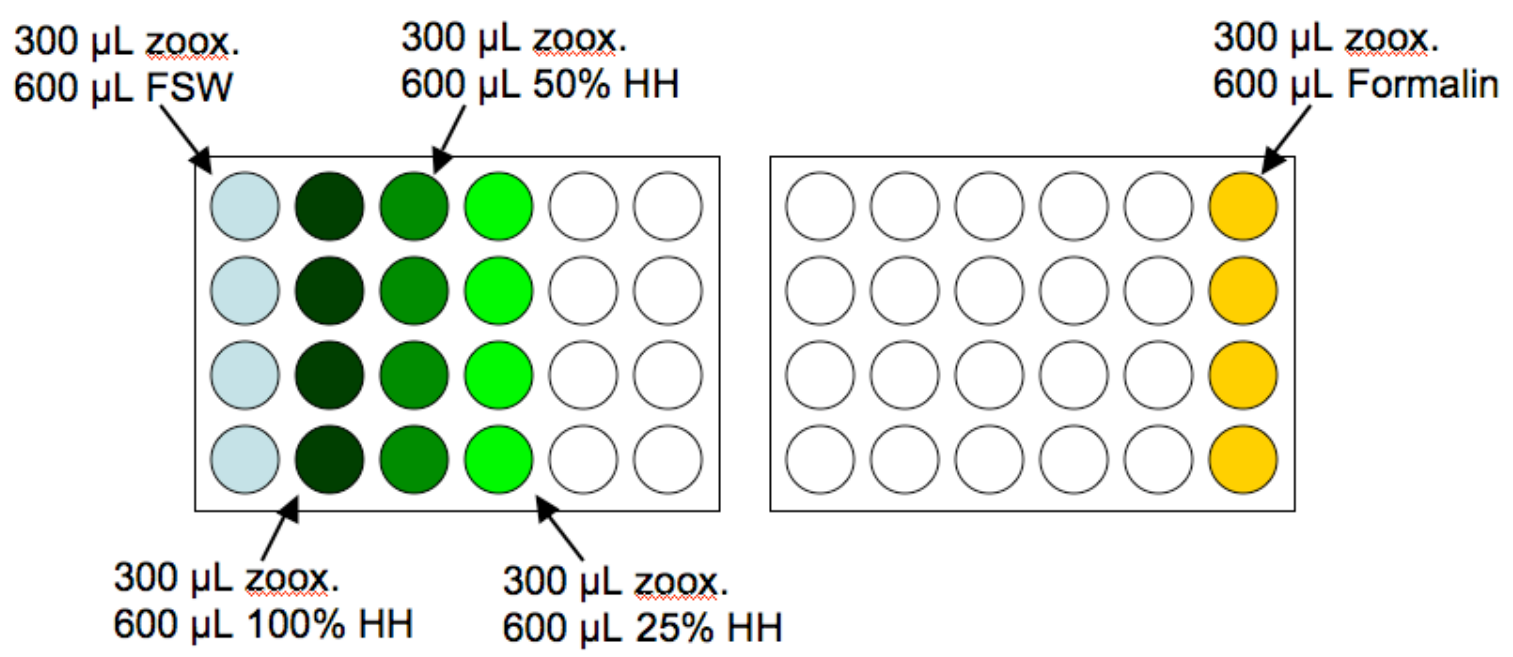

Figure 2.4: Well-plates as filled for PAM readings, all with $300 \mu \mathrm{L}$ zooxanthellae (zoox.), and $600 \mu \mathrm{L}$ of either FSW, host homogenate $(\mathrm{HH})$, or formalin. Formalin wells are on a separate plate to avoid contamination of other samples by formalin fumes.

Imaging PAM fluorometer readings were taken every 30 minutes for 5 hours, measuring the photosynthetic health $(\mathrm{Fv} / \mathrm{Fm})$ of the zooxanthellae over time when in the presence of the animal homogenate. Zooxanthella concentration was 1.41 million cells per $\mathrm{mL}$ in the first trial and 1.67 million cells per $\mathrm{mL}$ in the second trial. All PAM fluorometry was carried out using a Heinz Walz Imaging PAM unit, and all samples dark incubated for $\sim 2$ min before Fv/Fm was measured.

\section{6 - Statistical Analysis}

Photosynthetic rate, translocation rate, and percent translocation were compared between isolated and in hospite zooxanthellae using one-way ANOVA and Tukey post hoc analysis. Significant differences were determined at the $5 \%$ level. The same statistical methods were used to compare photosynthetic health among treatments. 


\section{Results}

\section{7 - Carbon Translocation in the Intact Symbiosis and Isolated Zooxanthellae}

Zooxanthellae in the intact symbiosis had an average photosynthetic rate of 1.175 +/- $0.452 \mathrm{pg} \mathrm{C/cell/h}$. Isolated zooxanthellae incubated in Anthopleura aureoradiata host homogenate had an average fixation rate of $1.48+/-0.417 \mathrm{pg}$ $\mathrm{C} / \mathrm{cell} / \mathrm{h}$, and isolated zooxanthellae incubated in FSW had an average fixation rate of $2.08+/-1.36 \mathrm{pg} \mathrm{C} / \mathrm{cell} / \mathrm{h}$ (Figure 2.5). None of the differences in fixation rates were significantly different (one-way ANOVA, $\mathrm{p}>0.05$ ). Note that all analyses of $\mathrm{HRF} /$ freshly isolated zooxanthellae include data from the freshly isolated zooxanthellae used in the cladal diversity/HRF experiments (see page 32).

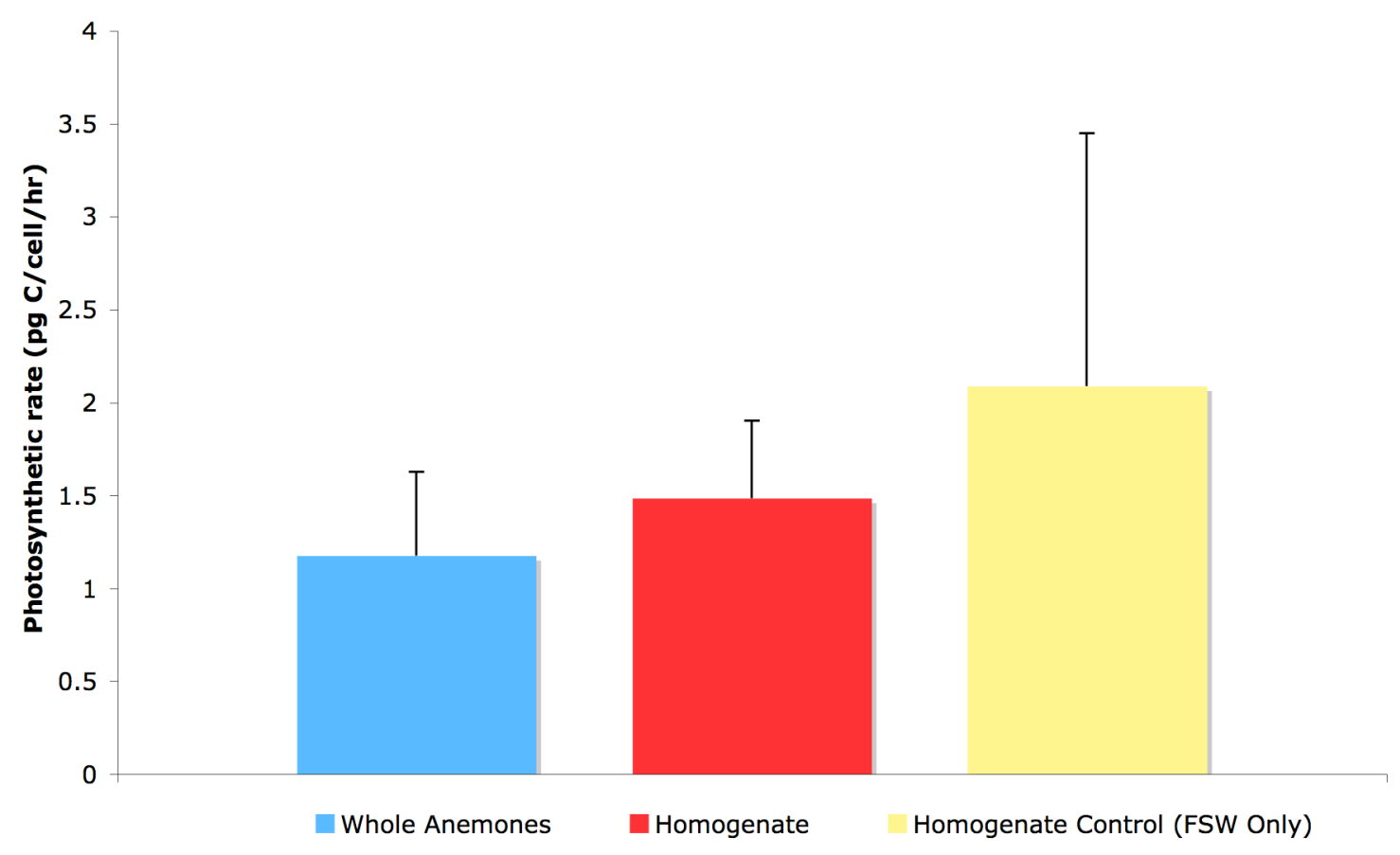

Figure 2.5: Photosynthetic rates of zooxanthellae in the intact symbiosis $(n=9)$, when incubated in host homogenate $(n=6)$, and when incubated in FSW $(n=6)$. All values are mean +1 s.d 
Percentage translocation values for the three treatments ranged from $40 \%+/-$ $11 \%$ in the intact symbiosis to $11 \%+/-8.5 \%$ in the freshly isolated seawater controls and $8 \%+/-5.5 \%$ in the freshly isolated homogenate incubations. Translocation values were significantly higher in the intact symbioses than with both trials of isolated zooxanthellae (Tukey post hoc one-way ANOVA, $\mathrm{p}<0.05)($ Figure 2.6).

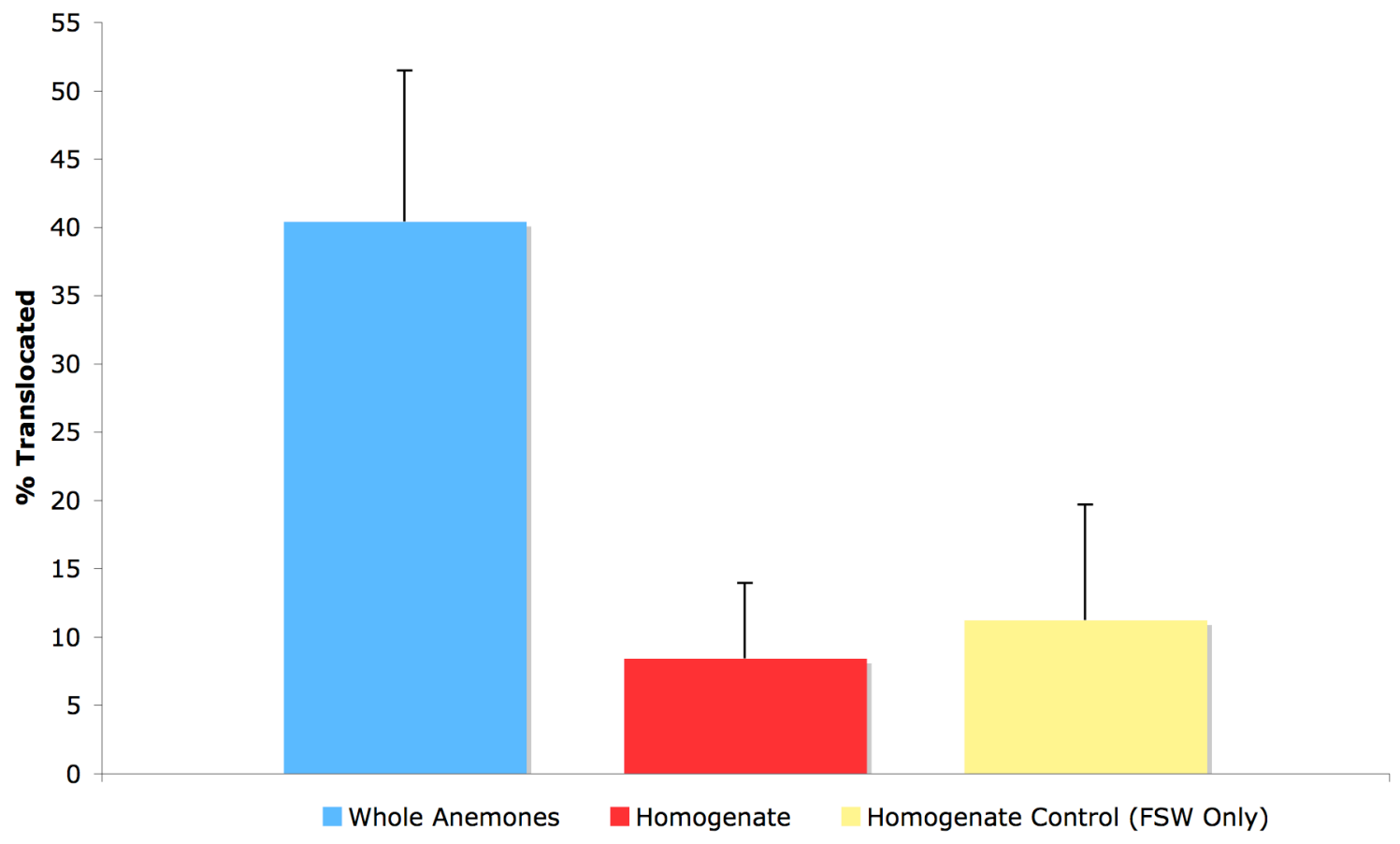

Figure 2.6: Translocation percents for the three treatments: zooxanthellae in the intact symbiosis $(n=9)$, isolated in host homogenate $(n=6)$, and incubated in FSW $(n=6)$. All values are mean +1 s.d. 
Translocation rates varied, with the rate in the intact symbiosis being $0.48+/$ $0.23 \mathrm{pg} \mathrm{C} / \mathrm{cell} / \mathrm{h}$, the rate in host homogenate $0.128+/-0.11 \mathrm{pg} \mathrm{C} / \mathrm{cell} / \mathrm{h}$, and the rate in FSW $0.243+/-0.24 \mathrm{pg} \mathrm{C/cell/h}$. However, the only significant difference was the higher rate in the intact symbiosis than when the freshly isolated zooxanthellae were incubated in host homogenate (Tukey post hoc one-way ANOVA, $\mathrm{p}<0.05$ )(Figure 2.7).

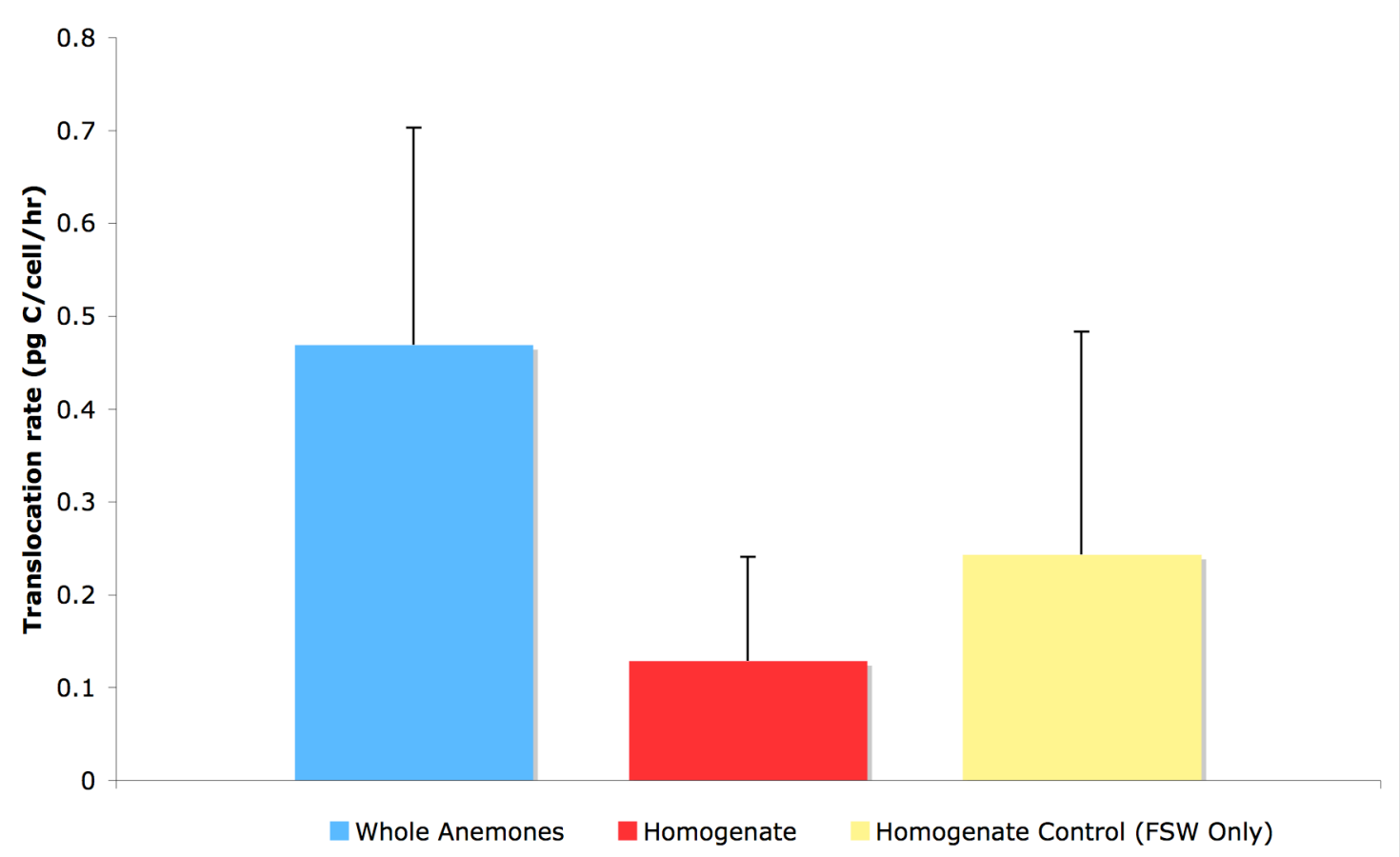

Figure 2.7: Translocation rates of zooxanthellae in the intact symbiosis $(n=9)$, incubated in host homogenate $(n=6)$, and incubated in FSW $(n=6)$. All values are mean +1 s.d. 


\section{8 - Influence of HRF on Photosynthetic Health}

Photosynthetic health of zooxanthellae freshly isolated from $A$. aureoradiata was measured with Imaging PAM (Figure 2.8). Health was measured as $F_{V} / F_{M}$ and plotted against time. Trials in FSW were consistently lower than those in host tissue, but were only significantly different from the $25 \%$ dilution. Values dipped at 4 hours, but then recovered at 5 hours. Table 2.1 shows the significant differences among these data (Tukey post hoc one-way ANOVA, $\mathrm{p}<0.05$ ).

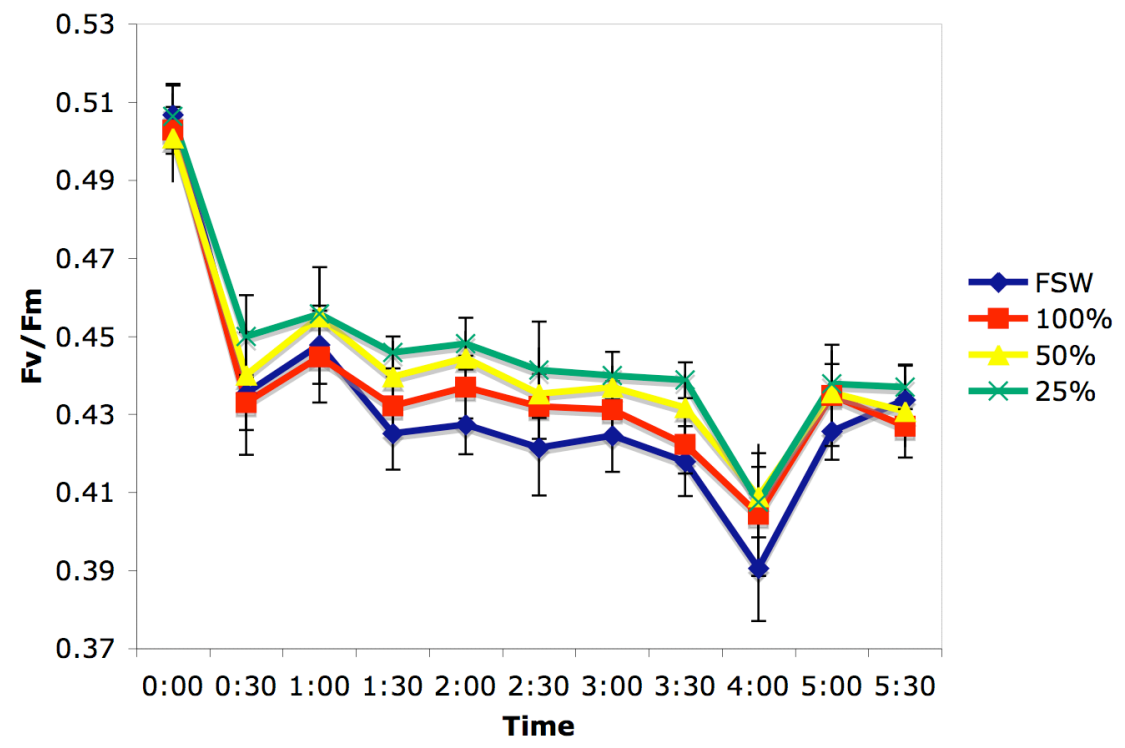

Figure 2.8: Photosynthetic health $(\mathrm{Fv} / \mathrm{Fm})$ of freshly isolated zooxanthellae incubated for 330 minutes in one of: FSW, $100 \%$ host homogenate, $50 \%$ dilute host homogenate, or $25 \%$ dilute host homogenate. No measurement was taken at 4:30. Values are means $+/-1$ s.d. All n=8.

Table 2.1: Significant differences (Tukey post hoc one-way ANOVA $p<0.05$ ) between Fv/Fm values at timepoints $(20-330 \mathrm{~min})$ when freshly isolated zooxanthellae were incubated in filtered seawater (FSW) or $25 \%, 50 \%$, or $100 \%$ host tissue homogenate.

\begin{tabular}{|c|c|c|}
\hline Time point & \multicolumn{2}{|c|}{$\begin{array}{c}\text { Significantly different } \\
\text { between: }\end{array}$} \\
\hline $30 \mathrm{~min}$ & $100 \%$ & $25 \%$ \\
\hline $90 \mathrm{~min}$ & FSW & $50 \%$ \\
\hline & FSW & $25 \%$ \\
\hline & $100 \%$ & $25 \%$ \\
\hline $120 \mathrm{~min}$ & FSW & $50 \%$ \\
\hline & FSW & $25 \%$ \\
\hline & $100 \%$ & $25 \%$ \\
\hline $150 \mathrm{~min}$ & FSW & $25 \%$ \\
\hline $180 \mathrm{~min}$ & FSW & $50 \%$ \\
\hline & FSW & $25 \%$ \\
\hline $210 \mathrm{~min}$ & FSW & $25 \%$ \\
\hline & $100 \%$ & $25 \%$ \\
\hline $240 \mathrm{~min}$ & FSW & $50 \%$ \\
\hline
\end{tabular}




\section{Discussion}

\section{9 - Host Release Factor}

Zooxanthellae in the intact symbiosis released $40 \%+/-11 \%$ of their fixed carbon to the host. This figure is comparable to those found in previous studies; for example, the temperate anemones Anemonia viridis and Anthopleura elegantissima have been found to have values of 40-50\% translocation (Trench 1971b; Stambler and Dubinsky 1987). Translocation percentages for other temperate species vary, with the soft coral Capnella gaboensis showing around 18\%, and the temperate zoanthid Zoanthus robustus showing 11-35\% (Sutton and Hoegh-Guldberg 1990). Values in tropical species tend to be similar; for example, algae in the tropical anemone Condylactis gigantea translocate $27 \%$ to the host, and the subtropical/tropical anemone Aiptasia pallida has shown translocation percentages from 40-82\% (von Holt and von Holt 1968; Clark and Jensen 1982). With percent translocation values as found, there is great potential for autotrophy under well-lit conditions in the field, particularly on rocky shores. However, Anthopleura aureoradiata is often found under the surface of mud, so it seems unlikely that autotrophy is essential for this species.

Freshly isolated zooxanthellae from Anthopleura aureoradiata did not show any conclusive effects of an HRF when incubated in host homogenate as compared to FSW incubations, as they released only $8 \%$ when incubated in host homogenate and $11 \%$ when incubated in FSW. However, zooxanthellae in the intact symbiosis released $\sim 40 \%$ of their fixed carbon to the host, so nutrient exchange is present in this symbiosis. Muscatine (1967) found that host tissue homogenates of the giant clam Tridacna crocea and scleractinian coral Pocillopora damicornis induced homologous algae to release nearly $40 \%$ of carbon fixed during host tissue homogenate incubations. In agreement with the results of Muscatine (1967), Withers et al. (1998) found in their trials with the coral Plesiastrea versipora that algae incubated in host homogenate consistently released more photosynthate than algae incubated in FSW, even when photosynthetic rates were lower in the host homogenate. Zooxanthellae from $P$. versipora released $13-41 \%$ of the total fixed carbon when incubated in host 
homogenate, as compared to 1-2\% when incubated in FSW (Withers et al., 1998). Similar results were found by Davy and Cook (2001) with the sub-tropical anemone Aiptasia pallida which released approximately $14 \%$ of photosynthate when incubated in host homogenate, and only 5\% when incubated in FSW.

Translocation rates were highest in the intact symbiosis and lowest in the host homogenate incubation. This shows that the zooxanthellae do release photosynthate to the host, but that homogenate of the host's tissue does not have the effect on the zooxanthellae as found in previous studies. Sutton and Hoegh-Guldberg (1990) looked at 4 temperate invertebrates: the soft coral Capnella gaboensis, the zoanthid Zoanthus robustus, the hard coral Plesiastrea versipora, and the nudibranch mollusc Pteraeolidia ianthina, and found significant effects of HRF only in P. versipora, leading them to conclude that host factors are likely not a universal property of symbiotic associations with zooxanthellae.

These differences of translocation rates and percentages between the intact symbiosis and the isolated symbionts could be due to some part of the homogenizing process damaging the HRF compound or zooxanthellae, or changing the physiology of the zooxanthellae to not respond to the HRF compound. If the HRF compound is damaged by the homogenization process, it perhaps argues against the HRF being a free amino acid and in favor of a more complex and thus, larger compound. Zooxanthellae in the intact symbiosis typically live in membrane-bound vacuoles that isolate them from the cytoplasm of host cells (Trautman et al. 2002). Not much is known about the conditions within the vacuoles, but it is possible that the membrane controls the compounds that the zooxanthellar cells are exposed to, and controls the contact of the zooxanthellae with the HRF compound; homogenization likely disrupts this symbiosome membrane.

It has previously been found that tissue extracts which induce HRF responses also increase photosynthetic rates in isolated zooxanthellae (Cook and Davy, 2001a). Photosynthetic rates in zooxanthellae isolated from $A$. aureoradiata were around $1 \mathrm{pg}$ $\mathrm{C} /$ cell $/ \mathrm{h}$, which is comparable to photosynthetic rates found by Davy and Cook (2001), who found rates of around $1 \mathrm{pg} \mathrm{C/cell/h}$ in zooxanthellae isolated from Aiptasia pallida. However, the data presented here show no increase in photosynthetic rate for $A$. aureoradiata when incubated in host tissue. They also show no significant decrease in photosynthetic rate in the presence of the host 
homogenate, so it does not appear that the host homogenate causes the zooxanthellae cells to lyse, as with C. gaboensis (Sutton and Hoegh-Guldberg, 1990), or to be photosynthetically inhibited as with Plesiastrea versipora homogenate (Grant et al. 2001; Grant et al. 2004). This was supported by the PAM experiments, which examined the photosynthetic health of the zooxanthellae in the presence of host homogenate. It was found that the lowest values of Fv/Fm were for the zooxanthellae incubated in FSW, though these values were only significantly lower than the $25 \%$ and $50 \%$ dilute homogenate incubations, and only at a few time points. Values of all algae at the first reading were consistent with those of healthy photosynthetic algae from previous studies (Jones et al. 1998; Fitt et al. 2001; Hill et al. 2004; Ralph et al. 2005). The initial drop in the Fv/Fm ratio can possibly be attributed to light shock of the algae (Fitt et al. 2001). This, however, cannot explain the dip after 4 hours, which may be an experimental artifact, as the values are averages of the two trials. It is interesting to note that photosynthetic rates appeared highest in FSW incubations, but that photosynthetic health was highest in host homogenate, possibly because the host homogenate slows photosynthetic fixation, while not affecting the health or potential of the algae to perform photosynthesis. This could be interpreted as evidence for a photosynthetic inhibiting factor (PIF) in A. aureoradiata host tissues, though it was not as evident in the $100 \%$ dilution incubation as would be expected. Grant et al. (2001) looked at photoinhibition by a fraction of host homogenate, but did not examine if it affected photosynthetic potential, or just limited fixation. In $A$. aureoradiata there may be some form of PIF that affects carbon fixation rate without damaging photosynthetic capabilities.

In conclusion, zooxanthellae from Anthopleura aureoradiata release $40 \%$ of fixed carbon in the intact symbiosis, but show no evidence for a host release factor when isolated and incubated in host tissue homogenate. Translocation and photosynthetic rates were consistently lower in host homogenate incubations when compared to FSW controls. The lack of an HRF response in homologous zooxathellae implies either the absence of such a compound in A. aureoradiata tissues, or that the isolated homologous algae lack the capacity to respond to it. The next chapter aims to determine if heterologous algae may be able to respond to the HRF of $A$. aureoradiata, or if it is not active in homogenized tissues of this anemone. 


\section{Heterologous Algae and HRF Response in A. aureoradiata Host Tissue Homogenate}

\section{1 - Heterologous zooxanthellae and host factor assays}

Exceptional diversity within the genus Symbiodinium has been discovered through advances in molecular techniques as discussed in the introduction (LaJeunesse 2001; Santos et al. 2001). Physiological variation amongst the molecularly defined types of zooxanthellae clearly exists, and may be responsible for some variation in host-symbiont pairings. Even with this diversity, some hosts have been found to pair with multiple types of zooxanthellae across their range, and can also be induced to take up different types of zooxanthellae (Trench 1971a; Kinzie and Chee 1979; Coffroth et al. 2001; LaJeunesse 2002).

Davy and Cook (2001b) found similar responses to host homogenate incubations of homologous and heterologous zooxanthellae, and suggested this could be indicative of a similar release mechanism in a number of host species. Such similarities could be important if hosts acquire a new type of zooxanthellae, for example after bleaching events (Buddemeier and Fautin 1993). In this case, HRF would need to have an effect on heterologous symbionts to induce the release of photosynthetic products to the host. Muscatine (1967) found that the host homogenate from Pocillopora damicornis induced release of photosynthate from zooxanthellae isolated from Tridacna crocea. A similar trend was also found by Sutton and Hoegh-Guldberg (1990) who found that zooxanthellae isolated from Plesiastrea versipora and Zoanthus robustus both showed HRF effects when incubated in host tissue homogenate from $P$. versipora.

In Chapter 2 there was no HRF response of Anthopleura aureoradiata homogenate in freshly isolated zooxanthellae (FIZ). This could have been because the algae do not respond, and/or because an active HRF compound is not present in $A$. 
aureoradiata tissues. This chapter aims to establish if host tissue homogenate from A. aureoradiata contains HRF that induces responses from heterologous zooxanthellae of clades A-E.

\section{Materials and Methods}

\section{2 - Algal Clades from Culture}

Cultures were acquired from Dr. Scott Santos (Auburn University, USA) and maintained in a Contherm incubator at $26^{\circ} \mathrm{C}$ on a $12 \mathrm{~h}$ light/ $12 \mathrm{~h}$ dark cycle (Figure $3.1)$.

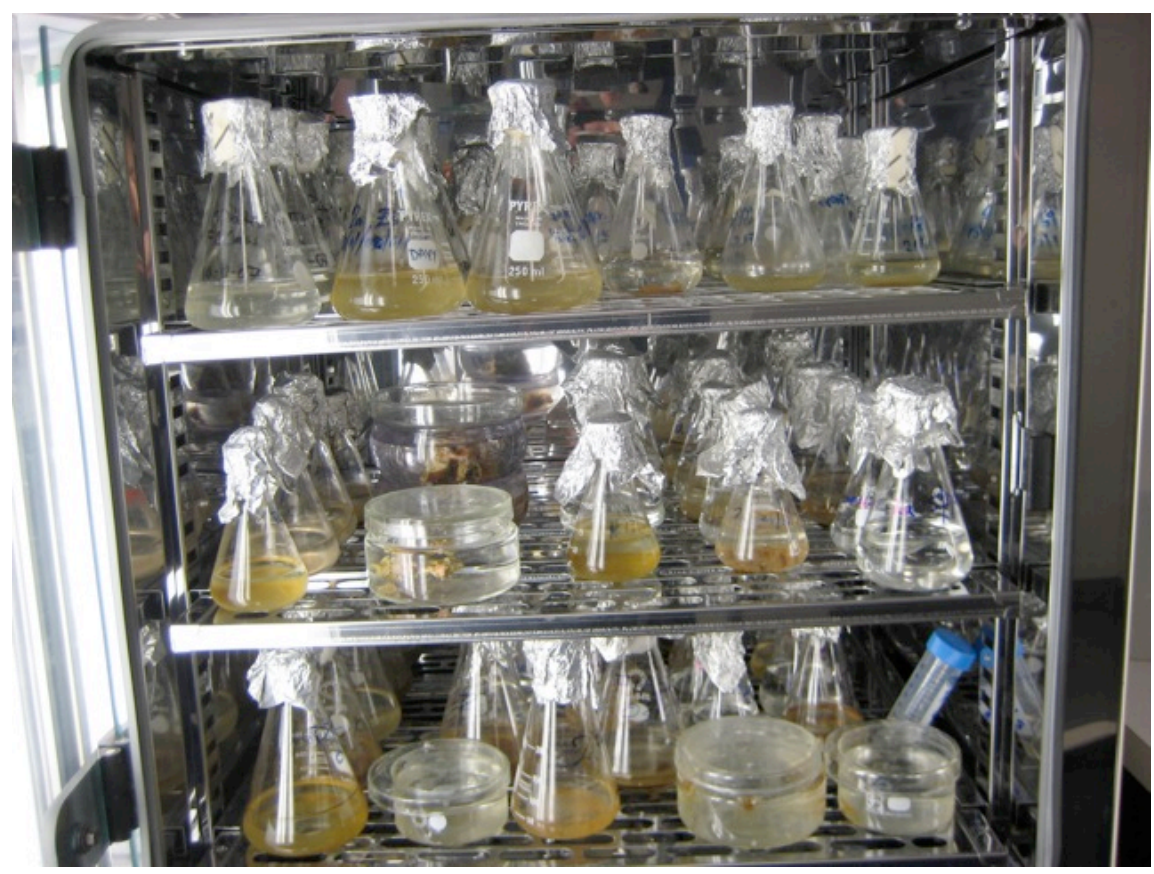

Figure 3.1: Cultured zooxanthellae as maintained in the Contherm incubator

Cultures were subcultured every 3-6 weeks and antibiotics were added about every 6 months to eliminate unwanted bacteria. Cultures used for experiments were used within 2 months of subculturing. All cultures were kept in $f / 2$ silica-free medium (Sigma) to eliminate growth of diatoms. The zooxanthellar types used for the $\mathrm{HRF} /$ zooxanthellae diversity experiments are shown in Table 3.1 (next page). 
Table 3.1: Table of host species, locations, clades, and sources of each of the zooxanthellar types used in HRF/zooxanthellae diversity experiments. All cultures except for zooxanthellae from Anthopleura aureoradiata.

\begin{tabular}{|c|c|c|c|c|c|}
\hline Clade & Abbreviation & Host & Organism & Location & Source \\
\hline A & FLCass & $\begin{array}{c}\text { Cassiopeia } \\
\text { xamachana }\end{array}$ & Jellyfish & Long Key, FL & S.R. Santos \\
\hline B & Pk13 & Plexaura kuna & Soft Coral & $\begin{array}{c}\text { Three Sisters, } \\
\text { FL }\end{array}$ & $\begin{array}{c}\text { M.A. } \\
\text { Coffroth }\end{array}$ \\
\hline B & Pd & $\begin{array}{c}\text { Pocillopora } \\
\text { damicornis }\end{array}$ & Hard Coral & Hawaii & $\begin{array}{c}\text { M.A. } \\
\text { Coffroth }\end{array}$ \\
\hline C & Mp & Mastigias paupa & Jellyfish & Palau & R.A. Kinzie \\
\hline C & Sin & Sinularia sp. & Soft Coral & Guam & M. Hidaka \\
\hline D & A001 & Acropora sp. & Hard Coral & Okinawa & $\begin{array}{c}\text { Bigelow } \\
\text { Marine Lab }\end{array}$ \\
\hline E & CCMP421 & Free-Living & & Wellington, NZ & S. Phillips \\
\hline A & FIZ & $\begin{array}{c}\text { Anthopleura } \\
\text { aureoradiata }\end{array}$ & $\begin{array}{c}\text { Sea } \\
\text { Anemone }\end{array}$ & Wellington, NZ & \\
\hline
\end{tabular}

\section{3 - HRF Response in Heterologous vs. Homologous Zooxanthellae}

HRF incubations were run as in chapter 2. Each trial consisted of 3 replicates of each of 2 clades of zooxanthellae and 3 replicates of freshly isolated zooxanthellae (FIZ) as a comparison. FIZ were prepared as in chapter 2. Zooxanthellae from cultures were prepared by swirling the culture and pipetting $10 \mathrm{~mL}$ into a clean $15 \mathrm{~mL}$ centrifuge tube and centrifuging at 12,000 g for 5 minutes. The culture-medium supernatant was poured off and the remaining algal pellet was re-suspended in $1.2 \mathrm{~mL}$ $1 \mu \mathrm{M}$ FSW to concentrate the algal suspension. Host homogenate for all experiments was prepared as in Chapter 2 and frozen for continued use in all trials. All experiments were completed in 14 days to limit effects of differences in growth cycles of the algae. Rates of photosynthesis and translocation were estimated as in Chapter 2.

\section{4 - Statistical Analysis}

Differences between host homogenate and FSW of the clades were analyzed using the students t-test. Photosynthetic and translocation rates, as well as percentage translocation were compared significance between clades using one-way ANOVA and Tukey post-hoc analyses. Significance was determined at the 5\% level. 


\section{Results}

\section{5 - HRF Effect vs. Cladal Diversity}

Heterologous zooxanthellae were incubated in Anthopleura aureoradiata host tissue homogenate to ascertain if there is evidence for HRF in A. aureoradiata tissue. Table 3.2 shows the clades of Symbiodinium that had photosynthetic or translocation rates that were significantly lower in host tissue homogenate incubation than the control FSW incubation. With regards to photosynthetic fixation rates (Figure 3.2A), all FSW incubations had higher fixation rates than host homogenate incubations, but were only statistically different as shown in Table 3.2.

Table 3.2: Summary of t-test comparisons between host homogenate incubations and FSW incubations with regards to photosynthetic rates and translocation rates of zooxanthellae from clades A-E. Significance was defined by t-test. ( $\mathrm{n}=6$ (clade $\mathrm{A}) \mathrm{n}=3$ (all other clades)). ** indicates a significant difference, $\mathrm{p}<0.05$.

\begin{tabular}{|c|c|c|}
\hline Clade & Photosynthetic rate & Translocation rate \\
\hline A & $* *$ & $* *$ \\
\hline B & ns & $\mathrm{Ns}$ \\
\hline $\mathrm{C}$ & $* *$ & $* *$ \\
\hline $\mathrm{D}$ & $* *$ & $* *$ \\
\hline $\mathrm{E}$ & $* *$ & Ns \\
\hline Freshly Isolated (A) & ns & $* *$ \\
\hline
\end{tabular}


Significantly different photosynthetic fixation rates in FSW incubations were 1.2-1.8 times higher than rates in host tissue incubations. When compared to one another, rates were different between clade A and the FIZ (also clade A), where fixation rates in the freshly isolated zooxanthellae were 6.5 times higher than those from cultured clade A. Rates were also different between the freshly isolated zooxanthellae and those from clade D, where the fixation rate of the FIZ was 3.7 times that of the clade D zooxanthellae (Figure 3.2).

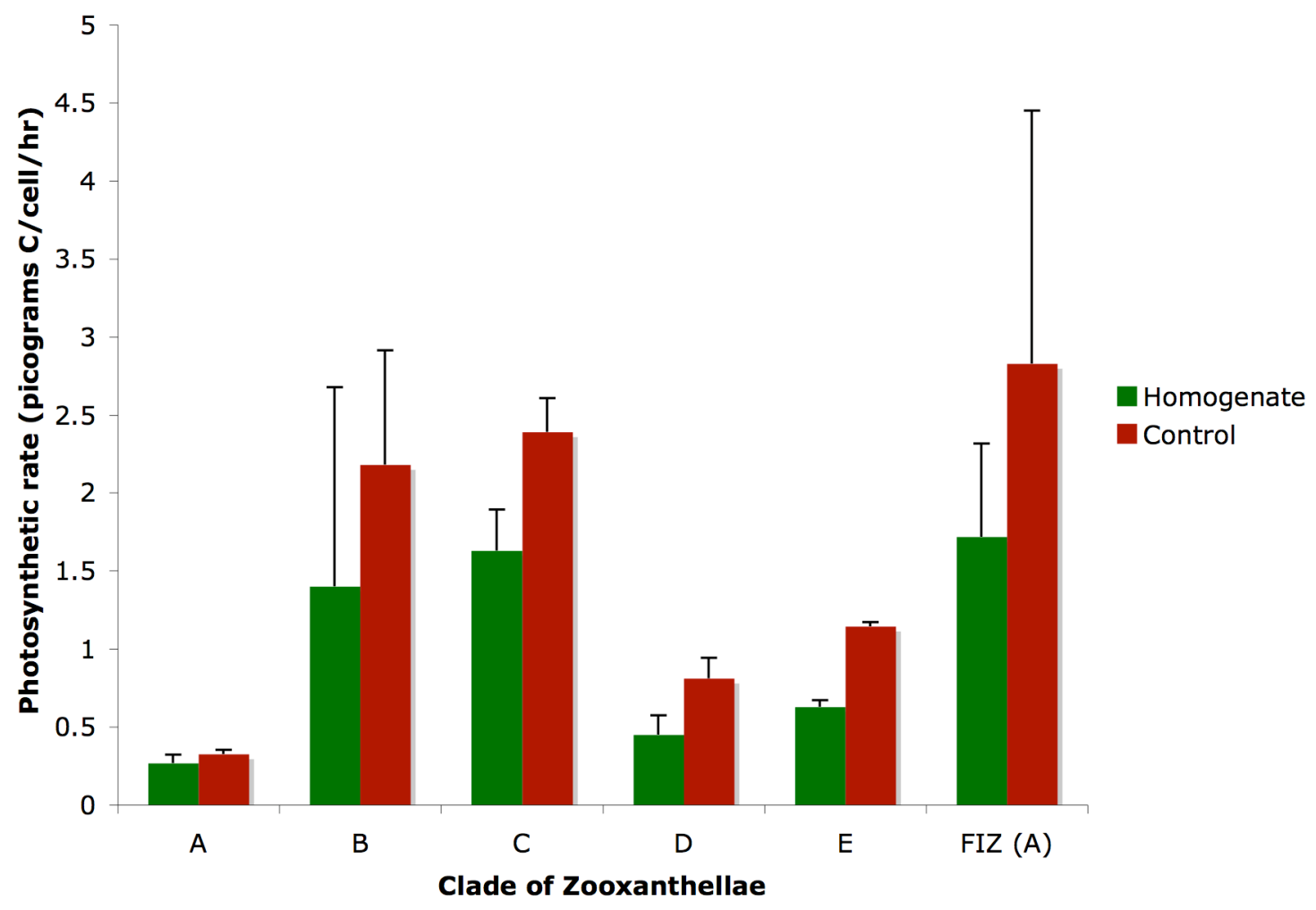

Figure 3.2: Photosynthetic rates of the clades A-E from culture and freshly isolated zooxanthellae (FIZ) (clade A), when incubated in host homogenate of Anthopleura aureoradiata and FSW. All values are mean +1 s.d. (clade A $n=6$, clades B-E $n=3$ ). 
Translocation rates (pg C/cell/hour) tended to be higher in the FSW incubations than in the host homogenates for all cultured algae, but these differences were only significant for clades A, C, D, and the freshly isolated algae (clade A) (ttest $\mathrm{p}<0.05)($ Figure 3.3). Translocation rates in FSW incubations were 1.7-4 times higher than rates in host homogenate incubations. Differences between the clades with respect to translocation rates were only evident amongst the FSW controls, and only between clades A and C (Tukey post hoc one-way ANOVA, $\mathrm{p}<0.05$ ). Clade C had translocation rates 3 times those in the cultured clade A.

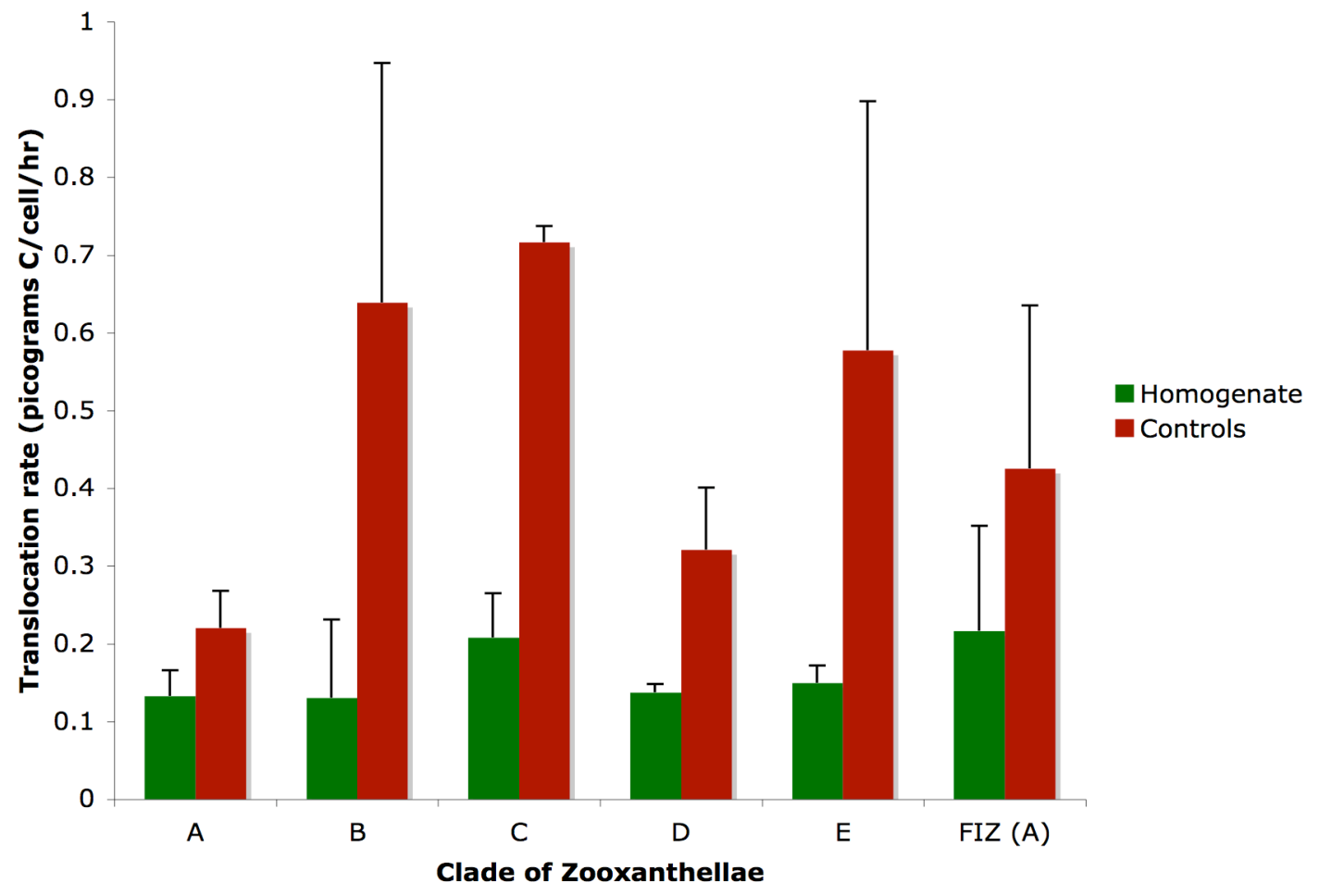

Figure 3.3: Translocation rates of clades A-E from culture and freshly isolated zooxanthellae (FIZ) (clade A), when incubated in $A$. aureoradiata host homogenate and FSW. All values are mean +1 s.d. (clade A $\mathrm{n}=6$, clades B-E $\mathrm{n}=3$ ). 
Percentage translocation showed the same trends as photosynthetic fixation and translocation rates, with percentages for FSW incubations 1.2-2.5 times higher than those from host homogenate incubations (Figure 3.4). Differences were only significant for the cultured clade $\mathrm{A}$, and clade $\mathrm{C}$ (t-test, $\mathrm{p}<0.05)$. Percentage translocation differences amongst the clades in host homogenate were only significant between the cultured clade A and all others except for clade E, with translocation percents more than 1.5 times greater than the rest. In FSW incubations, the cultured clade A again had translocation percents ranging from 1.3- nearly 4 times higher than all other clades. These differences were only significant, however, between the cultured clade A and clades B, C, and FIZ (Tukey post hoc one-way ANOVA, p $>0.05)$.

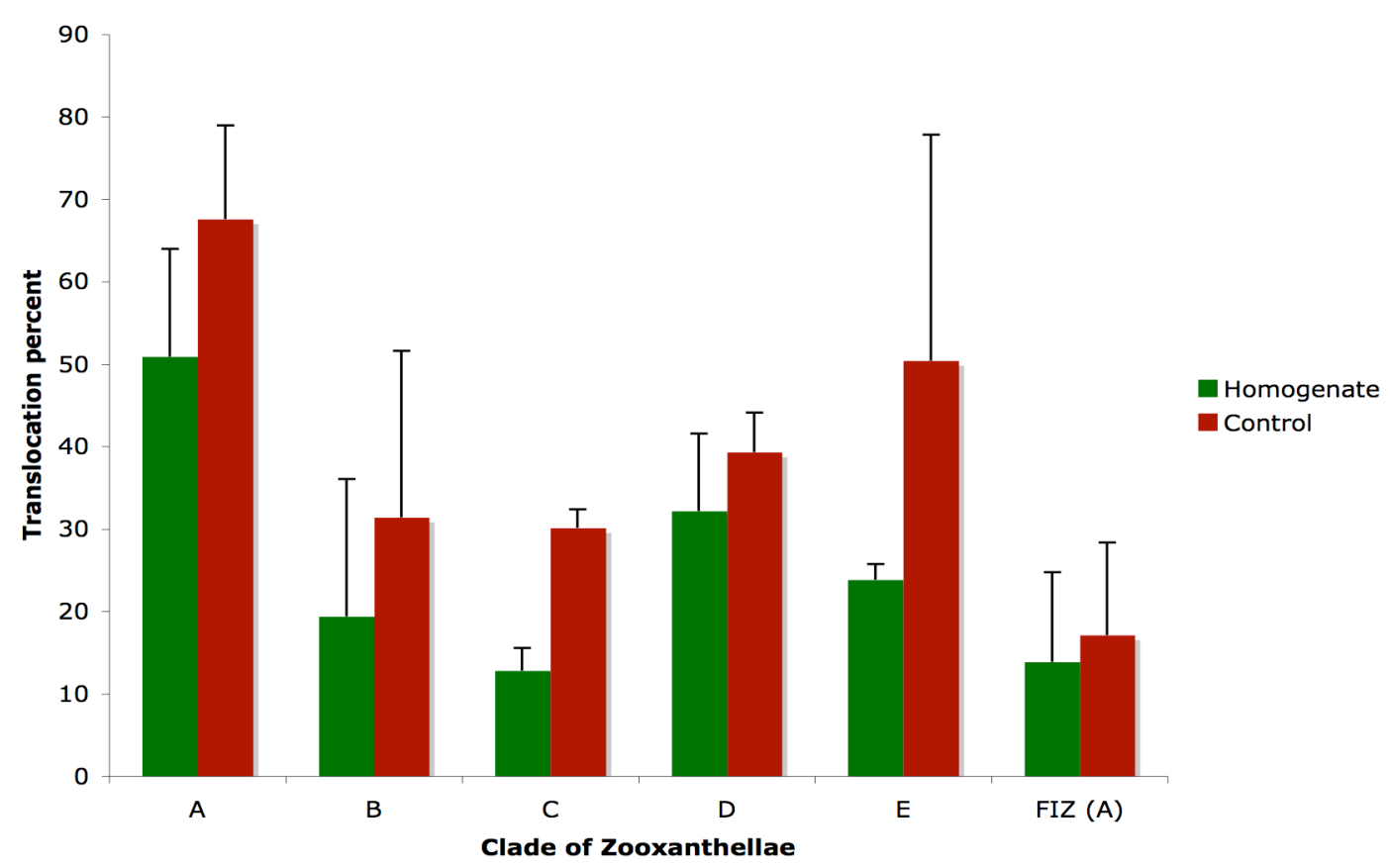

Figure 3.4: Percent translocation of zooxanthellae from 5 different clades (A-E) incubated for 30 minutes in Anthopleura aureoradiata homogenate or FSW. All values are mean +1 s.d. (clade A n=6, clades $B-E n=3$ ). 


\section{Discussion}

\section{6 - Diversity}

Anthopleura aureoradiata tissues were tested for evidence of HRF by incubating heterologous zooxanthellae in A. aureoradiata host tissue homogenate. All of the clades measured (A-E) showed higher photosynthetic rates and translocation rates in FSW incubations, with host tissue homogenate incubations usually significantly lower. These decreased photosynthetic rates of heterologous zooxanthellae incubated in host homogenate support the idea that there is a compound present in the host homogenate that inhibits carbon fixation. Grant et al. (2001) found evidence of a photosynthetic inhibiting factor (PIF) present in host tissue homogenate of Plesiastrea versipora; this is the only species that has been studied for PIF. Later studies showed that PIF in $P$. versipora tissue affected homologous zooxanthellae and some heterologous zooxanthellae (Grant et al. 2006). Evidence for PIF in $A$. aureoradiata was found in every clade except for "B", the only clade where the photosynthetic rates in the FSW incubations were not significantly higher than those in host homogenate.

No PAM fluorometry experiments were run on the heterologous zooxanthellae to see if, like the homologous zooxanthellae in Chapter 2, the photosynthetic health was still intact. It is interesting to note that the freshly isolated zooxanthellae, which are clade A, and the cultured clade A (from the jellyfish C. xamachana) had very different responses to the host homogenate. While both showed no increase in the rates of translocation or photosynthesis in host homogenate, the photosynthetic rates

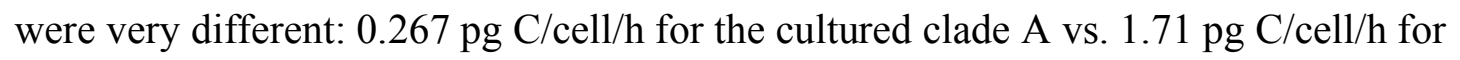
the freshly isolated clade A. Stat et al. (2008) looked at differences between clades A and $\mathrm{C}$ and determined that clade $\mathrm{A}$ is more closely related to free-living dinoflagellates, and closer to being parasitic than are other clades. This difference could be attributed to the inherent variation between a cultured symbiont and a freshly isolated one. Previous studies have shown physiological differences between cultured and freshly isolated zooxanthellae, perhaps resulting from the lack of the host-derived symbiosome membrane around cultured zooxanthellae (Trautman et al. 2002). These differences could also be attributed to the diversity within clades, though inter- and 
intra-cladal differences in photosynthesis and photosynthate release have not been studied in other systems to date (Rowan 1998).

Many differences have been found between HRF for different host species in terms of specificity, thermal stability, effects on the amount of fixation, and the type of compounds released by algae in their presence. As evidenced by Muscatine (1967), some HRFs are not specific to hosts and can stimulate photosynthate release in algae isolated from different symbiotic associations. Some are specific, as demonstrated by Sutton and Hoegh-Guldberg (1990) when HRF from Plesiastrea versipora did not elicit any response from algae isolated from Pteraeolidia ianthina, though it had an effect on its own algae. Thermal stabilities of HRF are also variable: Gates et al. (1995) found that boiling the host homogenate of Pocillopora damicornis had no effect on the HRF activity, while boiling the host homogenate of Anthopleura elegantissima and $P$. versipora destroyed their HRF activity (Trench 1971). This suggests that HRF may not be the same compound across different host species. However, the success of other experiments to induce HRF responses in heterologous zooxanthellae indicate that there must be some similarities between host species and the composition of any HRF present.

Data from this chapter continue to support the suggestion that there is no HRF present in Anthopleura aureoradiata. There was no response measured with either homologous or heterologous zooxanthellae. However, preliminary evidence suggested that different types of zooxanthellae have differing photo-physiologies and may release differing amounts of photosynthate. This could have implications for the health of the host organism. 


\section{Carbon translocation and nutritional status}

\section{1 - Nutritional Status and Carbon Translocation}

It has been suggested previously that carbon translocation from zooxanthellae to host may be inversely related to the nutritional status of the zooxanthellae. Nitrogen-limited zooxanthellae do not have the required nutrients to grow, and thus are thought to translocate carbon originally meant for growth to the host (Falkowski et al. 1993; Dubinsky and Jokiel 1994). Nutritional status of zooxanthellae is often measured using ammonium enhancement of dark carbon fixation (Cook et al. 1992, 1994; Davy and Cook 2001). Ammonium enhancement of dark carbon fixation to measure nutritional status of zooxanthellae is based on previous evidence that $\mathrm{NH}_{4}^{+}$ stimulates dark fixation in cells with low nitrogen supply (Morris et al. 1971; Yentsch et al. 1977).

Previous experiments have shown no 'host release factor' effects on either heterologous or homologous zooxanthellae incubated in Anthopleura aureoradiata host tissue homogenate. It is thought that as zooxanthellae are starved of nitrogen, they do not have the necessary nutrients for growth, and thus would release surplus carbon to the host. Davy and Cook (2001a) found that as they starved the sea anemone Aiptasia pallida over 114 days there was no change in the percent translocation in the intact symbiosis. However, Davy and Cook (2001b) ran a similar starvation experiment on freshly isolated zooxanthellae in host homogenate incubations for the sea anemones Aiptasia pallida and the coral Montastraea annularis and found that starvation increased percent translocation, and decreased photosynthetic rates. It follows that potentially starving zooxanthellae from 
Anthopleura aureoradiata could induce an HRF response in host homogenate incubations.

Nitrogen sufficiency in the field of temperate algal-invertebrate symbioses has not been widely studied, but the studies that exist show nitrogen sufficiency in temperate waters, and recent work by S. Morar (VUW; unpublished data) shows nitrogen sufficiency of the zooxanthellae in $A$. aureoradiata from Pauatahanui Inlet. If $A$. aureoradiata is nitrogen sufficient in the field and when well-fed in the lab, it could be inferred that the zooxanthellae have sufficient nutrients to grow, and may not have surplus carbon to release to the host. This chapter investigates the effects of starvation on nitrogen status of zooxanthellae isolated from A. aureoradiata and further, the possibilities of inducing a 'host release factor' response from zooxanthellae isolated from $A$. aureoradiata by limiting their nitrogen supply and hence growth.

\section{Materials and Methods}

\section{2 - Experimental Organisms}

Anthopleura aureoradiata specimens for nitrogen status experiments were collected from Pauahatanui Inlet on 11 September 2007, three weeks before the beginning of the experiment. All anemones were fed three times a week for the 3 weeks leading up to the experiment. Anemones used were kept in various size bowls containing $500 \mathrm{~mL}-1 \mathrm{~L}$ nitrogen-free artificial seawater (N-free ASW), which was made following the prodecure of Kester et al. (1967). This recipe was made up as in table 4.1. Anemones were kept under the same environmental regime as eachother.

Table 4.1: Recipe used for nitrogen-free artificial seawater used throughout trials.

\begin{tabular}{|l|l|}
\hline $\mathrm{Salt}$ & $\mathrm{g} / \mathrm{kg}$ of distilled water \\
\hline $\mathrm{NaCl}$ & 23.9 \\
\hline $\mathrm{Na}_{2} \mathrm{SO}_{4}$ & 4.01 \\
\hline $\mathrm{KCl}$ & 0.677 \\
\hline $\mathrm{NaHCO}$ & 0.196 \\
\hline $\mathrm{KBr}$ & 0.098 \\
\hline $\mathrm{H}_{2} \mathrm{BO}_{3}$ & 0.026 \\
\hline $\mathrm{NaF}$ & 0.003 \\
\hline
\end{tabular}




\section{3 - Nitrogen Status of Zooxanthellae}

Dark carbon fixation rates were measured using $\mathrm{NaH}^{14} \mathrm{CO}_{3}$ incubations The following method was adapted from the original design of Cook et al. (1992), and was repeated at 2 week intervals for 8 weeks to measure nutritional status of $A$. aureoradiata when kept in nitrogen-free artificial seawater and starved.

As outlined in figure 4.1, at each time point, 5 anemones $(\sim 5-8 \mathrm{~mm}$ oral disc diameter) were homogenized separately in a Wheaton ground glass tissue grinder in $\mathrm{N}$-free ASW. This homogenate was then centrifuged at $12000 \mathrm{~g}$ for 5 minutes and the supernatant poured off. The algal pellet was re-suspended in $5 \mathrm{~mL}$ FSW and centrifuged again at $12000 \mathrm{~g}$ for 5 minutes to rinse any residual animal tissue from the zooxanthellae. The supernatant was then decanted off once more and the zooxanthellae were re-suspended in $1.6 \mathrm{~mL} \mathrm{~N}$-free ASW. Six hemocytometer counts were then made of all 5 algal suspensions and zooxanthella concentrations were normalized to match the lowest recorded by dilution with N-free ASW. Plastic scintillation vials $(6 \mathrm{~mL})$ were wrapped in black electrical tape to prevent light exposure for dark fixation samples. For each of the anemones, 5 vials were filled with $0.5 \mathrm{~mL}$ of algal suspension and $0.5 \mathrm{~mL}$ of either $\mathrm{N}$-free ASW (x2) or $40 \mu \mathrm{M}$ $\mathrm{NH}_{4} \mathrm{Cl}$ in $\mathrm{N}$-free $\mathrm{ASW}$ (x2). All remaining zooxanthellae were combined, and 4 vials filled with $0.5 \mathrm{~mL}$ zooxanthellae and $0.5 \mathrm{~mL}$ of $20 \%$ formalin, saturated with sodium tetraborate; these acted as 'background' activity vials. Vials with black tape were then placed in the dark to pre-incubate for 45 minutes. Then in low light levels $(<1$ $\mu \mathrm{mol}$ photon $/ \mathrm{m}^{2} / \mathrm{s}$ ) to minimize ${ }^{14} \mathrm{C}$ incorporation, $20 \mu \mathrm{L}$ dilute $\mathrm{NaH}^{14} \mathrm{CO}_{3}$ stock (1 $\mu \mathrm{Ci}$ ) was added and the vials sealed. Vials were incubated in darkness for 4 hours. All dark incubations were at room temperature $\left(17^{\circ} \mathrm{C}\right)$, with vials kept in a dark box. Incubations were ended when $0.5 \mathrm{~mL}$ of $1 \mathrm{~N} \mathrm{HCl}$ was added to drive off unincorporated ${ }^{14} \mathrm{C}$. Samples were left to dry on a heating block at $37^{\circ} \mathrm{C}$ covered to ensure no light enhancement of carbon fixation.

During the pre-incubation of the dark fixation vials, incubations in saturating light were carried out. Twenty $\mu \mathrm{L}$ of dilute $\mathrm{NaH}^{14} \mathrm{CO}_{3}$ stock $(1 \mu \mathrm{Ci})$ was added to 5 vials to be incubated in the light. $100 \mu \mathrm{L}$ was immediately sampled from one formalin vial for added activity readings. Vials were then incubated for 30 minutes on a light rack, which consisted of a clear plexiglass box above 4 fluorescent bulbs 
and next to $4 \times 40-\mathrm{W}$ cool-white lamps, producing an irradiance of $\sim 250 \mu \mathrm{mol}$ photons $\mathrm{m}^{-2} \mathrm{~s}^{-1}$. This incubation was ended by the addition of $0.5 \mathrm{~mL} 1 \mathrm{~N} \mathrm{HCl}$. Vials were then left on a heating block at $37^{\circ} \mathrm{C}$ until dry to eliminate unincorporated ${ }^{14} \mathrm{C}$. 


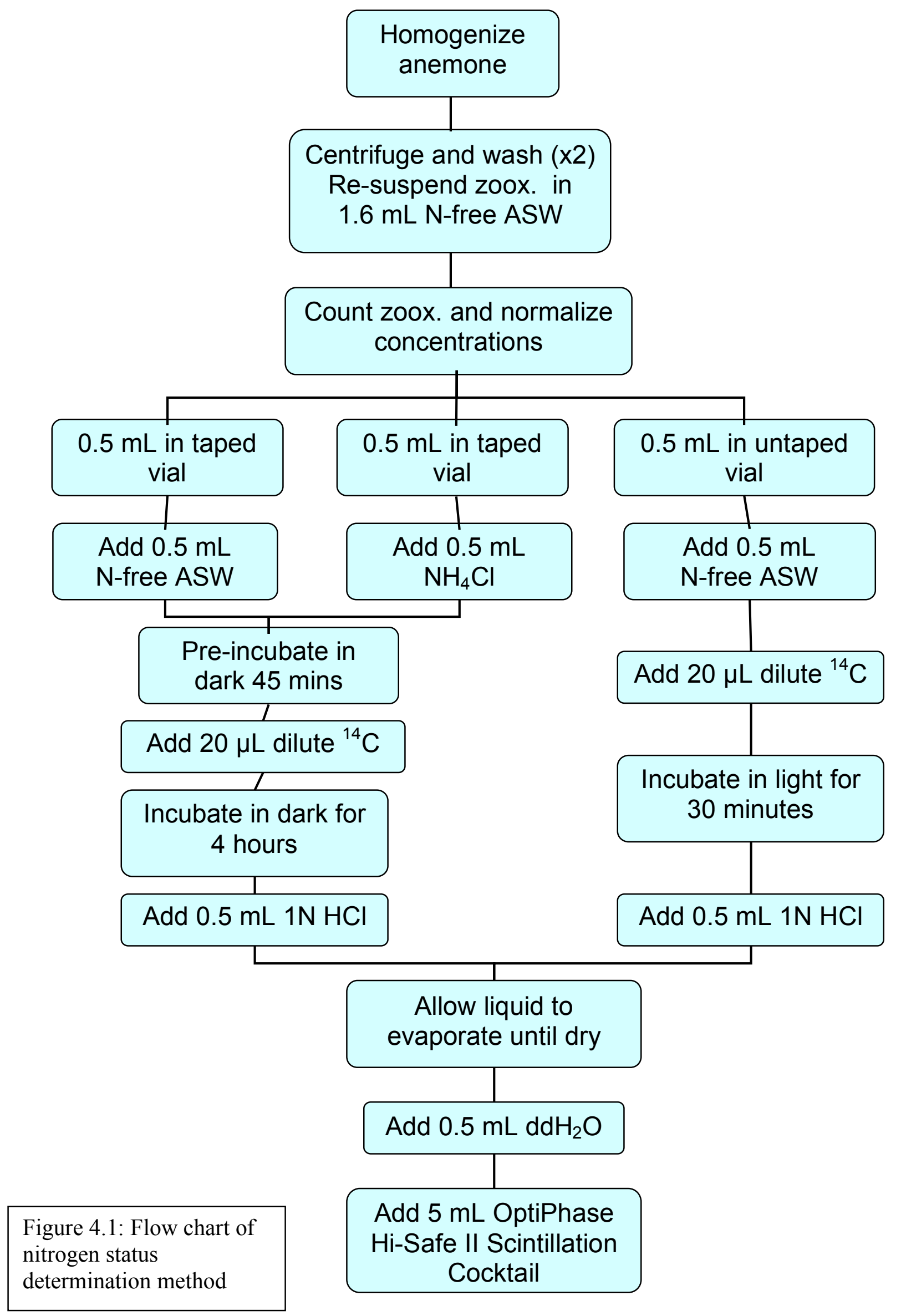


When all vials were dry, $0.5 \mathrm{~mL} \mathrm{ddH}_{2} \mathrm{O}$ was added, followed by $5 \mathrm{~mL}$ OptiPhase Hi-Safe II Scintillation Cocktail (Perkin-Elmer). Black tape was then removed from vials and all radioactivity was counted on a Wallac 1409 Liquid Scintillation Counter.

\section{4 - 'HRF' Activity vs. Nitrogen Status}

Measuring for a host release factor response was done following the procedure described in chapter 2, but with a few modifications. Instead of the zooxanthellae being isolated from several anemones homogenized together, each of 5 anemones was homogenized separately. Zooxanthellae were counted with 6 hemocytometer counts and all 5 algal suspension concentrations were normalized to the least concentrated extract. The animal tissue homogenate was prepared the day before the trials began and frozen until needed for weeks 0-2. A new batch of homogenate was prepared at week 4 and used thereafter. This new homogenate was adjusted to be the same protein concentration as the first batch, again using the Shakir (1994) modification of the Lowry procedure. Photosynthetic rates, translocation rates and percentages of photosynthate released were again calculated using the mean specific activity $(\mathrm{g} \mathrm{C}$ per dpm) which was estimated from the added activity and an assumed inorganic carbon content of 0.024 g C per litre of seawater (Cook et al., 1992, Davy and Cook 2001a).

\section{5 - Data Analysis}

Nitrogen status was analyzed using the ammonium enhancement ratio (dark $\mathrm{NH}_{4}^{+}$fixation rate/dark FSW fixation rate); calculated after all values were converted to grams carbon and zooxanthella counts were used to determine photosynthetic and dark fixation rates in grams carbon/cell/hour (as in Cook et al. 1992). Nitrogen status was also measured as the ratio $V_{D}: V_{L}$, where $V_{D},=\left(\right.$ dark $\mathrm{NH}_{4}^{+}$fixation rate - dark FSW fixation rate) and $V_{L}=$ light carbon fixation rate in FSW (Goldman and Dennett 1986).

Dark fixation rates in $\mathrm{FSW}$ and $\mathrm{NH}_{4}^{+}$were compared at each time point with the Students t-test. All time points were compared using one-way ANOVA, followed by a pairwise Tukey test. In HRF experiments, the Students t-test was used to test for 
differences between homogenate incubations and FSW incubations at each time point. Differences from FSW controls were tested with one-way ANOVA, again followed by pairwise Tukey comparisons.

\section{Results}

\section{6 - Nutritional History and Zooxanthellar Nitrogen Sufficiency}

Throughout the 8-week starvation period, the dark carbon fixation rates of zooxanthellae incubated in $40 \mu \mathrm{M}$ ammonium chloride were never significantly different than the controls incubated in filtered seawater ( $t$-test, all $p$ values $>0.05$ ). (Figure 4.2)

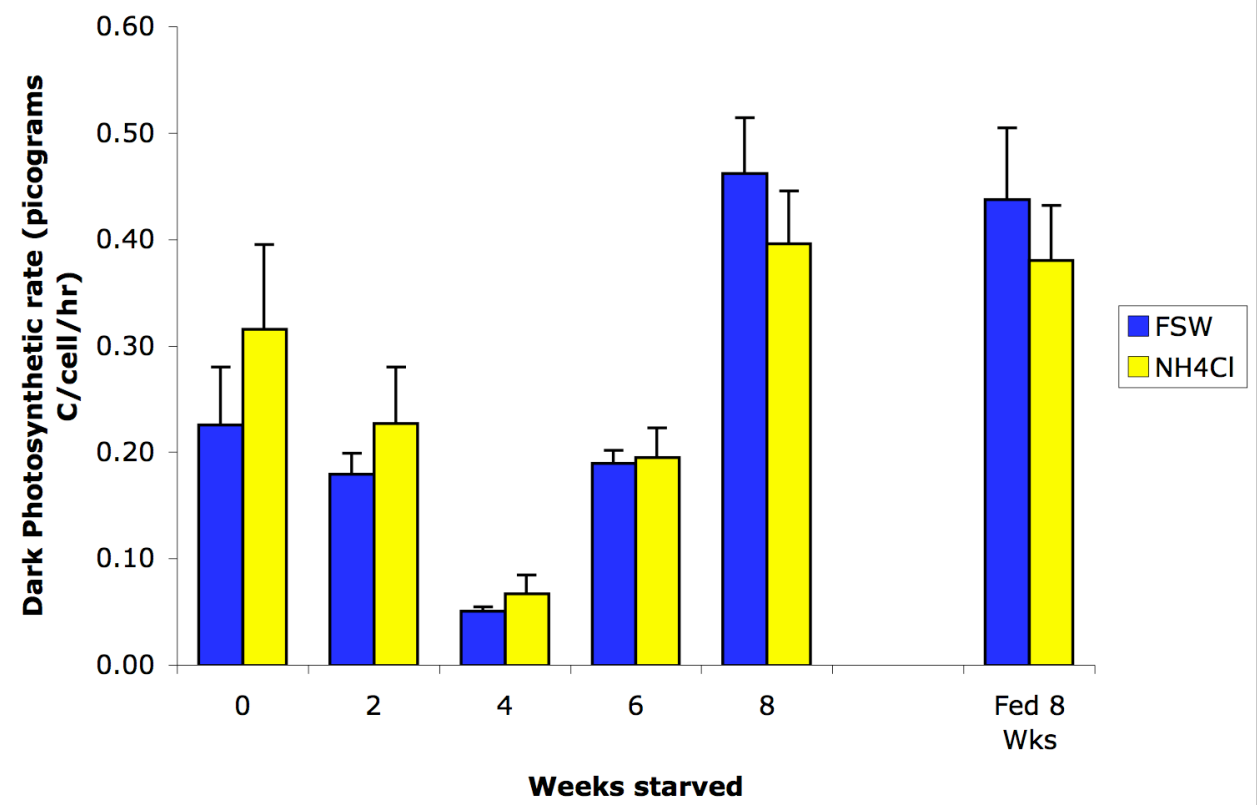

Figure 4.2: Dark fixation rates of zooxanthellae incubated in FSW or $40 \mu \mathrm{M} \mathrm{NH}_{4}^{+}$every 2 weeks throughout the 8-week starvation period. Values are mean + s.d. $(n=5)$. 
Throughout these trials, little evidence of nutritional deficiency of the zooxanthellae was seen in the ammonium enhancement ratios. No significant differences were detected throughout the 8 weeks of starvation, and the final value of 0.85 was no different from the value of the well-fed control group (0.87). (one-way ANOVA, $p>$ $.05)$.

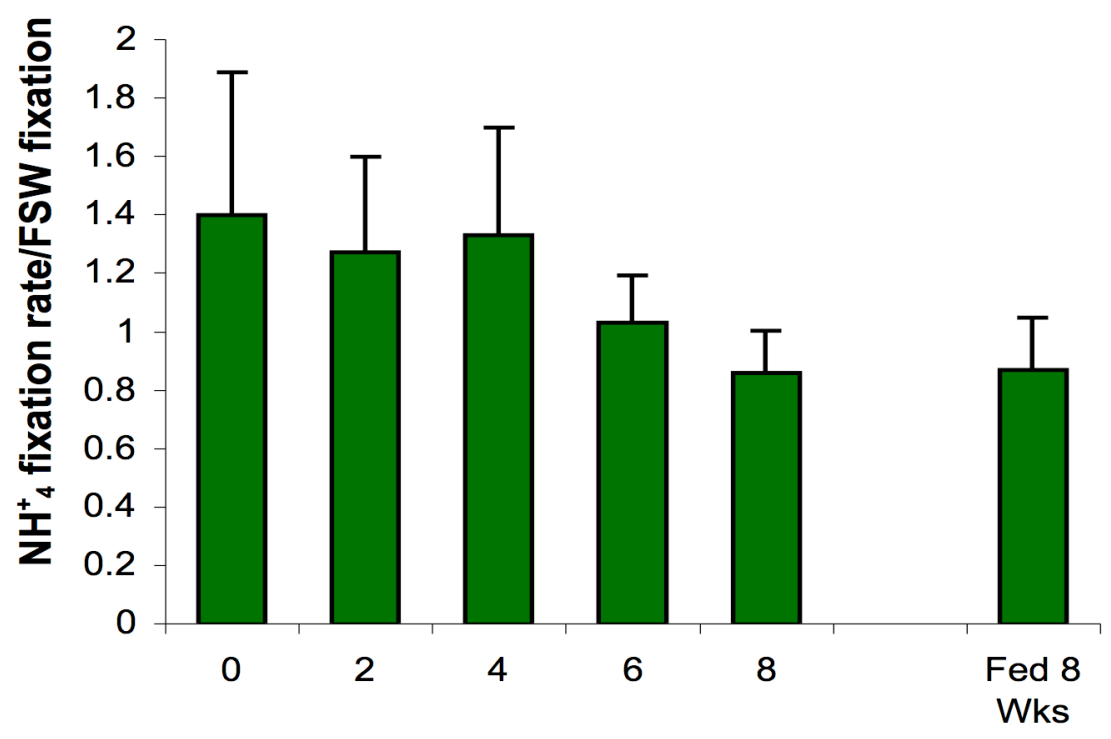

Weeks starved

Figure 4.3: Ammonium enhancement ratio of zooxanthellae isolated from A. aureoradiata and incubated in $40 \mu \mathrm{M} \mathrm{NH}_{4}^{+} \mathrm{Cl}$ or FSW (dark $\mathrm{NH}_{4}^{+}$fixation rate/dark fixation in FSW rate) over 8-week starvation period. Values are mean +1 s.d. $(n=5)$.

Photosynthetic rates throughout the starvation period dropped from $11.8 \mathrm{pg}$ $\mathrm{C} /$ cell $/ \mathrm{h}$ to $3 \mathrm{pg} \mathrm{C} /$ cell/h over the first 2 weeks of starvation. The photosynthetic rate at week 0 was significantly higher than all other weeks, and the algae that were well fed throughout the 8 weeks had significantly higher photosynthetic rates than those starved for 2-6 weeks. They were, however, not different from starved zooxanthellae at week 8 (Tukey post hoc one-way ANOVA, p <0.05) (Figure 4.4A).

Nitrogen status was also assessed by measuring $\mathrm{V}_{\mathrm{D}^{\prime}}: \mathrm{V}_{\mathrm{L}}$ (Figure 4.4B). This value was initially 0.007 and increased slightly before decreasing to -0.01 over the duration of the experiment. The only significant difference was for the starved algae at week 2 and week 8 (Tukey post hoc one-way ANOVA, $\mathrm{p}<0.05$ ). 
A)

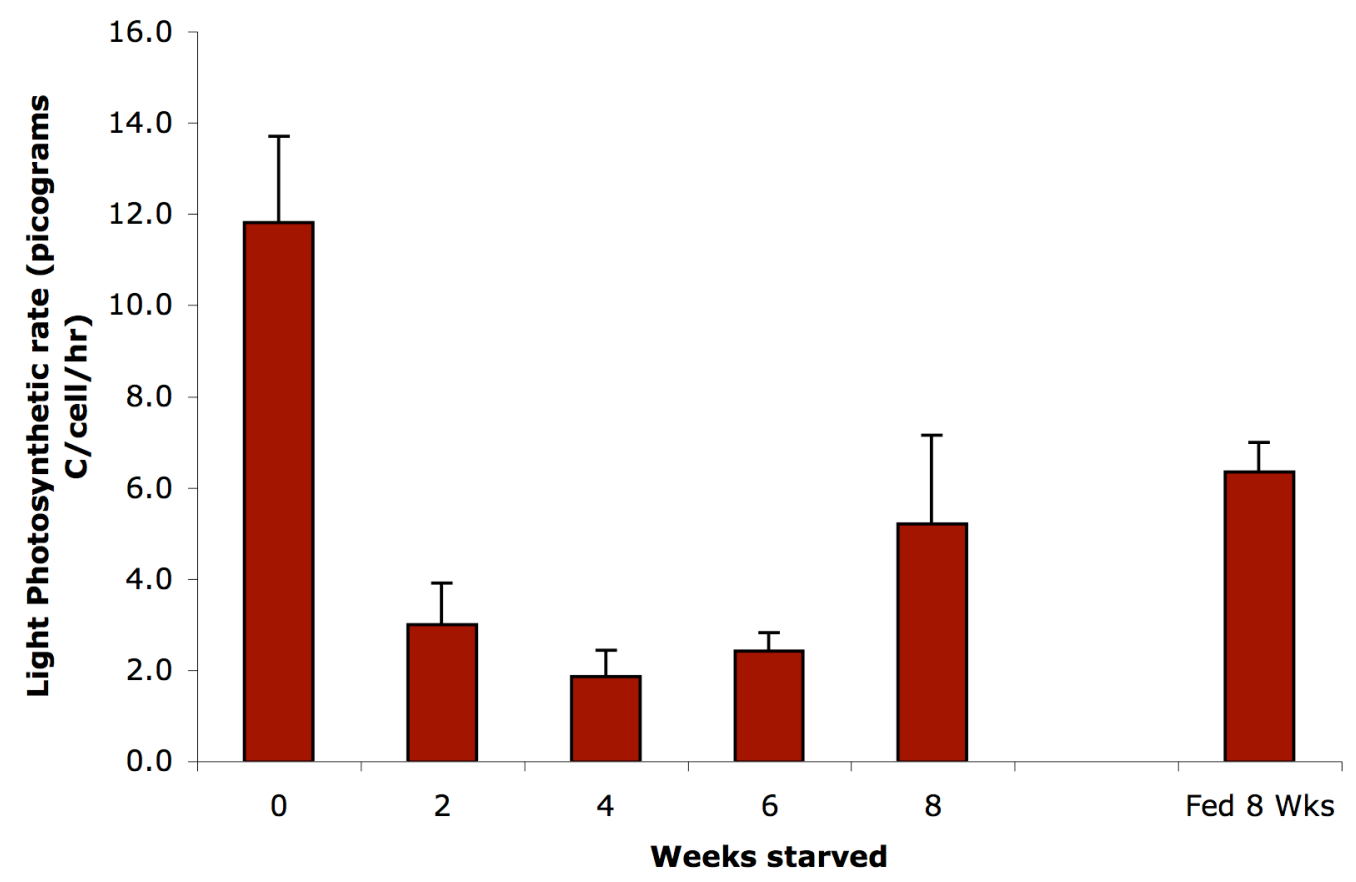

B)

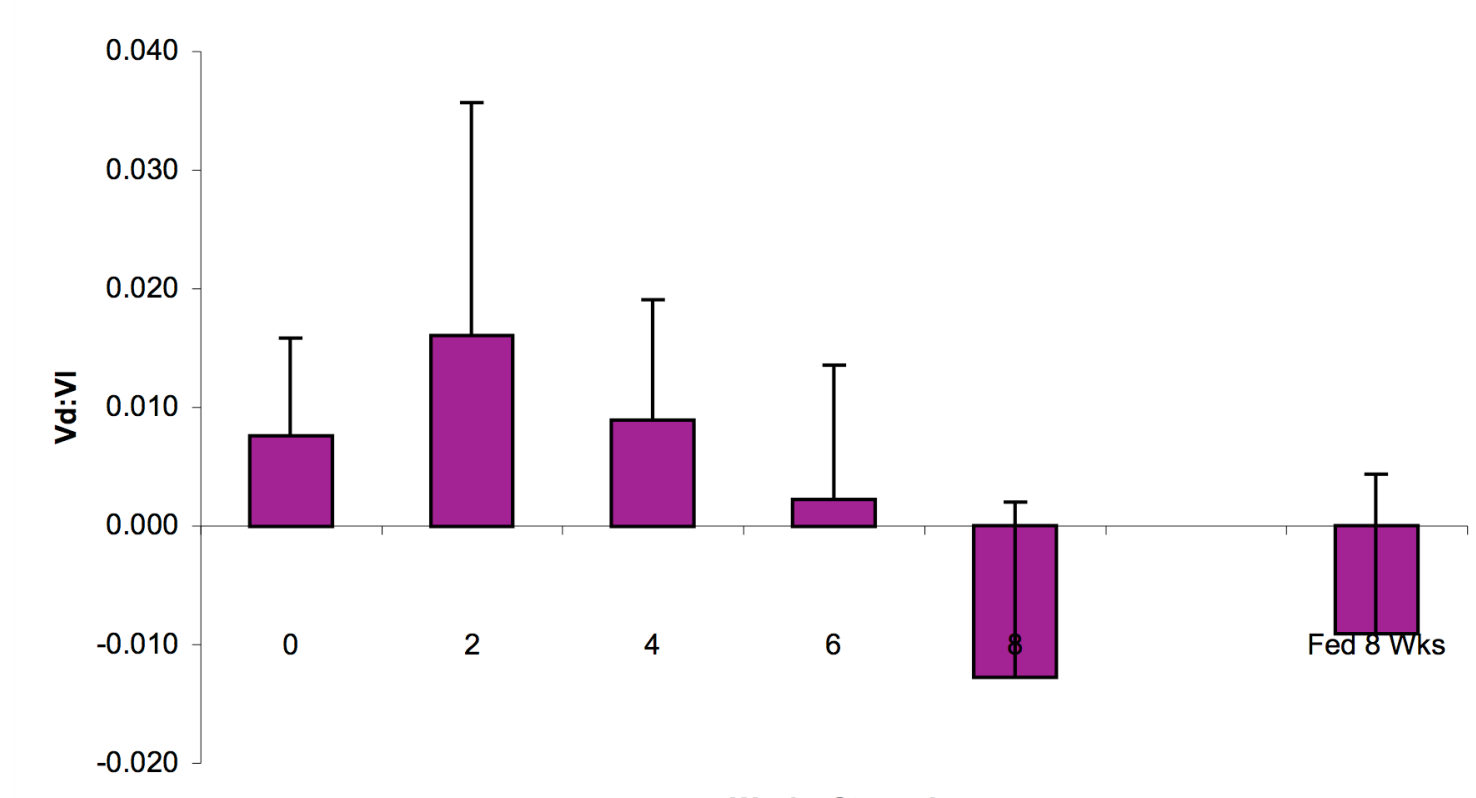

Weeks Starved

Figures 4.4A\&B: Figure 4.4A) Photosynthetic fixation rates of zooxanthellae in FSW isolated from $A$. aureoradiata incubated in the light every 2 weeks over the 8-week starvation period. Figure 4.4B) $\mathrm{V}_{\mathrm{D}}: \mathrm{V}_{\mathrm{L}}$ over 8 weeks of starvation for zooxanthellae isolated from $A$. aureoradiata. $\mathrm{V}_{\mathrm{D}}$, = dark fixation rate for $\mathrm{NH}_{4}^{+}$incubation - dark fixation rate for FSW incubation; $\mathrm{V}_{\mathrm{L}}=$ photosynthetic rate from FSW incubation in the light. All values are mean +1 s.d. $(n=5)$ 


\section{7 - Translocation Rates and Starvation}

Photosynthetic rates of zooxanthellae incubated in host homogenate were always lower than photosynthetic rates of those incubated in FSW throughout the 8week starvation period, but this difference was only significant at weeks 2 and 8 (ttest $\mathrm{p}<0.05)$. The photosynthetic rate did not change significantly from week 0 to week 8 , with the only significant difference being at week 4 for both the control and the homogenate incubations (Tukey post hoc one-way ANOVA, $\mathrm{p}<0.05$ ) (Figure $4.5)$.

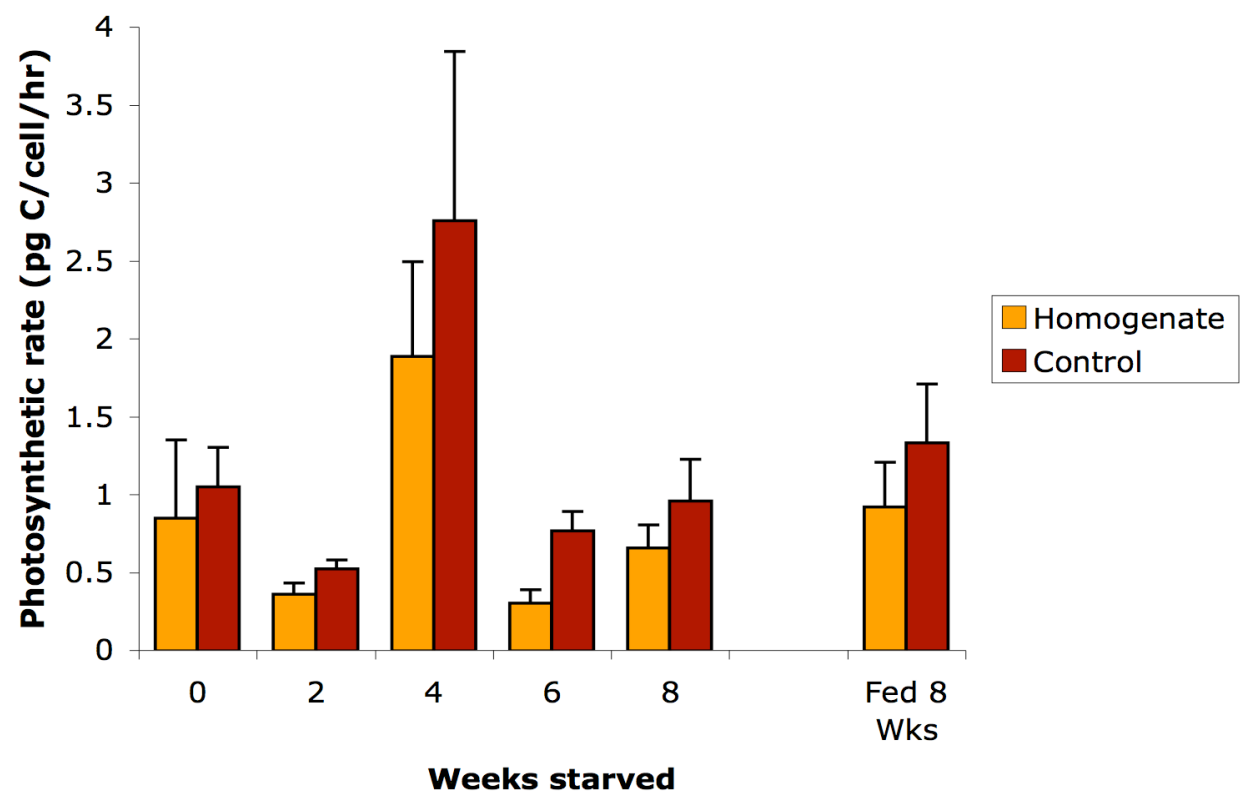

Figure 4.5: Photosynthetic rates of zooxanthellae isolated from Anthopleura aureoradiata incubated in host homogenate or in FSW controls over 8-week starvation period. All values are mean +1 s.d. $(\mathrm{n}=$ 5)

Translocation rates of photosynthetic carbon from zooxanthellae were significantly lower in homogenate incubations than FSW incubations throughout the trial period (t-tests, all $\mathrm{p}$ values $<0.05$ ). Week 4 had significantly higher translocation rates than any other week in both the control and host homogenate incubations, with a control rate nearly 5 times that of the next highest (Tukey post hoc one-way ANOVA, $\mathrm{p}<0.05)($ Figure 4.6A). 
The percent of total fixed carbon released by the zooxanthellae (Figure 4.6B) appeared higher in FSW than host homogenate incubations in all weeks except for week 6 , in which the two percents were nearly equal (t-test $\mathrm{p}<0.05$ ). The only differences that were significant were at week 2 and week 4. (Tukey post hoc oneway ANOVA, p <0.05)

A)

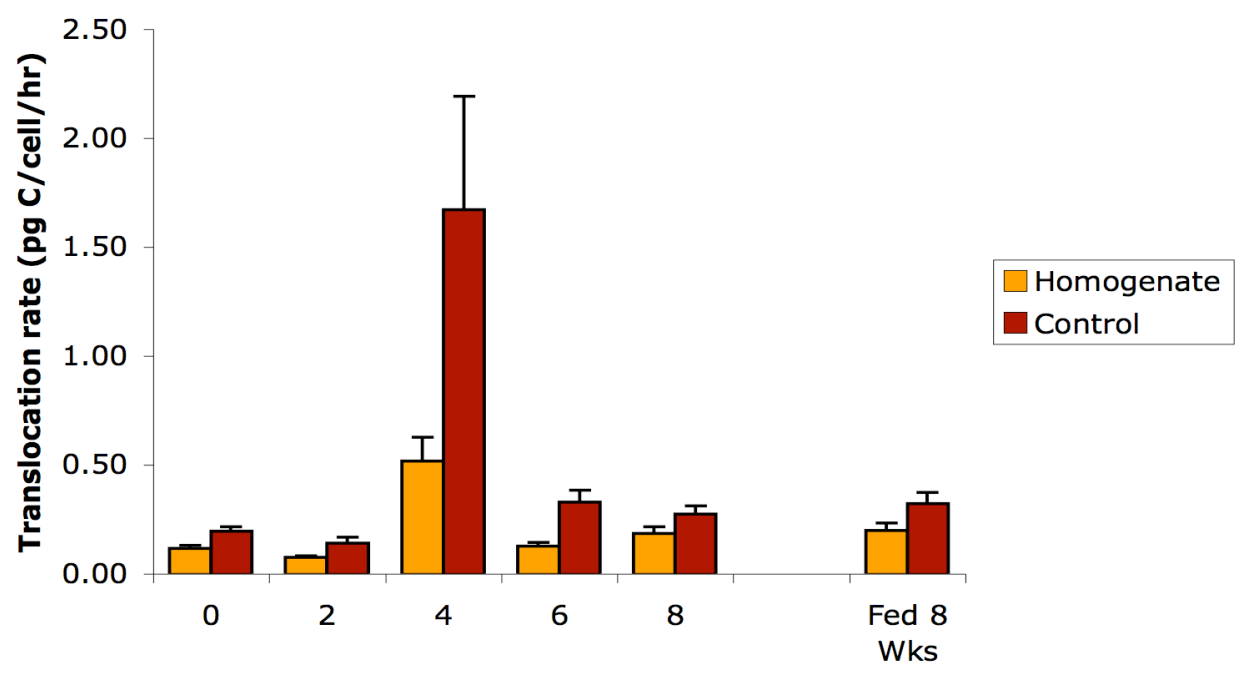

Weeks starved

B)

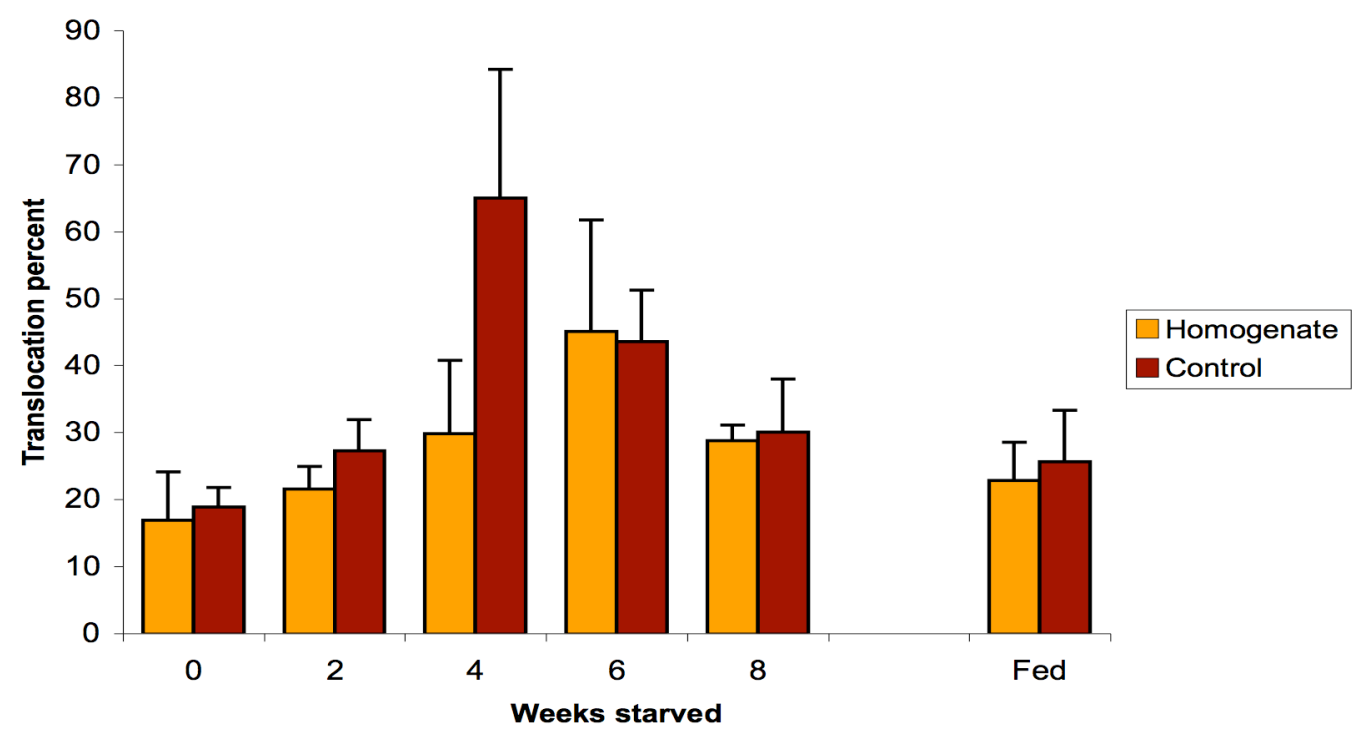

Figures 4.6A\&B: 4.6A) Translocation rates of $A$. aureoradiata zooxanthellae incubated in either host homogenate or FSW and measured every 2 weeks over the 8-week starvation period. 4.6B)

Translocation percent of zooxanthellae isolated from $A$. aureoradiata and incubated in either host homogenate or FSW. Percents measured every 2 weeks over the 8-week starvation period. All values are mean +1 s.d. $(n=5)$. 


\section{Discussion}

\section{8 - Nitrogen Status}

Typically the ammonium enhancement ratio and $\mathrm{V}_{\mathrm{D}}, \mathrm{V}_{\mathrm{L}}$ rise throughout the starvation period as less nitrogen becomes available for zooxanthellar growth and creates more surplus carbon for potential release to the host. Furthermore, photosynthetic rates have been found to drop with starvation in some species. For example, Cook et al. (1992) found a 50\% decline in the photosynthetic rate per cell when starved, and attributed it to decreasing chlorophyll $a$ levels. Davy et al. (2006) also have attributed decreases in photosynthetic rates from nitrogen limitation to reduced levels of photosynthetic pigments in the algae (Davy et al. 2006). However, starvation experiments on the intact symbiosis by Davy and Cook (2001b) found that photosynthetic rates were sustained and even increased after prolonged starvation. This was attributed to increased $\mathrm{CO}_{2}$ availability as zooxanthellar densities declined (Davy and Cook 2001b), though when isolated in FSW there is less likely to be $\mathrm{CO}_{2}$ limitation, so this increase in photosynthetic rate would not be expected.

Zooxanthellae isolated from starved Anthopleura aureoradiata never appeared to be nitrogen deficient, even by the end of the 8-week starvation period. This may imply that it takes longer than 8 weeks of starvation to see evidence of a decrease in nitrogen sufficiency. It has been shown in previous studies of temperate species that starvation can take much longer than in tropical species (Davy et al 2006). One study using the coral Plesiastrea versipora only found evidence for nitrogen deficiency after 2 weeks of starvation (Davy et al. 2006), while another study starved the European sea anemone Anemonia viridis for 47 days in both dissolved inorganic nitrogen-enriched and low dissolved inorganic nitrogen conditions, and found continuing nitrogen sufficiency (Roberts et al. 2001). This suggests that zooxanthellae from temperate anemones might be less reliant on host feeding as a source of nitrogen, or that the host might have greater internal stores of nitrogen to supplement zooxanthellae when exogenous sources are less available (Cook et al. 1994; McAuley and Cook 1994). McAuley and Cook (1994) have also suggested that 
zooxanthellae in some hosts might be more efficient at utilizing their own internal pools of nitrogen.

The lack of any response to nitrogen starvation in zooxanthellae from Anthopleura aureoradiata in these trials could also be due to some unknown external source of nitrogen, such as contamination of the nitrogen-free seawater, or even mortality and subsequent decomposition of other individuals in the bowl adding nitrogenous products to the water. During the first week of starvation, several of the anemones released brooded juveniles, some of which may have died during the 8 weeks and added ammonium to the water as they decomposed; in hindsight, removal of those juveniles may have resulted in a different response to starvation.

\section{9 - Effects of Starvation on HRF Effects}

In these trials, nitrogen deficiency was never achieved for the zooxanthellae, so conclusions cannot be drawn as to the influence of starvation on HRF response in the Anthopleura aureoradiata-zooxanthellae symbiosis. Previously, Davy and Cook (2001b) carried out a study looking at the effects of nitrogen limitation on translocation in starved zooxanthellae isolated from the anemone A. pallida and incubated in either FSW, A. pallida host tissue homogenate, or tissue homogenate from the coral Montastraea annularis. The results were markedly different from those found in the intact symbiosis. Translocation percentages in both host homogenate incubations increased from $14 \%-25 \%$ in A. pallida homogenate and $10 \%-30 \%$ in $M$. annularis homogenate over the 120 -day starvation period. This was offset by a decrease in photosynthetic rate to about $72 \%$ of the original value over the starvation period. This decrease is such that the actual amount of photosynthate released was similar to or greater than the amount from well-fed zooxanthellae (Davy and Cook 2001b).

A second study of starvation on the percent translocation in intact Aiptasia pallida (a sea anemone) found no effects of starvation on translocation over a 114-day starvation period (Davy and Cook 2001a). It was also found that photosynthetic rates initially decreased, but then increased significantly after 14 days, which was attributed to increased $\mathrm{CO}_{2}$ availability (due to lower densities of algae) that counteracted any 
decline in chlorophyll levels. Translocation rates per cell followed the same trend as photosynthetic rates, resulting in the total amount of fixed carbon per mg host protein being unaffected by prolonged starvation (Davy and Cook 2001a).

Another previous study by McGuire and Szmant (1997) found that the coral Porites astreoides maintained in nitrogen-enhanced seawater $(10 \mu \mathrm{M})$ had decreased translocation rates when compared to controls in FSW. This could lend evidence to the theory that zooxanthellae release more carbon when they have more surplus from growth; in high-nitrogen conditions, zooxanthellae have more nitrogen available for growth and hence would utilize more carbon.

These studies suggest an ability to cope with sustained periods with low food availability, however the mechanisms involved seem very different in the intact symbiosis and in isolated zooxanthellae. This raises the issue that some responses of isolated zooxanthellae may be experimental artifacts, and further study is needed to determine the specific causes for these outcomes (Davy and Cook 2001b). 


\section{Discussion}

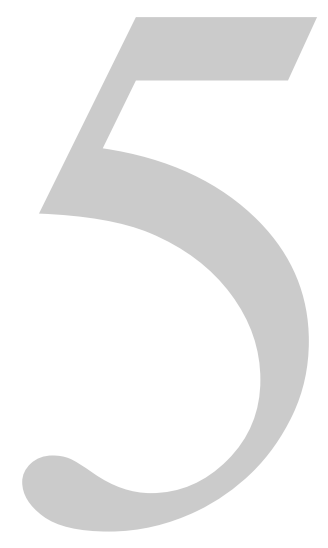

This study found that in the intact Anthopleura aureoradiata-zooxanthellae symbiosis, zooxanthellae release $40 \%$ of their photosynthetically fixed carbon for use by the anemone. This concurs with results for translocation percentages found in other symbioses (Muscatine 1967; Davy et al. 1996; Engebretson and Muller-Parker 1999). Unlike other species, however, isolated zooxanthellae incubated in host homogenate showed no effects of any host release factor (HRF). Furthermore, incubations of heterologous zooxanthellae in $A$. aureoradiata tissue homogenate also showed no effects of HRF. The translocation of a substantial amount of fixed carbon in the intact association, but lack of any HRF response when the zooxanthellae are in isolation, raises two questions: 1) How might Anthopleura aureoradiata benefit from photosynthetic carbon in the field; and 2) How is carbon translocation regulated if there is no HRF operating in the anemone tissues? There was also evidence in one trial for PIF.

\section{1 - How does the symbiotic relationship with zooxanthellae benefit Anthopleura aureoradiata?}

Anemones living on mudflats are found beneath the surface of the mud at low tide. This means that about half of their time is spent with no sunlight, and limited access to particulate food. At high tide, the cockles that $A$. aureoradiata attaches to rise to the surface of the mud, allowing for feeding of anemones on planktonic food, and exposing the zooxanthellae to light. This exposure is limited, as water around mudflats is often turbid and sunlight in temperate zones is highly variable. This argues for mudflat anemones being predominantly heterotrophic. 
A. aureoradiata living on rocky intertidal shores is exposed to much higher irradiance, more competition for space, and possibly fewer sources of exogenous carbon and nitrogen than when living on the mudflats. Rocky shores provide a greater potential for photosynthesis and thus may translocate more carbon to the anemones. This suggests that rocky shore anemones may be more autotrophic than mudflat anemones.

Even with the arguments for heterotrophy in A. aureoradiata, the carbon translocated may provide a competitive advantage for the anemones in all environments, especially those on the rocky shores. This is supported by several observations. This anemone is abundant and seems to be a dominant species in the environments in which it is found. In the mudflats the attachment to cockles allows the anemones to be above the surface of the mud at high tide and be exposed to sunlight, whereas on the rocky shores, anemones are found in positions with high exposure to sunlight, suggesting that they actively seek out sun exposure. Lastly, these anemones inherit zooxanthellae maternally through a closed system, so if there was no advantage to having the algae, it seems doubtful that they would go to such lengths to maintain the symbiosis. The benefit of translocated carbon may only be important to the anemones during periods of limited food availability, as even small amounts of translocated carbon can be stored and increase survival of anemones during periods of limited food supply.

Zooxanthellar carbon contributions may also only be important for rocky intertidal anemones, as with higher irradiance and more exposure to sunlight, there is greater potential for photosynthesis and more carbon translocated. Anemones living on mudflats may only have zooxanthellae because there is no pressure to get rid of them.

It is also possible that the zooxanthellae are actually parasitic, using the anemone for protection and nutrients, releasing carbon in the intact symbiosis to bypass defense mechanisms of the host. The zooxanthellae may also be an evolutionary artifact of tropical symbioses, or may have evolved to be of no consequence to the anemone while receiving protection in its tissues. 


\section{2 - How is carbon translocation regulated?}

No evidence was found throughout the previous experiments for the presence of a host release factor compound. The homogenization process for the host tissues has been shown to damage animal cell structure, and thus may destroy the compound responsible for inducing photosynthate release in zooxanthellae (Muscatine et al. 1994). It has also been shown that zooxanthellae isolated from the host undergo physiological changes that may affect their ability to respond to signals (Goiran et al. 1997). There is also no evidence for a host release factor compound in any intact symbiosis (Davy and Cook 2001b). However, $40 \%$ of fixed carbon is translocated to the animal by zooxanthellae in the intact symbiosis, which indicates some form of control by the host. If there is no specific HRF compound, how is the release of carbon from zooxanthellae controlled?

If zooxanthellae in the field were deficient in nitrogen, expectations would be to see surplus carbon released by zooxanthellae without stimulation, but as recent studies have shown that zooxanthellae in $A$. aureoradiata are nitrogen sufficient in the field (S. Morar, unpublished), this is unlikely to play a role in translocation control in this species. It has previously been suggested that carbon translocation in the intact symbiosis is regulated by the host reducing the permeability of the symbiosome membrane (Muscatine 1983; Rands et al. 1993). This is possible, but there is no empirical evidence for it and further study would be needed. Another possibility is the presence of some other type of signaling molecule in the host tissues, perhaps a protein, or other complex molecule that has not yet been considered in the release of carbon in the intact symbiosis, but is destroyed by the homogenization process.

With advances in genomic technologies and understanding, the role genetics might play in this symbiosis has been questioned. Current technologies make it possible to examine changes in gene expression of thousands of genes with changing conditions, such as a change in symbiotic state, change in age or form, or with the onset of environmental stress. Once identified by genomic studies, target genes and their associated pathways may be subjected to further empirical studies at the cellular level to uncover their role in symbiosis (Weis et al. in press.). On this topic, recent work has been done investigating the hypothesis that there are genes present in either the host or the zooxanthellae that are "switched on" when the symbiosis is formed 
that could possibly regulate translocation (Weis and Levine 1996, Weis and Reynolds 1998). DeBoer et al. (2007) found limited evidence for a change in protein profiles during the establishment of a symbiosis in the coral Fungia scutaria. Further studies have shown that protein profiles in established symbiotic and aposymbiotic anemones are different, and symbiotic anemones produce a unique set of proteins (Weis and Levine 1996; Rodriguez-Lanetty et al. 2006). Genetic techniques have led to the characterization of a "symbiosis protein" known as sym32 (Reynolds et al. 2000). This protein was discovered to be the most abundantly expressed symbiosis-enhanced protein in Anthopleura elegantissima and has been suggested to be involved in regulation of symbiosis (Reynolds et al. 2000). However, further work is needed to clarify the role of genetics in the control of translocation in symbiotic relationships.

In conclusion, Anthopleura aureoradiata shows no evidence of a host release factor present in homogenized tissues, but still receives photosynthetic carbon from symbionts in the intact symbiosis. This work suggests that not all organisms have an HRF that operates in vitro, but does not preclude the potential for its existence in the intact symbiosis. More work is needed to determine the controlling mechanism for translocation in cnidarian-dinoflagellate symbioses. With recent advances in genomic and molecular techniques to study gene expression, the host factor can be thoroughly studied to see if it is a protein expressed by a gene in symbiotic hosts only, or if it is an amino acid or other compound found in both symbiotic and aposymbiotic organisms. Only when the host factor in the intact symbiosis is defined can it be determined if host release factor in isolation experiments is an experimental artifact. 


\section{References}

Ambariyanto and Hoegh-Guldberg O (1996) Nutrient enrichment and the ultrastructure of zooxanthellae from the giant clam Tridacna maxima. Marine Biology 125(2): 359-364.

Baker AC (2003) Flexibility and specificity in coral-algal Symbiosis: Diversity, ecology, and biogeography of Symbiodinium. Annual Review of Ecology, Evolution, and Systematics 34: 661-689.

Baker AC and Rowan R (1997) Diversity of symbiotic dinoflagellates (zooxanthellae) in scleractinian corals of the Caribbean and eastern Pacific. Proceedings of the $8^{\text {th }}$ International Coral Reef Symposium, Panama 2: 1301-1305.

Barneah O, Weis VM, Perez S (2004) Diversity of dinoflagellate symbionts in Red Sea soft corals: mode of symbiont acquisition matters. Marine Ecology Progress Series 275: 89-95.

Battey JR and Patton JS (1987) Glycerol translocation in Condylactis-Gigantea. Marine Biology 95(1): 37-46.

Beer S, Ilan M, Eshel A, Weil A, Brickner I (1998) Use of pulse amplitude modulated (PAM) fluorometry for in situ measurements of photosynthesis in two Red Sea faviid corals. Marine Biology 131: 607-612.

Belda-Baillie CA, Baillie BK, Maruyama T (2002) Specificity of a model Cnidarian-dinoflagellate symbiosis. Biological Bulletin 202: 74-85.

Berkelmans R and van Oppen MJH (2006) The role of zooxanthellae in the thermal tolerance of corals: a 'nugget of hope' for coral reefs in an era of climate change. Proceedings of the Royal Society B 273: 2305-2312.

Berner T, Baghdasarian G, Muscatine L (1993) Repopulation of a sea anemone with symbiotic dinoflagellates: Analysis by in vivo fluorescence. Journal of Experimental Marine Biology and Ecology 170: 145-158.

Bhagooli R and Hidaka M (2004) Photoinhibition, bleaching susceptibility and mortality in two scleractinian corals, Platygyra ryukyuensis and Stylophora pistillata, in response to thermal and light stresses. Comparative Biochemistry and Physiology Part A 137: 547-555.

Biel KY, Gates RD, Muscatine L (2007) Effects of free amino acids on the photosynthetic carbon metabolism of symbiotic dinoflagellates. Russian Journal of Plant Physiology 54(2): 171-183.

Birkeland C (1997) Geographic differences in ecological processes in coral reefs. In: Life and Death of Coral Reefs. Edited by Birkeland, C. Chapman and Hall New York, New York. Pp. 273-287. 
Blank RJ and Huss VAR (1989) DNA Divergency and speciation in Symbiodinium (Dinophyceae). Plant Systematics and Evolution 163(3-4): 153-163.

Buddemeier RW and Fautin DG (1993) Coral bleaching as an adaptive mechanism: A testable hypothesis. Bioscience 43(5): 320.

Burnett WJ (2002) Longitudinal variation in algal symbionts (zooxanthellae) from the Indian Ocean zoanthid Palythoa caesia. Marine Ecology Progress Series 234: 105-109.

Carlos AA, Baillie BK, Kawachi M, Maruyama T (1999) Phylogenetic position of Symbiodinium (Dinophyceae) isolates from tridacnids (Bivalvia), cardiids (Bivalvia), a sponge (Porifera), a soft coral (Anthozoa), and a free-living strain. Journal of Phycology 35: 1054-1062.

Castro P and Huber ME (2005) Marine Biology, Fifth Edition. McGraw-Hill, Boston, USA.

Chen CA, Lam KK, Nakano Y, Tsai W (2003) A stable association of the stresstolerant zooxanthellae, Symbiodinium clade D, with the low-temperature-tolerant coral, Oulastrea crispate (Scleractinia: Faviidae) in subtropical non-reefal coral communities. Zoological Studies 42(4): 540-550.

Clark KB and Jensen KR (1982) Effects of temperature on carbon fixation and carbon budget partitioning in the zooxanthellal symbiosis of Aiptasia pallida (Verrill). Journal of Experimental Marine Biology and Ecology 64: 215-230.

Coffroth MA and Santos SR (2005) Genetic diversity of symbiotic dinoflagellates in the genus Symbiodinium. Protist 156: 19-34.

Coffroth MA, Santos SR, Goulet TL (2001) Early ontogenetic expression of specificity in a cnidarian-algal symbiosis. Marine Ecology Progress Series 222: 8596.

Colley NJ and Trench RK (1983) Selectivity in phagocytosis and persistence of symbiotic algae by the scyphistoma stage of the jellyfish Cassiopeia-xamachana. Proceedings of the Royal Society of London-Series B 219(1214): 61.

Cook CB and Davy SK (2001) Are free amino acids responsible for the 'host factor' effects on symbiotic zooxanthellae in extracts of host tissue? Hydrobiologia 461: 7178 .

Cook CB and D'Elia CF (1987) Are natural populations of zooxanthellae ever nutrient-limited? Symbiosis 4(1-3): 199-211.

Cook CB, D'Elia CF, Muller-Parker G (1988) Host feeding and nutrient sufficiency for zooxanthellae in the sea anemone Aiptasia pallida. Marine Biology 98: 253-262. 
Cook CB, Muller-Parker G, D'Elia CF (1992) Ammonium enhancement of dark carbon fixation and nitrogen limitation in symbiotic zooxanthellae: Effects of feeding and starvation of the sea anemone Aiptasia pallida, Limnology and Oceanography 37(1): 131-139.

Cook CB, Muller-Parker G, Orlandini CD (1994) Ammonium enhancement of dark carbon fixation and nitrogen limitation in zooxanthellae symbiotic with the reef corals Madracis mirabilis and Montastrea ammularis. Marine Biology 118: 157-165.

Darius HT, Dauga C, Grimont PAD, Chungue E, Martin PMV (1998) Diversity in symbiotic dinoflagellates (Pyrrhophyta) from seven scleractinian coral species: Restriction enzyme analysis of small subunit ribosomal RNA genes. Journal of Eukaryotic Microbiology 45: 619-627.

Davies PS (1984) The role of zooxanthellae in the nutritional energy requirements of Pocillopora eydouxi. Coral Reefs 2(4): 181-186.

Davies PS (1991) Effect of daylight variations on the energy budgets of shallowwater corals. Marine Biology 108(1): 137-144.

Davy SK and Cook CB (2001a) The relationship between nutritional status and carbon flux in the zooxanthellate sea anemone Aiptasia pallida. Marine Biology 139: 999-1005.

Davy SK and Cook CB (2001b) The influence of 'host release factor' on carbon release by zooxanthellae isolated from fed and starved Aiptasia pallida (Verrill). Comparative Biochemistry and Physiology Part A. 129: 487-494.

Davy SK and Turner JR (2003) Early development and acquisition of zooxanthellae in the temperate symbiotic sea anemone Anthopleura ballii (Cocks). Biological Bulletin 205: 66-72.

Davy SK, Lucas IAN, Turner JR (1996) Carbon budgets in temperate anthozoandinoflagellate symbioses. Marine Biology 126: 773-783.

Davy SK, Lucas IAN, Turner JR (1997) Uptake and persistence of homologous and heterologous zooxanthellae in the temperate sea anemone Cereus pedunculatus (Pennant). Biological Bulletin 192: 208-216.

Davy SK, Turner JR, Lucas IAN (1997) The nature of temperate anthozoandinoflagellate symbioses. Proceedings of the $8^{\text {th }}$ International Coral Reef Sympiosium 2: $1307-1312$.

Davy SK, Withers KJT, Hinde R (2006) Effects of host nutritional status and seasonality on the nitrogen status of zooxanthellae in the temperate coral Plesiastrea versipora (Lamarck). Journal of Experimental Marine Biology and Ecology, 335: 256-265. 
D'Elia C (1988) The cycling of essential elements in coral reefs. Ecological Studies Vol. 67. Concepts of Ecosystem Ecology: A Comparative View; Conference XII. Edited by Pomeroy L.R. and Alberts J.J. Springer-Verlag: New York, New York USA; p. 195.

DeBoer ML, Krupp DA, Weis VM (2007) Proteomic and transcriptional analyses of coral larvae newly engaged in symbiosis with dinoflagellates. Comparative Biochemistry and Physiology Part D: Genomics and Proteomics 2(1): 63-73.

Diekmann OE, Olsen JL, Stam WT, Bak RPM (2003) Genetic variation within Symbiodinium clade B from the coral genus Madracis in the Caribbean (Netherlands Antilles). Coral Reefs 22: 29-33.

Domotor SL and D'Elia CF (1984) Nutrient-uptake kinetics and growth of zooxanthellae maintained in laboratory culture. Marine Biology 80(1) 93-101.

Douglas AE and Smith DC (1987) The Biology of Symbiosis. Edward Arnold Publishers Ltd. UK.

Dubinsky $Z$ and Jokiel PL (1994) Ratio of energy and nutrient fluxes regulates symbiosis between zooxanthellae and corals. Pacific Science 48: 313-324.

Edmunds PJ and Davies PS (1986) An energy budget for Porites-Porites (Scleractinia). Marine Biology 92(3): 339-347.

Engebretson HP and Muller-Parker G (1999) Translocation of photosynthetic carbon from two algal symbionts to the sea anemone Anthopleura elegantissima. Biological Bulletin 197: 72-81.

Fabricius KE and De'Ath G (2004) Identifying ecological change and its causes: A case study on coral reefs. Ecological Applications 14(5): 1448-1465.

Falkowski PG, Dubinsky Z, Muscatine L, McCloskey LR (1993) Population control in symbiotic corals. Bioscience 43: 606-611.

Farrant PA (1986) Gonad development and the planulae of the temperate Australian soft coral Capnella gaboensis. Marine Biology, 92: 381-392.

Fautin DG and Buddemeier RW (2004) Adaptive bleaching: a general phenomenon. Hydrobiologia 530/531: 459-467.

Fitt WK and Cook CB (2001) The effects of feeding or addition of dissolved inorganic nutrients in maintaining the symbiosis between dinoflagellates and a tropical marine cnidarian. Marine Biology 139: 507-517.

Fitt WK and Trench RK (1983) Endocytosis of the symbiotic dinoflagellate Symbiodinium microadriaticum Freudenthal by endodermal cells of the Scyphistomae of Cassiopeia xamachana and resistance of the algae to host digestion. Journal of Cell Science. 64: 195-212. 
Fitt WK, Pardy RL, Littler MM (1982) Photosynthesis, respiration, and contribution to community productivity of the symbiotic sea anemone Anthopleura elegantissima (Brandt, 1835). Journal of Experimental Marine Biology and Ecology 61: 213-232.

Fitt WK, Brown BE, Warner ME, Dunne RP (2001) Coral bleaching: interpretation of thermal tolerance limits and thermal thresholds in tropical corals. Coral Reefs 20:51-65.

Franzisk L (1973) Uptake and accumulation of nitrate and nitrite by reef corals. Die Naturwissenschaften 60(12): 552.

Freudenthal HD (1962) Symbiodinium Gen Nov and Symbiodinium microadriaticum Sp. Nov. A Zooxanthella-Taxonomy, Life Cycle, and Morphology. Journal of Protozoology, 9(1): 45.

Fowden L (1981) Contrasts in nitrogen metabolism between animals and plants. In Waterlow J.C. and Stephen J.M.L. editors. Nitrogen Metabolism in Man. Applied Science Publishers, London. P. 87-95.

Gates RD, Bil KY, Muscatine L (1999) The influence of an anthozoan "host factor" on the physiology of a symbiotic dinoflagellate. Journal of Experimental Marine Biology and Ecology 232: 241-259.

Gates RD, Hoegh-Guldberg O, McFall-Ngai MJ, Bil KY, Muscatine L (1995) Free amino acids exhibit anthozoan "host factor" activity: They induce the release of photosynthate from symbiotic dinoflagellates in vitro. Proceedings of the National Academy of Sciences of the USA. 92(16): 7430-7434.

Grant AJ, Remond M, Hinde R (1998) Low molecular-weight factor from Plesiastrea versipora (Scleractinia) that modifies release and glycerol metabolism of isolate symbiotic algae. Marine Biology 130: 553-557.

Grant AJ, Remond M, People J, Hinde R (1997) Effects of host-tissue homogenate of the scleractinian coral Plesiastrea versipora on glycerol metabolism in isolated symbiotic dinoflagellates. Marine Biology 128: 665-670.

Grant AJ, Remond M, Withers KJT, Hinde R (2001) Inhibition of algal photosynthesis by a symbiotic coral. Hydrobiologia 461: 63-69.

Grant AJ, Starke-Peterkovic T, Withers KJT, Hinde R (2004) Aposymbiotic Plesiastrea versipora continues to produce cell-signalling molecules that regulate the carbon metabolism of symbiotic algae. Comparative Biochemistry and Physiology, Part A 138: 253-259.

Goiran C, Allemand D, Galgani I (1997) Transient $\mathrm{Na}^{+}$stress in symbiotic dinoflagellates after isolation from coral-host cells and subsequent immersion in seawater. Marine Biology 129: 581-589, 
Goldman JC and Dennett MR (1986) Dark $\mathrm{CO}_{2}$ uptake by the diatom Chaetocerossimples in response to nitrogen pulsing. Marine Biology, 90(4): 493-500.

Grover R, Maguer JF, Reynaud-Vaganay S, Ferrier-Pages C (2002) Uptake of ammonium by the scleractinian coral Stylophora pistillata: Effect of feeding, light, and ammonium concentrations. Limnology and Oceanography 47(3): 782-790.

Hill R, Larkum AWD, Frankart C, Kuhl M, Ralph PJ (2004) Loss of functional photosystem II reaction centres in zooxanthellae of corals exposed to bleaching conditions: Using fluorescence rise kinetics. Photosynthesis Research 82: 59-72.

Hinde R (1988) Control of translocation in some associations between invertebrates and algae. Endocytobiosis and Cell Research 5(1): 115.

Hoegh-Guldberg O (1999) Climate change, coral bleaching and the future of the world's coral reefs. Marine and Freshwater Research, 50(8): 839-866.

Hoegh-Guldberg $O$ and Smith GJ (1989) Influence of the population density of zooxanthellae and supply of ammonium on the biomass and metabolic characteristics of the reef corals Seriatopora hystrix and Stylophora pistillata. Marine Ecology Progress Series 57(2): 173-186.

Iglesias-Prieto R and Trench RK (1997) Acclimation and adaptation to irradiance in symbiotic dinoflagellates. II. Response of chlorophyll-protein complexes to different photon-flux densities. Marine Biology 43: 201-208.

Jensen SL and Muller-Parker G (1994) Inorganic nutrient fluxes in anemonedominated tide pools. Pacific Science 48(1): 32-43.

Jones RJ, Kildea T, Hoegh-Guldberg O (1999) PAM chlorophyll fluorometry: a new in situ technique for stress assessment in scleractinian corals, used to examine the effects of cyanide from cyanide fishing. Marine Pollution Bulletin 38(10): 864-874.

Karako-Lampert S, Katcoff DJ, Achituv Y, Dubinsky Z, Stambler N (2004) Do clades of symbiotic dinoflagellates in scleractinian corals of the Gulf of Eilat (Red Sea) differ from those of other coral reefs? Journal of Experimental Marine Biology and Ecology 311: 301-314.

Kawaguti S (1953) Ammonium metabolism of the reef corals. Biological Journal Okayama University. 1(3): 171-176.

Kellogg RB and Patton JS (1983) Lipid droplets, medium of energy exchange in the symbiotic anemone Condylactis gigantea - A Model Coral Polyp. Marine Biology 75(2-3): 137-149.

Kester DR, Duedall IW, Connors DN, Pytkowicz RM (1967) Preparation of artificial seawater. Limnology and Oceanography, 12(1): 176-179.

Kinzie III RA, (1974) Experimental infection of aposymbiotic Gorgonian polyps with zooxanthellae. Journal of Experimental Marine Biology and Ecology 15(3): 335. 
Kinzie III RA, Takayama M, Santos SR, Coffroth MA (2001) The Adaptive bleaching hypothesis: Experimental tests of critical assumptions. Biological Bulletin 200: 51-58.

Knowlton N and Rohwer F (2003) Multispecies microbial mutualisms on coral reefs: The host as a habitat. The American Naturalist 162: S51-S62.

LaJeunesse T (2001) Investigating the biodiversity, ecology, and phylogeny of endosymbiotic dinoflagellates in the genus Symbiodinium Using the ITS region: In search of a "species" level marker. Journal of Phycology 37: 866-880.

LaJeunesse T (2002) Diversity and community structure of symbiotic dinoflagellates from Caribbean coral reefs. Marine Biology 141: 387-400.

LaJeunesse T (2004) Closely related Symbiodinium spp. differ in relative dominance in coral reef host communities across environmental, latitudinal and biogeographic gradients. Marine Ecology Progress Series 284: 147.

LaJeunesse T and Trench RK (2000) Biogeography of two species of Symbiodinium (Freudenthal) inhabiting the intertidal sea anemone Anthopleura elegantissima (Brandt). Biological Bulletin 199(2): 126-134.

LaJeunesse T, Loh WKW, van Woesik R, Hoegh-Guldberg O, Schmidt GW, Fitt WK (2003) Low symbiont diversity in southern Great Barrier Reef corals relative to those of the Caribbean. Limnology and Oceanography 48: 2046-2054.

LaJeunesse T, Thornhill DJ, Cox EF, Stanton FG, Fitt WK, Schmidt GW (2004) High diversity and host specificity observed among symbiotic dinoflagellates in reef coral communities from Hawaii. Coral Reefs 23: 596-603.

Lewis DH and Smith DC (1971) Autotrophic nutrition of symbiotic marine coelenterates with special reference to hermatypic corals. 1. Movements of photosynthetic products between symbionts. Proceedings of the Royal Society of London Series B, Biological Sciences. 178(1050): 111.

Lobban C (1992) Ciliate-Symbiodinium symbiosis spotted on reefs. Coral Reefs 21(4): 332 .

Loh WKW, Loi T, Carter D, Hoegh-Guldberg O (2001) Genetic variability of the symbiotic dinoflagellates from the wide ranging coral species Seriatopora hystrix and Acropora longicyathus in the Indo-West Pacific. Marine Ecology Progress Series 222: 97-107.

Markell DA and Trench RK (1993) Macromolecules exuded by symbiotic dinoflagellates in culture-amino acid and sugar composition. Journal of Phycology 29(1): 64-68. 
Masuda K, Miyachi S, Maruyama T (1994) Sensitivity of zooxanthellae and nonsymbiotic microalgae to stimulation of photosynthate excretion by giant clam tissue homogenate. Marine Biology 118(4): 687-693.

McAuley PJ (1994) Amino acid content of zooxantehllae freshly isolated from Pocillopora damicornis. Pacific Science 48(3): 247-253.

McAuley PJ and Cook CB (1994) Effects of host feeding and dissolved ammonium on cell division and nitrogen status of zooxanthellae in the hydroid Myrionema amboinense. Marine Biology 121: 343-348.

McCloskey LR, Muscatine L, Wilkerson FP (1994) Daily photosynthesis, respiration, and carbon budgets in a tropical marine jellyfish (Mastigias sp.). Marine Biology 119: 13-22.

Mcguire MP and Szmant AM (1997) Time course of physiological responses to $\mathrm{NH}_{4}$ enrichment by a coral-zooxanthellae symbiosis. Proceedings of the $8^{\text {th }}$ International Coral Reef Symposium. 1: 909-914.

Miller DJ and Yellowlees D (1989) Inorganic nitrogen uptake by sumbiotic marine cnidarians: a critical review. Proceedings of the Royal Society of London. B, Biological Sciences 237: 109-125.

Morris I, Yentsch CM, Yentsch CS (1971) The physiological state with respect to nitrogen of phytoplankton from low-nutrient subtropical water as measured by the effect of ammonium ion on dark carbon dioxide fixation. Limnology and Oceanography 16(6): 859-868.

Muller-Parker G (1984) Photosynthesis-irradiance responses and photosynthetic periodicity in the sea anemone Aitasia pulchella and its zooxanthellae. Marine Biology 82(3): 225-232.

Muller-Parker G and Davy SK (2001) Temperate and tropical algal-sea anemone symbioses. Invertebrate Biology, 120(2): 104-123.

Muller-Parker G and D'Elia CF (1997) Interactions between corals and their symbiotic algae. Life and Death of Coral Reefs. Edited by Birkeland C., Chapman and Hall, New York p. 96-113.

Muscatine L (1967) Glycerol excretion by symbiotic algae from corals and Tridacna and its control by the host. Science 156: 516-518.

Muscatine L, and Cernichi E (1969) Assimilation of photosynthetic products of zooxanthellae by a reef coral. Biological Bulletin 137(3): 506.

Muscatine L and D'Elia CF (1978) The uptake, retention, and release of ammonium by reef corals. Limnology and Oceanography 23(4): 725-734.

Muscatine L and Hand C (1953) Direct evidence for the transfer of materials from symbiotic algae to the tissues of a coelenterate. 44(12): 1259-1263. 
Muscatine L and Porter JW (1977) Reef corals: Mutualistic symbioses adapted to nutrient-poor environments. BioScience, 27(7): 454-460.

Muscatine L and Weis V (1992) Productivity of zooxanthenllae and biogeochemical cycles. In : Primary Productivity and Biogeochemical Cycles in the Sea. Edited by Falkowski P.G. and Woodhead A.D. Plenum Press, New York. P. 257-271.

Muscatine L, Falkowski PG, Dubinsky Z (1989) The effect of external nutrient resources on the population dynamics of zooxanthellae in a reef coral. Proceedings of the Royal Society of London Series B, Bioogical Sciences 236(1284): 311-324.

Muscatine L, McCloskey LR, Marian RE (1981) Estimating the daily contribution of carbon from zooxanthellae to coral animal respiration. Limnology and Oceanography 26(4): 601-611.

Muscatine L, Pool RR, Cernichiari E (1972) Some factors influencing selective release of soluble organic material by zooxanthellae form reef corals. Marine Biology 13: 298-308.

Muscatine L, Pool RR, Trench RK (1975) Symbiosis of algae and invertebrates: Aspects of the symbiont surface and the host-symbiont interface. Transactions of the American Microscopical Society 94(4) Sympiosium on Biological Surfaces: 450-469.

Muscatine L, Falkowski PG, Porter JW, Dubinsky Z (1984) Fate of photosynthetic fixed carbon in light- and shade-adapted colonies of the symbiotic coral Stylophora pistillata, Proceedings of the Royal Society of London B, 222: 181-202.

Norton J (1992) The zooxanthellal tubular system in the giant clam. Biological Bulletin, 183(3): 503.

Perez SF, Cook CB, Brooks WR (2001) The role of symbiotic dinoflagellates in the temperature-induced bleaching response of the subtropical sea anemone Aiptasia pallida. Journal of Experimental Marine Biology and Ecology 256(1): 1-14.

Phillips S (2006) Latitudinal diversity of the symbiotic dinoflagellate Symbiodinium in New Zealand. MSc Thesis, Victoria University.

Pochon X, LaJeunesse TC, Pawlowski J (2004) Biogeographic partitioning and host specialization among foraminiferan dinoflagellate symbionts (Symbiodinium; Dinophyta). Marine Biology 146(1): 17-27.

Pochon X, Pawlowski J, Zaninetti L, Rowan R (2001) High genetic diversity and relative specificity among Symbiodinium-like endosymbiotic dinoflagellates in soritid foraminiferans. Marine Biology 139: 1069-1078.

Porter JW, Muscatine L, Dubinsky Z, Falkowski PG (1984) Primary production and photoadaptation in light- and shade-adapted colonies of the symbiotic coral Stylophora pistillata. Proceedings of the Royal Society of London B, 222: 161-180. 
Rahav O, Dubinsky Z, Achituv Y (1989) Ammonium metabolism in the zooxanthellate coral, Stylophora pistillata. Proceedings of the Royal Society of London Series B, Biological Sciences. 236(1284): 325-337.

Ralph PJ, Gademann R, Larkum AWD (1999) In situ underwater measurements of photosynthetic activity of coral zooxanthellae and other reef-dwelling dinoflagellate endosymbionts. Marine Ecology Progress Series 180: 139-147.

Ralph PJ, Schreiber U, Gademann R, Kuhl M, Larkum AWD (2005) Coral photobiology studied with a new imaging pulse amplitutde modulated fluorometer. Journal of Phycology 41: 335-342.

Rands ML, Loughman BC, Douglas AE (1993) The symbiotic interface in an algainvertebrate symbiosis. Proceedings of the Royal Society of London Series B, Biological Sciences 253(1337): 161-165.

Rees TAV (1991) Are symbiotic algae nutrient deficient? Proceedings of the Royal Society of London B, Biological Sciences 243: 227-233.

Reynolds WS, Schwarz, Weis VM (2000) Symbiosis-enhanced gene expression in cnidarian-algal associations: cloning and characterization of a cDNA, sym32, encoding a possible cell adhesion protein. Comparative Biochemistry and Physiology Part A 126: 33-44.

Rinkevich B (1989) The contribution of photosynthetic products to coral reproduction. Marine Biology 101(2): 259-263.

Roberts JM, Fixter LM, Davies PS (2001) Ammonium metabolism in the symbiotic sea anemone Anemonia viridis. Hydrobiologia 461: 25-35.

Rodriguez-Lanetty M, Chang S, Song J (2003) Specificity of two temperate dinoflagellate-anthozoan associations from the north-western Pacific Ocean. Marine Biology 143: 1193-1199.

Rodriguez-Lanetty M, Krupp DA, Weis VM (2004) Distinct ITS type of Symbiodinium in Clade C correlate with cnidarian/dinoflagellate specificity during onset of symbiosis. Marine Ecology Progress Series 275: 97-102.

Rodriguez-Lanetty M, Phillips W, Weis VM (2006) Transcriptome analysis of a cnidarian-dinoflagellate mutualism reveals complex modulation of host gene expression. BMC Genomics 7: 23-34.

Rodriguez-Lanetty M, Loh W, Carter D, Hoegh-Guldberg O (2001) Latitudinal variability in symbiont specificity within the widespread scleractinian coral Plesiastrea versipora. Marine Biology 138: 1175-1181.

Rodriguez-Lanetty M, Wood-Charlson EM, Hollingsworth LL, Krupp DA, Weis VM (2006) Temporal and spatial infection dymanics indicate recognition events in the early hours of a dinoflagellate/coral symbiosis. Marine Biology 149: 713-719. 
Roth E, Jeon K, Stacey G (1988) Homology in endosymbiotic systems: the term 'symbiosome'. In: Palacios R.D. and Verma P.S. Editors, 1988. Molecular Genetics of Plant-Microbe Interactions. Proceedings of the $4^{\text {th }}$ International Symposium of Molecular Genetics of Plant-Microbe Interactions. Acapulco, Mexico. APS Press, USA. P. 220-225.

Rowan R (1998) Diversity and ecology of zooxanthellae on coral reefs. Journal of Phycology, 34(3): 407-417.

Rowan R and Knowlton N (1995) Intraspecific diversity and ecological zonation in coral-algal symbiosis. Proceedings of the National Academy of Sciences of the USA 92(7)L 2850-2853.

Rowan R and Powers DA (1991a) Molecular genentic identification of symbiotic dinoflagellates (zooxanthellae). Marine Ecology Progress Series 71: 65-73.

Rowan R and Powers DA (1991b) A molecular genetic classification of zooxanthellae and the evolution of animal-algal symbiosis. Science 251: 1348-1351.

Rowan R and Powers DA (1992) Ribosomal RNA sequences and the diversity of symbiotic dinoflagellates (zooxanthellae). Proceedings of the National Academy of Sciences. USA 89: 3639-3643.

Ryther JH and Dunstan WM (1971) Nitrogen, phosphorus, and eutrophication in coastal marine environment. Science 171(3975): 1008.

Santos SR, Taylor DJ, Coffroth MA (2001) Genetic comparisons of freshly isolated versus cultured symbiotic dinoflagellates: Implications for extrapolating to the intact symbiosis. Journal of Phycology 37: 900-912.

\section{Savage AM, Goodson MS, Visram S, Trapido-Rosenthal H, Wiedenmann J,} Douglas AS (2002) Molecular diversity of symbiotic algae at the latitudinal margins of their distribution: dinoflagellates of the genus Symbiodinium in corals and sea anemones. Marine Ecology Progress Series 244: 17-26.

Schmitz K and Kremer BP (1977) Carbon fixation and analysis of assimilates in a coral-dinoflagellate symbiosis. Marine Biology 42(4): 305-313.

Schoenberg DA and Trench RK (1980a) Genetic variation in Symbiodinium (=Gymnodinium) microadriaticum Freudenthal, and specificity in its symbiosis with marine invertebrates. I. Enzyme and soluble protein patterns of axenic cultures of Symbiodinium microadriaticum. Proceedings of the Royal Society of London Series B, Biological Sciences 207(1169):405-427.

Schoenberg DA and Trench RK (1980b) Genetic variation in Symbiodinium (=Gymnodinium) microadriaticum Freudenthal, and specificity in its symbiosis with marine invertebrates II. Morphological variation in Symbiodinium microadriaticum. Proceedings of the Royal Society of London Series B, Biological Sciences 207(1169): 429-444. 
Schoenberg DA and Trench RK (1980c) Genetic variation in Symbiodinium (=Gymnodinium) microadriaticum Freudenthal, and specificity in its symbiosis with marine invertebrates III. Specificity and infectivity of Symbiodinium microadriaticum. Proceedings of the Royal Society of London Series B, Biological Sciences 207(1169): 445-460.

Schwarz JA and Weis VM (2003) Localization of a symbiosis-related protein, sym32, in the Anthopleura elegantissima-Symbiodinium muscatinei association. Biological Bulletin 205(3): 339-350.

Schwarz JA, Weis VM, Potts DC (2002) Feeding behavior and acquisition of zooxanthellae by planula larvae of the sea anemone Anthopleura elegantissima. Marine Biology 140: 471-478.

Shakir FK, Audilet D, Drake AJ, Shakir KMM (1994) A rapid protein determination by modification of the Lowry procedure. Analytical Biochemistry 216(1): 232-233.

Smith GJ and Muscatine L (1999) Cell cycle of symbiotic dinoflagellates: variation in $\mathrm{G}(1)$ phase-duration with anemone nutritional status and macronutrient supply in the Aiptasia pulchella-Symbiodinium pulchrorum symbiosis. 134(3): 405-418.

Stachowicz JJ (2001) Mutualism, facilitation, and the structure of ecological communities. BioScience, 51(3): 235-246.

Stambler N and Dubinsky Z (1987) Energy relationships between Anemonia sulcata and its endosymbiotic zooxanthellae. Symbiosis 3: 233-248.

Stat M, Morris E, Gates R (2008) Functional diversity in the symbiotic interactions between coral and Symbiodinium. Proceedings of the $11^{\text {th }}$ International Coral Reef Symposium: Abstracts.

Steen RG (1986) Evidence for heterotrophy by zooxanthellae in symbiosis with Aiptasia pulchella. Biological Bulletin 170: 267-278.

Steen RG and Muscatine L (1984) Daily budgets of photosynthetically fixed carbon in symbiotic zoanthids. Biological Bulletin 167(2): 477-487.

Stimson J and Kinzie RA (1991) The temporal pattern and rate of release of zooxanthellae from the reef coral Pocillopora damicornis (Linnaeus) under nitrogen enrichment and control conditions. Journal of Experimental Marine Biology and Ecology 153(1): 63-74.

Stoddart DR (1969) Ecology and morphology of recent coral reefs. Biological Review 44: 433-498.

Streamer M, McNeil YR, Yellowlees D (1993) Photosynthetic carbon dioxide fixation in zooxanthellae. Marine Biology 115: 195-198. 
Stuckey FGA (1908) Notes on a New Zealand Actinian, Bunodes aureoradiata. Transactions of New Zealand Institutions XLI.

Sutton DC and Hoegh-Guldberg O (1990) Host-Zooxanthella interactions in four temperate marine invertebrate symbioses: Assessment of effect of host extracts on symbionts. Biological Bulletin 178: 175-186.

Szmant-Froelich A and Pilson MEQ (1984) Effects of feeding frequency and symbiosis with zooxanthellae on nitrogen metabolism and respiration of the coral Astrangia danae. Marine Biology 81: 153-162.

Szmant-Froelich A, Yevich P, Pilson MEQ (1980) Gametogenesis and early development of the temperate coral Astrangia danae (Anthozoa: Scleractinia). Biological Bulletin 158: 257-269.

Takabayashi M, Santos SR, Cook CB (2004) Mitochondrial DNA phylogeny of the symbiotic dinoflagellates (Symbiodinium, Dinophyta). Journal of Phycology 40(1): 160-164.

Tchernov D, Gorbunov MY, de Vargas C, Yadav SN, Milligan AJ, Haggblom M, Falkowski PG, Field CB (2004) Membrane lipids of symbiotic algae are diagnostic of sensitivity to thermal bleaching in corals. Proceedings of the National Academy of Sciences of the USA, 101(37): 13531-13535.

Thomas WH (1970) Nitrogen deficiency in tropical pacific cceanic phytoplanktonphotosynthetic parameters in poor and rich water. Limnology and Oceanography 15(3): 380 .

Trautman DA, Hinde R, Cole L, Grant A, Quinnell R (2002) Visualisation of the symbiosome membrane surrounding cnidarian algal cells. Symbiosis 32: 133-145.

Trench RK (1971a) The physiology and biochemistry of zooxanthellae symbiotic with marine coelenterates. I. The Assimilation of photosynthetic products of zooxanthellae by two marine coelenterates. Proceedings of the Royal Society of London B, Biological Sciences 177: 225-235.

Trench RK (1971b) The physiology and biochemistry of zooxanthellae symbiotic with marine coelenterates. II. Liberation of fixed ${ }^{14} \mathrm{C}$ by zooxanthellae in vitro. Proceedings of the Royal Society of London B, Biological Sciences 177: 237-250.

Trench RK (1971c) The physiology and biochemistry of zooxanthellae symbiotic with marine coelenterates. III. The Effect of homogenates of host tissues on the excretion of photosynthetic products in vitro by zooxanthellae from two marine coelenterates. Proceedings of the Royal Society of London B, Biological Sciences 177: 251-264.

Trench RK (1979) The cell biology of plant-animal symbiosis. Annual Review of Plant Physiology 30: 485-531. 
Trench RK (1993) Microalgal-Invertebrate symbioses-A review. Endocytobiosis and Cell Research, 9(2-3): 135-175.

Van Oppen MJJ (2004) Mode of zooxanthella transmission does not affect zooxanthella diversity in acroporid corals. Marine Biology 144: 1-7.

Verde EA and McCloskey LR (1996) Carbon budget studies of symbiotic cnidarian anemones-Evidence in support of some assumptions. Journal of Experimental Marine Biology and Ecology 195: 161-171.

Von Holt C and von Holt M (1968) Transfer of photosynthetic products from zooxanthellae to coelenterate hosts. Comparative Biochemistry and Physiology 24(1): 73.

Wakefield TS, Farmer MA, Kempf SC (2000) Revised description of the fine structure of in situ "Zooxanthellae" genus Symbiodinium. Biological Bulletin 199: 7684 .

Wang JT and Douglas AE (1997) Nutrients, signals, and photosynthate release by symbiotic algae: The impact of taurine on the dinoflagellate alga Symbiodinium from the sea anemone Aiptasia pulchella. Plant Physiology 114: 631-636.

Wang JT and Douglas AE (1998) Nitrogen recycling or nitrogen conservation in an alga-invertebrate symbiosis? The Journal of Experimental Biology 201: 2445-2453.

Weis VM and Levine RP (1996) Differential protein profiles reflect the different lifestyles of symbiotic and aposymbiotic Anthopleura elegantissima, a sea anemone from temperate waters. Journal of Experimental Marine Biology 199: 883-892.

Weis VM and Reynolds WS (1998) Symbiosis-enhanced synthesis and expression of carbonic anhydrase in the sea anemone Anthopleura elegantissima. American Zoologist 38.5: 94A.

Weis VM, Davy SK, Hoegh-Guldberg O, Rodriguez-Lanetty M, Pringle JR (in press) Cell biology in model systems as the key to understanding corals. Trends in Ecology and Evolution. In press.

Whitehead LF and Douglas AE (2003) Metabolite comparisons and the identity of nutrients translocated from symbiotic algae to an animal host. Journal of Experimental Biology 206: 3149-3157.

Wilkerson FP and Muscatine L (1984) Uptake and assimilation of dissolved inorganic nitrogen by a symbiotic sea anemone. Proceedings of the Royal Society of London B, Biological Sciences 221: 71-86.

Wilkerson FP and Trench RK (1986) Uptake of dissolved inorganic nitrogen by the symbiotic clam Tridacna gigas and the coral Acropora sp. Marine Biology 92 (2): 237-246. 
Withers KJT, Grant AJ, Hinde R (1998) Effects of free amino acids on the isolated symbiotic algae of the coral Plesiastrea versipora (Lamarck): absence of a host release factor response. Comparative Biochemistry and Physiology Part A 120: 599607.

Yellowlees D, Rees TAV, Fitt WK (1994) Effect of ammonium-supplemented seawater on glutamine synthetase and glutamate dehydrogenase activities in host tissue and zooxanthellae of Pocillopora damicornis and on ammonium uptake rates of the zooxanthellae. Pacific Science 48(3): 291-295.

Yentsch CM, Yentsch CS, Strube LR (1977) Variations in ammonium enhancement, and indication of nitrogen deficiency in New England coastal phytoplankton populations. Journal of Marine Research 35(3): 537-555. 


\section{Appendix}

\section{Re-infection of $A$. aureoradiata with heterologous and homologous zooxanthellae}

To test whether any different responses to host homogenate by the cultured heterologous or freshly isolated homologous zooxanthellae were affected by the capacity to form a symbiosis with Anthopleura aureoradiata, aposymbiotic (anemones with no algal symbionts present) were established by heat-shocking symbiotic anemones by immersion in $32^{\circ} \mathrm{C}$ sea water for 6 hours, then placement in darkness for 6-12 months. During this period, anemones were fed Artemia sp. nauplii every 2 weeks and bowls were cleaned out in low light 24 hours after each feeding. Aposymbiotic status was established by fluorescent microscopy (Olympus Pro AX 70) and 6 hemocytometer counts done by homogenizing single anemones in a Wheaton ground glass tissue grinder with $2 \mathrm{~mL}$ FSW. Anemones were then fed once weekly with Artemia sp. nauplii and bowls were again cleaned out 24 hours after each feeding. This more regular feeding was to prevent too much shrinkage of the anemones. All feeding and cleaning was carried out under red light to prevent regrowth of residual zooxanthellae.

To establish a time frame for full re-infection of anemones, a preliminary reinfection study (Experiment 1) was conducted. Twelve aposymbiotic anemones were infected with 4 different clades of zooxanthellae: 3 of these clades were from cultures: Pd, Sin, A001 (see Table 3.1 p.32) for clade assignment and geographical information), with the fourth clade (clade A) being represented by the freshly isolated zooxanthellae (FIZ) from A. aureoradiata. FIZ were obtained by homogenizing 15 anemones in a Wheaton ground glass tissue grinder. The homogenate was centrifuged at $12,000 \mathrm{~g}$ for 5 minutes and the supernatant poured off. The algal pellet was resuspended and then spun again at $12,000 \mathrm{~g}$ for 5 minutes and the supernatant decanted. The algal pellet was then resuspended in $5 \mathrm{~mL} \mathrm{FSW}$ and 8 hemocytometer counts conducted. Cultures were prepared by swirling the culture flask and pipetting $10 \mathrm{~mL}$ into a clean centrifuge tube. Zooxanthellae were then centrifuged at 12,000 g 
and resuspended in $3 \mathrm{~mL} \mathrm{FSW}$ to concentrate algal cells. 8 hemocytometer counts were taken of each culture and FSW added to normalize algal suspensions to 2.78 million cells $/ \mathrm{mL}$ (the lowest cell concentration). All infections were carried out under a dissecting microscope. Anemones were allowed to settle each in an individual container overnight. Infection was done using a $1 \mathrm{~mL}$ syringe with the sharp tip trimmed off the needle for better control (Figure A1.1). $1 \mathrm{~mL}$ of concentrated zooxanthellae extract ( 2.78 million algal cells per $\mathrm{mL}$ ) was injected into the mouth of the anemone. This was followed with an injection of Artemia sp. nauplii extract, prepared by homogenizing then freezing concentrated Artemia sp. nauplii to facilitate zooxanthellae uptake (Davy et al. 1997). Water was changed 24 hours after reinfection to remove any zooxanthellae and Artemia sp. not captured by the anemone. Zooxanthellar concentrations for this re-infection were standardized to 2.78 million cells per $\mathrm{mL}$ for all clades.

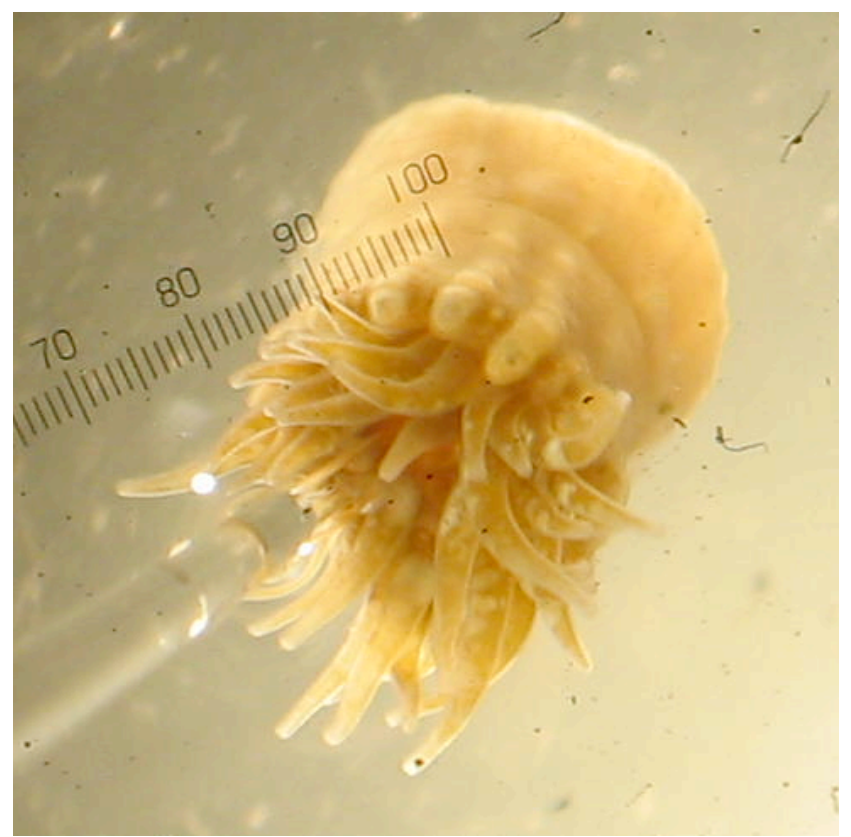

Figure A1.1 - Re-infection technique for infection of $A$. aureoradiata with homologous and heterologous zooxanthellae.

Infection status was checked after 2 weeks by homogenizing anemones in 5 $\mathrm{mL} \mathrm{FSW}$ in a Wheaton ground glass tissue-grinder, centrifuging for 5 minutes at $12,000 \mathrm{~g}$ and resuspending in FSW, then centrifuging and resuspending in FSW a second time to ensure that little animal material remained. Cells were then counted using a Fuchs Rosenthal hemocytometer $(n=8)$. Infection status was re-checked after 4 weeks, still using 8 hemocytometer counts for each anemone. The trial was ended at this point, as no zooxanthellae were detected in re-infected anemones. 
After preliminary attempts to re-infect $A$. aureoradiata with heterologous or homologous zooxanthellae were unsuccessful, concerns were raised about the accuracy of the placement of zooxanthellae into the mouth, and the possibility that $A$. aureoradiata would not take up hetereologous zooxanthellae. The infection method was modified to use magnesium chloride $\left(\mathrm{MgCl}_{2}\right)$ as an anesthetizing agent prior to re-infection. $\mathrm{MgCl}_{2}$ was used by Davy et al. (1997) with successful re-infection and no apparent negative or ongoing effects of the $\mathrm{MgCl}_{2}$ on the anemones. In experiment 2, five $\mathrm{mL} \mathrm{MgCl}_{2}$ were added to each container 4 hours before the reinfection. Eight anemones were re-infected with freshly isolated zooanthellae at a density of 3.13 million cells per $\mathrm{mL}$ using the same technique as before. Symbiotic status was checked 2 and 4 weeks after re-infection with 8 hemocytometer cell counts and anemone squashes under the fluorescent microscope.

Re-infection following continued exposure of aposymbiotic anemones to symbiotic anemones or to a suspension of zooxanthellae was tested in experiment 3. Three treatments were used: a control consisting of 5 aposymbiotic anemones, each in a separate dish; Five dishes, each containing 1 re-infected anemone and 1 symbiotic anemone; Five dishes, each containing 1 aposymbiotic anemone that was re-infected daily, as described previously. Symbiotic status was checked after 2 weeks using 8 hemocytometer counts of each anemone.

It is possible that there is incorporation of the algae on a short-term timescale, then subsequent expulsion at a later point in time. Experiment 4 was done to test for this short-term re-infection potential. Nine aposymbiotic anemones were re-infected as described previously, with the zooxanthellae at a concentration of 3.66 million cells per mL. Water was changed 1 hour after re-infection. Symbiotic status was checked at 0 hours, 12 hours, 24 hours, and 48 hours using hemocytometer counts. For each count, each anemone was homogenized separately in $2 \mathrm{~mL}$ FSW and centrifuged at $12,000 \mathrm{~g}$ for 5 minutes to isolate zooxanthellae. The algal pellet was resuspended in $1.5 \mathrm{~mL}$ FSW and counts taken from this. Anemones checked at 0 and 12 hours were cut in half and the gut was rinsed to eliminate unincorporated zooxanthellae before homogenization. 
A fifth experiment was run to further investigate the possibility of short-term incorporation of the zooxanthellae. Aposymbiotic anemones $(n=45)$ were allowed to settle, each in separate dishes, overnight. Freshly isolated zooxanthellae were prepared at a concentration of 2.98 million cells $/ \mathrm{mL}$ as previously described. Anemones were re-infected as before using a $1 \mathrm{~mL}$ syringe, and the FSW was changed after 1 hour. Five control aposymbiotic anemones and 5 re-infected anemones were homogenized separately in $5 \mathrm{~mL}$ FSW in a Wheaton ground glass tissue grinder and counted with a hemocytometer at 0 hours. Counts of 5 re-infected anemones were then taken at 1, 2, 4, 6, 12, and 24 hours. Anemones at time points from 0 to 6 hours were cut in half and the gut rinsed before counts to wash away unincorporated algae.

\section{Results}

\section{Re-Infection}

None of the first three re-infection attempts showed evidence of incorporation after either 2 or 4 weeks. All attempts were checked with 8 hemocytometer counts per anemone, and none came up with a value greater than 2500 cells per $\mathrm{mL}$ when anemone was homogenized, centrifuged and re-suspended in $1 \mathrm{~mL}$ FSW, which was judged to indicate lack of incorporation by $A$. aureoradiata.

The continued exposure trial (experiment 3) also found no evidence for uptake of homologous zooxanthellae and was ended when all stock of photosynthetic anemones to provide freshly isolated zooxanthellae were used. This trial lasted 10 days and no incorporation was seen.

In experiment 4,8 hemocytometer counts were taken 0 hours, 12 hours, 24 hours, and 48 hours after re-infection (Table A1.1). 
Table A1.1: Average of 8 hemocytometer counts taken at timpoints after re-infection of aposymbiotic A. aureoradiata with homologous zooxanthellae

\begin{tabular}{|c|c|}
\hline Timepoint & Count $($ cell $/ \mathrm{mL})$ \\
\hline $0 \mathrm{~h}$ control & 0 \\
\hline $0 \mathrm{~h}$ & 2000 \\
\hline $12 \mathrm{~h}$ & 35800 \\
\hline $24 \mathrm{~h}$ & 5000 \\
\hline $48 \mathrm{~h}$ & 5000 \\
\hline
\end{tabular}

\section{Experiment 5}

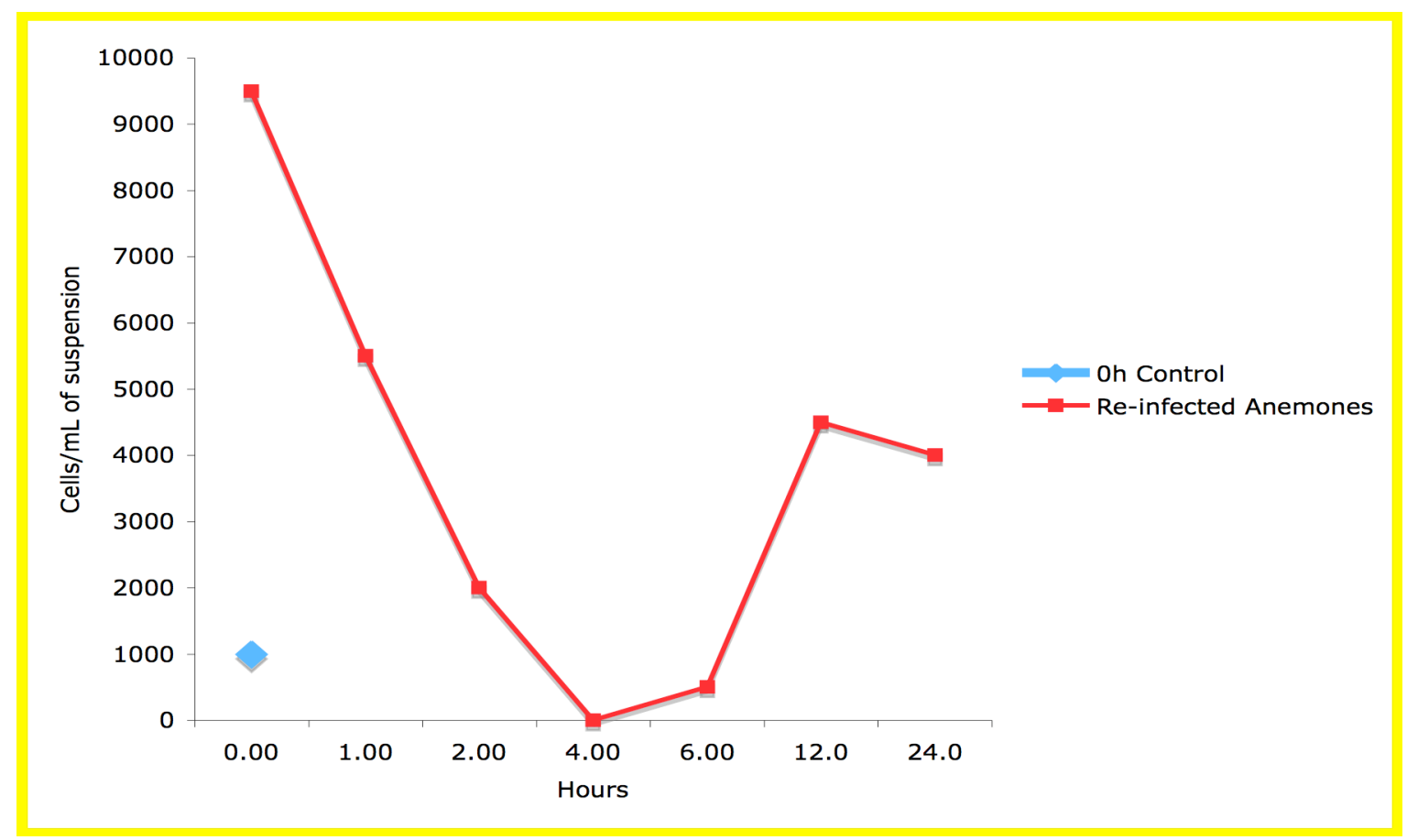

Figure A1.2: Cell counts of homologous zooxanthellae in reinfected Anthopleura aureoradiata at 0, 1, $2,3,6,12$, and 24 hours after infection from experiment 5 as described above.

Short-term re-infection, as in experiment 5 , showed decreasing incorporation for 4 hours and then an increase until 12 hours, when it seemed to level off (Figure A1.3).

\section{Discussion}

Aposymbiotic hosts from other species have previously been successfully reinfected with both homologous and heterologous zooxanthelle (Berner et al. 1993; Davy et al. 1997; Rodriguez-Lanetty et al. 2003). None of the attempted re-infections of aposymbiotic Anthopleura aureoradiata were successful as carried out above. 
This is potentially due to short experiment lengths, incorrect counting, and assuming the infection had failed when there were in fact small numbers of zooxanthellae. Davy et al. (1997) found the sea anemone Cereus pedunculatus re-infected with heterologous and homologous zooxanthellae to have detectable numbers within 4 days, and to have levels similar to natural symbioses within 4 weeks. RodriguezLanetty et al. (2003) judged re-infection of the anemone Heteractis sp. to be when the anemones showed color, and was found after up to 60 days. Trials in this section were often abandoned after 4 weeks if levels of zooxanthellae were low, raising the possibility that re-infection is possible in A. aureoradiata, it just needs more time and better designed experiments.

There is also the possibility that this anemone cannot be re-infected once it is rendered aposymbiotic. Rodriguez-Lanetty (2003) also found a few specimens that did not re-infect after 4 months of exposure. Perhaps aposymbiotic specimens of $A$. aureoradiata lose some cell-signalling molecule or fail to recognize zooxanthellae.

These studies above were often cut short and were side experiments meant as an introduction to a longer experiment. As re-infection did not appear successful after 4 weeks, the side experiments were abandoned completely and no further work was carried out to investigate if the lack of re-infection was based on poor experimental design or some change in the anemones themselves. 